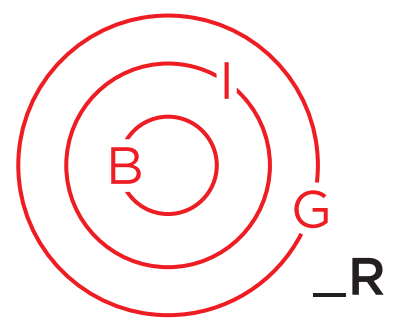

SPECIAL SECTION

\title{
Introduction: New Border Studies in South Asia
}

\section{Dhananjay Tripathi *}

In this special section, New Border Studies in South Asia, BIG_Review Board Member and regional specialist Dhananjay Tripathi edits a collection by emerging scholars in the Indian subcontinent. 1 Through new research and fieldwork, themes explored include identity formation, postcoloniality, forced displacement, and looking beyond the human-centric world in border governance.

\section{Introduction}

International borders, in simplest terms, are about the demarcation of territories. However, borders not only define territorial limits but also imply the extent of state sovereignty. On an uncritical analysis, the border appears necessary to ensure order in the international system. The real complications emerge from a deeper analysis of the concept, how it originated and became characterised in different regions. In this special section, New Border Studies in South Asia, the main objective is to engage with some of the distinct challenges border management faces in this region, and how the borders influence social, cultural and everyday life of individuals.

\section{Borders in South Asia: Colonial Construct, Violence and Artificiality}

When we discuss borders in South Asia, there is an interesting contradiction not discussed much by the scholars in both IR and Border Studies. This is not surprising because Border Studies itself is a new subject for the region, which mainly was part of the British colony until the first half of the twentieth century. The contradiction concerns the cultural and political history of South Asia and how the borderthe way it was introduced/created in South Asia has permanently altered the region. As a matter of fact, contemporary borders in South Asia were drawn in the last two centuries by the British primarily for political, administrative and strategic considerations (Tripathi \& Chaturvedi 2019). In 1816 for the first time, the India-Nepal border was established after signing the Sugauli treaty. This treaty marked an end to the Anglo-Nepali war started in 1814 and popularly known as 'Gurkha War'. There was no strict border between India and Nepal before 1816 (Tripathi 2019). Likewise, one of the most controversial borders in South Asia is Durand Line, dividing Pashtuns into two different countries-Pakistan and Afghanistan. The Durand Line was also drawn by the British in 1893. The primary reason was to make Afghanistan a buffer state. While

\footnotetext{
* Dhananjay Tripathi, Senior Assistant Professor, Departmeent of International Relations, South Asian University, New Dehli, India. Email: dhananjay@sau.ac.in and Twitter: @dhananjayjnu
} 
the British left this region in 1947, the Durand Line is still a cause of contention between Pakistan and Afghanistan.

The British created another crucial border during the end of their rule in India. This border divided India into two different states-India and Pakistan in 1947. As Brunet-Jailly identified, "there are complex social processes that establish borders" (Brunet-Jailly 2005, 643). The India-Pakistan partition should be regarded as among of the most "complex social processes", some still reverberating in Indo-Pak relations, not least the issue of Kashmir. Also, the creation of the India-Pakistan border concerns uncontrolled communal violence and traumatic displacement of people. Scholars of Border Studies view borders differently, "not just hard territorial lines-they are the institutions that result from bordering policies-they are thus about people" (Brunet-Jailly 2011, 2). In the case of India and Pakistan, we can notice that the border is also psychological. Chaturvedi explains that the India-Pakistan border "is a good example of how peoples and places with distinctive histories, cultures and ethno-linguistic identities can be reduced to the status of mere 'issues' in the geopolitical imaginations of the intellectuals and institutions of statecraft. At the heart of the dominant Indian discourse on Kashmir lies the polemical two-nation theory" (Chaturvedi 2003, 336). If borders are about exclusion, inclusion and othering (Newman 2003), we can see this clearly in the case of India and Pakistan.

Another border that emerged in South Asia after the departure of the British is the India-Bangladesh border. This border was created in 1971, after a determined struggle of the people of Bangladesh against the control of the Pakistani state. The liberation of Bangladesh is not a simple episode in South Asian history. In the 1947 partition, "15 million people were displaced and one million dead". Similarly, "horrifying numbers of people were killed and many hundreds of thousands of women raped in 1971" (Ghosh 2017, 26 ). These horrific events that led to physical borders also profoundly impacted people's minds, creating some permanent mental borders in South Asia.

In brief, most of these borders created in South Asia narrate the tale of war, conflict, and brute violence. No wonder these borders reveal "cartographic anxieties" (Krishna 1994) of South Asian states. Thus, it is not a giant puzzle for a student of South Asian borders that the South Asian region is one of the least integrated in political and economic terms, contradicting its deep socio-cultural connection. The highly securitised, state-centric understanding of borders in South Asia inhibits integration efforts. Regional integration requires cross-border political, social and economic ties. Interestingly, South Asian states hardly hesitate in embracing globalisation, linking themselves to the international economy. Still, there is a visible political aversion noted in every South Asian capital pertaining to regionalism. This is quite perfectly captured by Banerjee (1998), who believes that border politics help us understand the contours of relations between the South Asian states. So even when the British left the region, the South Asian states have not taken policy initiatives to bridge the borders. On the contrary, most of them maintained these hard artificial borders endorsing and propagating the idea of security compulsion. Thus, South Asian states essentially maintained the artificiality of hard borders by negating the natural linkages between the culture and people of South Asia (Tripathi 2021).

\section{Studying South Asian Borders}

While borders in South Asia explain so much about the region, there is still a lack of academic engagement. This has been noted by scholars from within and outside South Asia. Moreover, there is a need for expanding the canvass of academic inquisitiveness by going beyond the security-centric understanding of borders. South Asian scholars must focus on equally relevant themes for generating a clear intellectual and much-needed debate on borders. It is also imperative that young scholars get involved in Border Studies in South Asia. Without new scholarship and research, we risk boxing ourselves into overly conventional descriptions of borders in South Asia that primarily revolve around state and national security. In this respect, this collection is an attempt to draw the attention of scholars to focus on South Asian borders. There is much to learn from each of these studies about the wide-ranging borders of South Asia.

This section has five papers on themes pertinent to South Asian borders. The first paper in this section is on Bengal borderlands bringing out the living experience of borderland communities. While the border is a security concern from national capitals, it is about life and livelihood at the periphery. Sampurna Bhaumik, through her field study of two border districts, Cooch Behar and South Dinajpur (along the India-Bangladesh border), presents how people in borderlands remain under constant check by security agencies that only add complication to their life. This is prior to recognizing that the India-Bangladesh border is not as intricate as the India-Pakistan border. The second paper in this section is again on a borderland that is regarded as one of the most securitised borders of the world. Politics amongst states have repercussions on borderlands. It is first and foremost theatre of state politics, which is quite apparent in the paper by Malvika Sharma. She maps how state politics influence identity formation in the borderland. This is quite evident in the Poonch district of Jammu and Kashmir. In this district, the India-Pakistan partition 
deeply impacted the identity formation process. While there is a history of community cooperation, it is entirely changed in the Poonch district. This borderland is somehow made to bear the burden of the power politics between the states.

In the present global context, any discussion of borders must discussion of the essential issue of refugees. For some humans, Border border crossing may be for leisure, business, or education, but not for those forced by political and economic circumstances. For the forcibly displaced, crossing the border may be necessary for survival. While privileged travellers with valid documents may be welcomed culturally and economically, the perception of foreigners changes when a person or a group enters the border under a distressing situation. Refugees are not so welcomed by many states and are viewed as an economic and political burden. They are also vilified in local politics, and excesses against refugees at times go unnoticed. In short, refugees cannot be ignored in Border Studies, and in this section, we have two captivating papers on Rohingya refugees. The Rohingya community is from Myanmar, a country of the Southeast Asian region. The international community are well aware of their ordeal, and they have crossed borders to save themselves from persecution. South Asia is a populated developing region, and therefore, any such mass influx of refugees from outside is likely to give birth to several controversies. Rohingya refugees are mainly concentrated in two South Asian countries, Bangladesh and India, and the following two papers of this special section are on this subject.

Rachel Irene D'Silva conducted a field survey of Rohingya refugees settled in Hyderabad, a capital city of Telangana, a southern state in India. D'Silva interviewed refugees staying in this city and brought out some of the important issues generally not covered in news stories. Sariful Islam authored the next article in this section. According to the Bangladesh government, more than one million Rohingya refugees are in Bangladesh. This is a large number for a country like Bangladesh that has recently graduated from the least developing country to a developing country. This number of refugees is likely to create political and social tension, which is quite well addressed in the paper. The paper is conceptually engaged with the Border Studies literature by looking into the differences between territorial and mental borders. Islam draws from the analysis of Azmeary Ferdoush into how insiders and outsiders shape the overall discourse on borders.

The last paper in this section is from Uddipta Ranjan Boruah, and it is on one of the most debated subjects in the region: the management of the India-Bangladesh border. India-Bangladesh is the fifth longest land border globally that runs across more than 4000 kilometres. India fenced this border with Bangladesh giving security reasons to check infiltration and smuggling.
While it is easier said than done, India-Bangladesh border fencing is a complex process like the riverine sector, which Boruah considers as a non-human actor. This is a good paper to comprehend the artificiality of human-made borders. Also, the paper reflects how rivers change their course and keep creating difficulty for human ambition to fence the border completely.

\section{Conclusion}

To conclude, all five papers are on themes that are much discussed and will add to the Border Studies literature in South Asia. I hope this collection will generate the necessary debate, discussion, and curiosity in South Asian borders and draw young scholars towards this subject.

\section{Note}

1 These papers are the outcome of the South Asian University (SAU)-Borders in Globalization (BIG) Border Studies scholarship. Though I was also responsible for coordinating the SAU-BIG scholarship, as SAU was the implementing institute, the BIG team, especially project lead Brunet-Jailly, was particularly supportive. I would also like to thank colleagues in my department, particularly Dr. Jayashree Vivekanandan and Dr. Nabarun Roy, for helping me during this project. A special thanks to Prof. Sasanka Perera, then the vice-president of the SAU, when SAU signed this project with BIG. I would also like to thank Prof. Sanjay Chaturvedi, a prominent Border Studies scholar, former Dean of our faculty and senior colleague, for extending his support and guiding me throughout the project. Lastly, a big thank you to the SAU administration, SAU finance department and office staff of my department for their contribution and for making this project a success.

\section{Works Cited}

Banerjee, Paula. 1998. "Borders as Unsettled Markers in South Asia: A Case Study of the Sino-Indian Border" International Studies 35(2): 180-191. https://dx.doi.org/10.1177/002088179 8035002004

Brunet-Jailly, Emmanuel. 2011. "Borders, Borderlands and Theory: An Introduction" Geopolitics 16(1): 1-6. https://doi. org/10.1080/14650045.2010.493765

Brunet-Jailly, Emmanuel. 2005 . "Theorizing borders: an interdisciplinary perspective" Geopolitics 10(4): 633-649. https://doi.org/10.1080/14650040500318449

Chaturvedi, Sanjay. 2003. "Indian" geopolitics: unity in diversity or diversity of unity?" Ekistics 70 (422/423): 327-339. https://doi.org/10.5281/ekistics.v70i422/423.260

Ghosh, Bishwanath. 2017. Gazing at neighbours travels along the line that partitioned India. New Delhi: Tranquebar Press. 
Krishna, Sankaran. 1994. "Cartographic Anxiety: Mapping the body politics in India" Alternatives: Global, Local, Political 19(4): 507-521. https://doi.org/10.117 7\%2F030437549401900404

Newman, David. 2003. "On borders and power: a theoretical framework." Journal of Borderland Studies 18(1): 13-25. https://doi.org/10.1080/08865655.2003.9695598

Tripathi, Dhananjay. 2019. "Influence of borders on bilateral ties in South Asia: A study of comtemporary India-Nepal
Relations" International Studies 56(2-3): 186-200. https:// doi.org/10.1177\%2F0020881719851420

Tripathi, Dhananjay , and Sanjay Chaturvedi. 2019. "South Asia: Boundaries, Borders and Beyond" Journal of Borderlands Studies 35: 173-181. https://doi.org/10.1080/08865655.2019 .1669483

Tripathi, Dhananjay. 2021. "Introduction" in Re-imagining Border Studies in South Asia, edited by Dhananjay Tripathi, 3-19. London: Routledge Publication. 


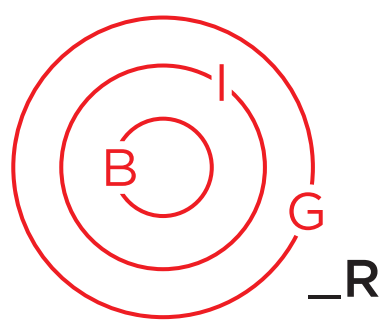

ARTICLE SPECIAL SECTION

\section{Everyday Lives in Peripheral Spaces: A Case of Bengal Borderlands}

\section{Sampurna Bhaumik *}

This article (part of a special section on South Asian border studies) is an ethnographic study of the daily lives and narratives of borderlands communities in the border districts of Cooch Behar and South Dinajpur along the West-Bengal-Bangladesh border. In order to emphasise the significance of borderland communities' narratives and experiences to our understanding of borders, this paper explores the idea of borders as social spaces that are inherently dynamic. In attempting to understand the idea of borders through everyday lives of people living in borderland communities, this paper highlights tensions and contradictions between hard borders manifested through securitization practices, and the inherently dynamic social spaces that manifest themselves in people's daily lives. Conceptually and thematically, this paper is situated within and seeks to contribute to the discipline of borderland studies.

Key Words: Borders, Social Spaces, Security, Bengal Borderlands, South Asia

\section{Introduction}

This paper is a critical reflection on the everyday narratives of identity discourse in context of India-Bangladesh borderlands. Based on ethnographic fieldwork conducted in border districts of Cooch Behar and South Dinajpur in the state of West Bengal, this paper brings out the tensions and contestations between the fluid nature of dynamic social processes and the rigidity of hard national boundaries. Political borders have long been the focal point of academic research dominated by Realist approaches in International Relations (Laine 2015). In Realist ontologies, the State is taken to be the reference point-considering political borders only in their geographical capacity for state (Herz 1957; Gilpin 1981).

However, this security-centric understanding of borders has come to be countered by contemporary scholars of border studies who argue for borders to be viewed in their capacity of being social places, defined by several markers of social identity, such as culture and ethnicity
(Schendel 2002; Paasi 2005; Newman 2006). Taking the idea of borders as dynamic social spaces (Paasi 1998), and a realm of contestations between rigid and security centric approaches by state and inherent nature of fluidity of borderland spaces (Konrad 2015), this paper, therefore, brings forth these dynamic exchanges through everyday life experiences and narratives of borderland communities.

The idea of everyday narratives is used here as a crucial site of the dynamic tensions that exist between the social narratives of identity, spaces, and belonging, and the meta nation-state narratives of identity, security, and control over resources in the borderland regions (Misra 2014; Scott 1998). These tensions are central to the disciplinary concerns of borderland studies and are fundamental for understanding the problems of nation-state building and the experiences of communities living in South Asian borderland regions, in particular the Bengal Borderland region.

* Sampurna Bhaumik, M.Phil, Political Science, University of Hyderabad, India.

Contact: sampurnabhaumik31@gmail.com 
Borders in Globalization Review | Volume 3 | Issue 1 | Fall/Winter 2021 Bhaumik, "Everyday Lives in Peripheral Spaces: A Case of Bengal Borderlands"

Located in the disciplinary debates about fluid social spaces and border making processes in post-colonial South Asia, this paper looks at the ways in which local narratives of identity and fluid social spaces clash with state driven homogeneity building narratives that focus on border management practices and national identity narratives. These state centred narrative are used as tools of controlling the social fluidity that has existed in the peripheral spaces in contradiction to the nationbuilding processes in post-colonial times (Misra 2014; Krishna 1998). Borderlands represent a zone of tensions between state and society where the notions of identity, loyalty and belonging are fluid (Gellner 2013; Schendel 2005; Sur 2021). Thus, the discourses of national identity become entangled with state securitization and border management practices to legitimize securitization of borderlands and reinforce the homogeneity of nation at the periphery through narratives of homogeneous national identity (Donnan \& Wilson 1999; Vaughn-Williams 2012). By looking at narratives and everyday lives of people in borderlands through narrative research, this paper traces out different dimensions of the development of local social narratives and dynamics of its clash with meta-national narratives of identity and nation-building.

This article focuses on everyday life and narratives to understand the dynamics of hard borders imposed by the state, and fluid social life of people. In the Post-colonial people, the state has become central to defining everyday lives of people in borderlands (Chatterjee et al. 2021). However, the agency of the people in negotiating hard and securitized borders cannot be underestimated (Chaturvedi 2000). Therefore, the focus on everyday life and individual narratives of how people in borderlands negotiate, interact, and make sense of hard border resulted in a variety of border management and securitization practices. This paper uses ethnographic methods to understand the everyday lives of people. Everyday lives, in this paper, therefore become a methodological tool to access the ways people make sense of the hard borders.

The paper is organized into five sections. The first two sections begin with the conceptual debates in border studies, focusing primarily on the two central elements of space and territory, as well as how the State instrumentalizes the boundary-making discourse to reinforce certain binaries that are central to maintaining the state's sovereign character and the perception of a homogenous community. The third section then goes on to explore the idea of nation-building and how the State, through practices of territoriality and othering, attempts to construct a common homogenous narrative of identity, its leap from being a geographical container to a social space marked by a sense of belonging, home to people who live there. This section also contextualizes how these processes and ideas bear upon the lives of people in Bengal Borderlands. The fourth section brings out ideas and narratives from an ethnographic field study to discuss the tensions between security-centric state practices as informed by core-periphery differences, and everyday lives of people living in two districts: Cooch-Bihar and South Dinajpur in West Bengal. The final section concludes the paper.

\section{Spatial Borders and Everyday Lives in Borderlands}

This section explicates the critiques of Realist ontologies of borders and sets out how borders get entangled with inherently fluid social spaces as part of the territorial compartmentalization of nation-states. The category of space here is a relevant conceptual tool whereby the dynamics of how borders come into tensions with social processes in borderlands across the world (Massey 1998). Borders, especially in South Asian Region, were drawn in spaces where the boundaries between societies were fluid, resulting in fragmentation despite the commonalities in terms of social identities (Paasi 1998, 73).

The spatial shift in social sciences and international relations came in the context of increasing globalization processes in the Post-Cold war era. Globalization has made cross-border flows of people, goods and ideas easier hence, globalization was argued to be the trigger to the demise of hard borders and, in some cases, even nation-states. Yet, territorial nation-states have been more resilient than it was thought in the immediate aftermath of the collapse of the Soviet Union (Paasi 1998, 74-76). To understand the resilience of territorial nation-states, the spatial shift in question has to be situated in an understanding of how space is organized politically (Brenner et al. 2009). This helps explicate why and how controlling spaces, politically and militarily, is crucial to understand how uncontainable social processes and spaces in borderlands come into tension with security-centric border management and security practices of nation-states.

The notion of space has a longstanding geographical influence, possibly owing to the fact that it is the idea of physical space that is arguably most tangible to us, becoming a starting point of discussions on space more often than not (Massey 1998). The very organization of human society is fundamentally spatial in nature (Massey 2005). The organizing pillars of modern state, the notions of territory and sovereignty, stem from the political organization of space and its impact on human behaviour. Edward Soja points out the 'localization' of human activities, that is, such activities occupy an extent of physical space on earth, much like the creation of boundaries that sovereign states engage in (Soja 1971, 3-11). The differences between such physical spaces essentially define human activities and their consequences, space being the focal point. But there are differences between the term 'space' and 'place' (Soja 1971; Harvey 1991).

The difference in meaning and significance, of course, varies across disciplines, shaped by the context it is being used for. For example, Andrew Riggsby (2009) notes that in order to bring forth the distinction that is often drawn between the respective ideas of space and place, there 
are two crucial parameters that play a role: the degrees of constructed-ness, and the degrees of extension. That is, while 'space' is taken to be given, the idea of place is taken to be constructed, in terms of experiences or interpretations. While a 'place' is particularly located, the idea of 'space' is more universal and somewhat abstract (Riggsby 2009, 153-160). Caroline Rosenthal argues, "spaces are not significant in and by themselves but are produced as intelligible entities by how we organize them, by the social practices and symbolic ways in which we set them off from other spaces. The city, for instance, only gains significance as a space with distinct characteristics when separated from rural or unsettled" (Rosenthal 2011, 11). Referring to the concept of national iconography, Rosenthal notes that 'nations define themselves spatially against other nations not only through geographic borders, history, and politics, but also through the specific ways they have found to classify and represent spaces' (Ibid). Therefore, space is central to political organization, i.e. territorial nation-states, but it encompasses social, political, and geographical dimensions rather than just the physical manifestations of space outlined in Realist ontologies.

The shift from physical space to social space in context of borders is one marked by representations and imageries (Schendel 2005). Border here becomes a dynamic process, an institution that is to provide to people some sort of identity that can link them back to the idea of 'nation', the identity manifested through social and cultural practices (Schendel 2002; Ghosh 2016). In view of the discussion above, the contemporary border studies scholars focus on borders that have gone from being physical space to social space. This shift from geographical space to social space marks the departure from traditional perspective in the contemporary trends in border research (Vladivostok \& Wastl-Walter 2011). David Newman argues that borders are lines. It is the spatial shift in the conceptualization of that allows for the consideration of creation of borderlands, one that Newman argues, "...is an area within which people residing in the same territorial or cultural space may feel a sense of belonging to either one of the two sides, to each of the two sides, or even to a form of hybrid space in which they adopt parts of each culture and/or speak both languages" (Newman 2011, 37).

The tensions between security and border management practices and the everyday lives of people in fluid social spaces, therefore, emerge from the very nature of borders as socially and politically constructed. These tensions, as they are analysed in the next sections, play out in the everyday lives and narratives of people living in borderlands. Looking at borders as processes that are in constant motion rather than rigid lines therefore allows us to explicate and understand these tensions through the examination of the daily lives of people and their interactions with political borders, and the administrative and security apparatuses to manage it (Schendel 2005). Additionally, the very idea that there exist tensions between fluid social spaces and hard borders in borderlands make the concept of 'bordering' crucial (Houtum 2016). To put it another way, these tensions point towards inherent dynamic nature of borders. As Paasi notes, "Boundaries are both symbols and institutions that simultaneously produce distinctions between social groups and are produced by them. Nevertheless, they not only separate groups and social communities from each other but also mediate contacts between them" $(1998,80)$. The practice of bordering is one controlled by the state and one aimed at marking differences, distinguishing 'self' from the 'other'. The fluidity of social spaces and dynamic nature of borders make everyday lives of people a crucial site.

\section{Territory and Territoriality in Borderlands: Securitization, State, and Everyday Lives}

The tensions between hard borders and fluid social spaces can be further located in particular state practices that produce territory. This section contextualizes how a constructed notion of borders as social processes, developed in borderland studies literature, can help us understand the everyday practices of states and institutions namely police, the Border Security Force (BSF), and other agencies with respect to how they regulate and control fluidity of 'social' in borderland regions (Sur 2021). These state practices are often tasked to regulate fluidity and, therefore, they come into conflict with local society. Since they are governed by the dominant ideas and notions of borders as physical, social, and cultural barriers as manifested in Realist ontologies. In realist ontology, the territoriality of state is defined as "in that substratum of statehood where the state unit confronts us, as it were, in its physical, corporeal capacity: as an expanse of territory encircled for its identification and its defense by a "hard shell" of fortifications. In this lies what will be here referred to as the "impermeability," or "impenetrability," or simply the territoriality of the modem state" (Herz 1957). Therefore, the bounded territoriality of the state works as a hard shell of political community is central to Realist ideas of borders.

By linking the ideas of space and its centrality to the political organization of space developed in the first part of this section, this paper attempts to bring in two other crucial concepts, namely territory and territoriality, to contextualize how state practices like securitization and administration, and the security apparatus function in borderlands. However, it is not to deny that there are security challenges to maintain order, especially at the peripheries. Rather the emphasis here is on the way these state practices and apparatus work in contradiction to the fluid nature of social spaces in borderlands. This also helps us understand why problems of borderland communities are linked to the tensions and contradictions between hard shell of territoriality manifested in securitization practices and inherently fluid social spaces in borderlands.

In the borderland districts, administrative agencies and the police have exceptions to the rules and regulations. In border districts, the Union Home Ministry gave the Border 
Security Force (BSF) jurisdiction over areas lying within 15 kilometres from the international border which allows them policing power beyond the scope of other police and administrative agencies. In October 2021, this range of BSF jurisdiction was expanded to up to 50 kilometres to reflect the increasing securitization of border areas (Tiwary 2021). As a result of these exceptions, border communities in these districts face higher securitization of their daily life.

Borders are the building block of territory (Carter \& Goemans 2011; Elden 2013), which, in turn, plays a defining role in bringing about the physical existence of modern sovereign states. According to Robert Sack, territoriality is a spatial strategy employed by modern nation states to exert control over people and the society they constitute; thus, translating essentially into the geographical manifestation of social power (2009). For traditional International Relations scholars, particularly Realists, "the territorial state acts as the geographical 'container' of modern society, that is, the boundaries of the state are also considered to be the boundaries of political and social processes" (Agnew 1994). State borders are to not only limit the sovereignty of the state, but also its subjects, in order to emphasize a binary difference between 'us' and 'them'. Keeping in line with the state-centrism in the discipline of International Relations, territory has primarily been understood not only as one of the central defining traits of the modern nation state but also a self-evident category, leading to noticeable gaps in conceptual clarity (Herz 1957).

This 'territorial instinct' to defend and protect is part and parcel of the territorial state, and has led to what John Agnew calls the 'territorial trap' (1994), a Realist tendency that has dominated the boundary discourse in International Relations. Stuart Elden explores the emergence of territory as a concept and notes that physical territory and the control over it as a variety of spatial dimensions have consistently played a crucial role in the conduct of human affairs even in the early stages of modern society (Elden 2013). While territorial disputes have received attention from scholars with regard to the development of International Relations, such developments have been studied in geographical contexts with territory being assumed as a self-evident term. Elden notes that the historical dimension of the term is neglected when territory is assumed to be a category understood as an outcome of state territoriality (2013).

Territory has been a major instrument employed by modern states to construct the intended image of a homogenous sovereign entity (Agnew 1994; Elden 2013). In this regard, the production of geographical knowledge in different institutional settings and the quality of such knowledges varies from one site to another. Given the impact of globalization as a phenomenon that has propelled the re-conceptualization of boundaries and borders, it is important to note the dependence of globalization upon the accumulation of certain kinds of geographical knowledge and the evolution of geography as a distinctive way of knowing permeates social thought and political practices. The state apparatus itself has become a primary site for the collection and analysis of geographical information. David Harvey observes that geographers, while situating themselves within such frameworks of geographical knowledge production, may unconsciously become tacit agents of state power. The interests of individual states can even lead to the production of specific kinds of geographical knowledge that serves respective national interests. Such an impact of geographical influences in the discussion of territory has also been a major factor in its conceptualization, a factor particularly significant in the context of borderland studies as borderlands became the sites for the production of geographical knowledge (Harvey 2007).

However, whether conceptualized in terms of physical space or the more contemporary social interpretation, borders are still part of the state's strategy of exercising control over its subjects and borders draw their meaning from the way the State instrumentalizes them. The process of bordering is put into practice by the States not only to establish its sovereignty, but also to demarcate its own population from the 'Other'. Borders are constructed and constantly reproduced through conscious social and legal discourses (Tripathi \& Chaturvedi 2020). While borders separate one sovereign territory from another, Newman notes, demarcating a boundary is not only about the lines on the map which are then transformed into physical fences and walls that mark a tangible sign of separation. He argues that not only are borders products of social and political discourses, they are also created by those in the position of power who think that they are representing a collective identity (a set of people sharing the same social, political, or cultural marker) and thus these power elites create border to keep out those who do not share the same trait (Newman 2011). These political ontologies of borders, territorial nation-state, and consequent territorial practices reflect in state practices through the administrative and security apparatuses namely, the BSF, the police, and the special security agencies in borderland regions. These organizations use processes of securitization and other border management practices. Security practices and institutions, however, do not exist in a vacuum. Rather they are located within social-cultural and political ideas and practices of where the boundaries between 'self' and 'other' lie. The next section brings out how dominant ideas of national identity and national community come into play in the borderland regions with reference to Bengal Borderlands.

\section{Between Hard Borders and Fluid Social Spaces: Situating Bengal Borderlands}

The fieldwork for this study was conducted in border districts of West Bengal, namely Cooch Behar and South Dinajpur. It emphasizes the similar characteristics between these regions, namely the social-cultural demography and the political history of both West Bengal and Southern Assam along the border with Bangladesh. Therefore, it is appropriate for the purpose of generalization to take 
a broader definition of Bengal Borderlands rather than a narrow definition. The creation of Bengal Borderlands is entangled with the socio-cultural and political history of South Asia in the Post-1947 period. Therefore, national identity and border making and unmaking are entangled with each other. As in other parts of the world, borders have played a crucial role in the construction of national identity in Bengal borderlands (Schendel 2002; Penrose 2002). The modern nation-states follow the line of thinking that all individuals should belong to a nation, and all citizens of one such nation should have a national identity in common. Essentially, nationalism is an ideology employed by the State to bring about such a homogeneous identity that people within a certain territory would subscribe to (Anderson 2016). Katherine Verdery (1999), in the context of Europe, provides detailed insights on the concept of nationalism and how it relates to states' conceptions of border. She points out the idea of a nation has become a category, a symbol within the international system of states where it not only defines the relations between a state and its subjects but also the relations between states themselves. A nation is the link between a state and the subjects it governs.

Borders as markers of identity between self and other are central to current conceptualization of nationalism (Penrose 2002, 7-8). Modern national territorialities differ from traditional territorialities in the sense that modern nationalism draws emotional or latent feeling from the territory under its control (Penrose 2002, 7). David Kaplan and Guntram Herb emphasize the impact of geography on the discourse of national identity and argue that "nationalism is an intrinsically geographical doctrine in that it seeks to conjoin a self-identified group of people-a 'nation'-within a sovereign, bounded geographical area-a "state" (Kaplan \& Herb 2011, 349). Hence, the kind of national identity portrayed at the geographic core of the state differs vastly from the one at the peripheries.

Borderlands represent contradictions and tensions between the nation-state and local society (Gellner 2013). Resolving these contradictions and tensions are at the heart of nation-state building processes in the borderlands. Nation-state building processes involve claims of nation-state transcending local communities or those communities which cut-across social and cultural boundaries (Emerson 1960; Smith 1991). Hence, nation-state and nationalism attempt to fold local communities within themselves through border making and larger national identity reinforced through national identity discourses and the securitization of borders. In fact, it is the securitization of borderlands as national space. National identity discourses legitimize and reinforce the securitization of identity and border management practices to smooth the social fluidity into the larger national identity.

Nationalism also singularly focuses on homogeneity (Krishna 1994; Ghosh 2016). It aims not only at bringing people together but also excludes those subscribing to a different identity other than the national one. However, such a homogenizing project does not work the same way in the region of South Asia as it does in Europe. Borders in Asia arising out of interstate rivalries were in stark contrast with those of Europe in the sense that, according to the prevalent European scholarship, the Asian region previously lacked the notion of a linear boundary-the states were not bounded by a marked line. Instead, the area controlled by one particular state would slowly pan outwards. That is, states in Asia did not conceptualise boundaries in linear terms, in contrast with how Europe saw it (Iwashita \& Boyle 2015).

Borders and identity have a complex relationship. Identity can be defined with reference to geography, society, culture, and other dimensions. International Relations essentially focuses on national identity in understanding borders due to statist bias. However, the concept of identity becomes significant to understand in the context of borderlands because "borders can construct, challenge or even reaffirm national identity" (Kaplan \& Herb 2011). Thus, identity is defined within the sovereign territory of the nation-state and territory becomes the central axis through which identity carries meaning. However, given that territory is socially constructed, the relationship between identity and territory remains unstable and dynamic (Ruggie 1993; Forsberg 2003).

Discourses of national identity, the securitization of fluid social spaces in borderlands, and border management practices attempt to construct a stable and fixed idea of the border that demarcates the boundaries between self and other. Kaplan and Herb note that, "without a stable boundary to demarcate a particular nation, national identity cannot really be conceived. Without the presence of a nationalist territorial ideology, national identities must always contend with their geographic manifestations" (Kaplan \& Herb 2011).

In the specific case of South Asia, state borders on the other hand, struggle with 'cartographic anxiety' (Krishna 1994). Sankaran Krishna refers to 'cartography' as representational practices with regard to society, culture, and other elements that go beyond the geographical mapping of a state that render meaning to the idea of a 'nation', thus forming a link between the sovereign territory and the people that make it a nation. The struggle between the identity dimensions of a former colony and that of a newly formed state is manifested in aggressive and violent nation-building processes. The boundary lines that are drawn on the physical map, "geo-coding" as it is officially recognized, does not always reconcile with the on the ground reality, often turning borderlands into volatile conflict zones.

In his book 'Seeing Like a State', James Scott notes the modern nation-states' tendency to clearly project where one nation ends and another begins, is an embodiment of high-modernist tragedy (Scott 1999). These arguments clearly portray the statist bias in Realism that perceives nations as spatially contiguous entities, in keeping with 
the nationalist imagination. In post-colonial societies, the boundary lines drawn by the colonial rulers are not in sync with the social history or cultural setting of that region. Norms of spatial rationality are overlooked as physical boundaries cut across social markers. Like in the case of the Radcliffe Line in 1947, the boundary divided the region of Bengal on the basis of religion, leaving large numbers of both communities on either side of the boundary which in turn resulted in blurring the notions of inclusion and exclusion. Shankaran Krishna further notes that:

\begin{abstract}
At the same time, people who live along borders are wont to regard this latest discursive universe of nationality and territoriality as, at a minimum, one more minefield to be navigated safely, or-better-one to be profited from. The encounters between the state and the people along frontiers is suggestive of the contested and tortured production of sovereign identity. Ultimately, cartographic anxiety is a facet of a larger postcolonial anxiety: of a society suspended forever in the space between the "former colony" and "not-yet-nation." This suspended state can be seen in the discursive production of India as a bounded, sovereign entity and the deployment of this in everyday politics and in the country's violent border (1994, 508).
\end{abstract}

Such insecurities are only further triggered by the nature of borders in South Asia, what Suba Chandran calls 'rigid, porous, simple and open' (Chandran \& Rajamohan 2007). He points out that borders in South Asia are often an artificial imposition and a historical anomaly as most of them were created and imposed by the colonial rulers (Chandran \& Rajamohan 2007). Managing borders that were products of interest to the previous power-holders has led to a practical dilemma, giving rise to border disputes that still remain unresolved after decades as the states in South Asia struggle with reconciling post-colonial realities with their colonial legacies.

However, it is the relationship of the post-colonial states with its peripheral spaces that remains understudied. James Scott notes how the discourse of state-making processes, encompassing all the aspects from trade to territory to governance, has steadfastly made it a point to not acknowledge the resistance it has faced from peripheral regions, in times both past and present. This claim holds true for nearly all the regions, but particularly in the case of South Asia and Bengal Borderlands. The modern Indian state, both colonial and post-colonial, has dealt with people who are deliberately out of its span of control, a history Scott calls anarchist (Scott 1999).

Whilst looking at state-making in South Asia, one has to take note of the difference between people living in the lowlands as opposed to those living in the hills-or the peripheries (Suan2009, 269). The peripheral space has long been a point of concern for the core-centric state primarily operating out of the lowlands, given that geographical as well as demographic complexities had made most of the peripheral regions inaccessible. However, the resources that peripheries had to offer were economically too lucrative to pass on, while it also meant the peripheral regions did not need the core, thus affecting the sovereign nature of the State. The borderlands in Eastern and North-Eastern India had long been excluded out of the 'core' imagination, marked by not only different dimensions of identity but also social, cultural, and economic practices vastly different from those of the lowland people. As Sanghamitra Misra (2014) notes, the colonial exploitation of the region's resources implied a massive change in the political, social, and economic space of the peripheries. She goes on to note how the exclusion of peripheral spaces continues to take place even in post-colonial history.

The different societies and communities living on the Bengal borderland are arbitrarily categorized-or worse, clubbed together-the region becoming only a 'frontier' within the larger spaces of Mughal or Colonial Empire. The historical borders are easily allowed to overlap with the contemporary state borders, reflecting the bias of a core-centric imagination that systematically continues to overlook the periphery. Misra (2014) goes on to point out how the pre-colonial spatial order that had earlier categorized the region that fall outside the Western framework of sovereignty (suchas ethnic groupsco-existing on the principle of shared sovereignty), continues to be ignored by national historians who are unwilling to look beyond a core-centric national imagination, but also the colonial spatial order that was imposed on the region for the sake of reflecting shared history, an element crucial to the project of nationalism.

Attempts at constructing such a homogenous, singular history have steadfastly ignored how the region's social and ethnic fabric were changed during the colonial period, resulting in several ethnic identity conflicts threatening to disrupt post-colonial India's federal establishment. The Radcliffe line that first separated the two nation-states of India and Pakistan, and then Bangladesh since 1971, has been criticised by scholars working on South Asian borders, and particularly the event of Partition, given its irregularities that completely ignored the spatial realities of the region, but also its strategy of dividing the population based on religion (Chatterji 2002; Banerjee 2018). The influx of immigrants crossing this particular border has always remained a central concern in India's border management policies, but it is particularly crucial in the North-eastern region which is already ethnically distinct from the so-called heartland of India. That demographic changed when settlers were invited over to the region to meet economic demands which, in case of both Assam and Tripura, altered the demographic reality of each area.

It is important to point out that the partition of 1947 and its religious nature particularly affects India's border management policies. Although illegal immigrants remain a concern for the state, there is also a strange burden on India to unofficially accept the Hindu political immigrants while keeping out the Muslim immigrants. While the peripheral spaces dealing with the burden of immigrants 
do not make distinct divisions on whom they consider an 'outsider', history has not been particularly kind to Muslim immigrants in India. Other bordering states with Bangladesh, such as West Bengal and Tripura also face a large influx of immigrants with the Indian population becoming particularly hostile towards refugees as they are considered 'outsiders' despite sharing mostly similar ethnic markers. Such phenomena expose certain changes in the binary difference between 'us' versus the 'other' as well as insecurities in the peripheral spaces, even within the larger national narratives. Therefore, national identity, security, and border management practices reflected in practices of administrative and security apparatuses on the border come into tension with the fluid nature of social spaces in Bengal Borderlands. The next section further discusses these dynamics through the everyday lives and narratives of communities in Cooch-Bihar and South Dinajpur along India-Bangladesh border in West Bengal State of India.

\section{Everyday Narratives of Borderland Communities: Evidences from Cooch-Bihar and South Dinajpur in West Bengal, India}

Having established in the previous sections that there are tensions between fluid spaces and hard borders in borderlands, this section examines these dimensions through everyday narratives and lives of people based on field trips in two districts along India-Bangladesh border. India and Bangladesh share the fifth longest land border in the world, spanning along the vast distance of 4096 kilometres. The Indian state of West Bengal shares the longest stretch of 2217 kilometres with the neighbouring state, a complicated history that goes back as far as the event of Partition in 1947. Part of the field study that this paper draws upon* was conducted from 15 January 2017 to 14 February 2017 in the Mekhliganj sub-division of Cooch Behar district that housed 51 Bangladeshi enclaves prior to the historic Land Boundary Agreement in 2015 (Bhattacharya 2015) [Figure 1].

The study was based on informal, open-ended interviews as well as personal interactions carried out by the researcher who spoke to almost eighty people, including both the enclave community as well as members of the local community that are officially Indian citizens. India and Bangladesh shared the largest enclave complex in the world, the count reaching almost 162, including the world's only third-order enclave named Dahala Khagrabari that was an Indian enclave encircled by a Bangladeshi village which itself was located in Indian territory, again encircled by Bangladeshi territory. Swapping of the enclaves resulted in Bangladesh gaining a little over 17 thousand acres of

\section{Note}

* Data collected from the fieldtrip has also contributed to the author's M.Phil. dissertation awarded by University of Hyderabad in 2018. land, whereas India received a little over 7000 acres, a significant loss of territory from a realist perspective (Banerjee, Basu Ray Chaudhury \& Guha 2017).

The second part of the field study was conducted in April 2017 in the Balurghat sub-division of South Dinajpur that houses the Hilli border check post on the boundary between India and Bangladesh. The South Dinajpur district was a direct result of the Partition of 1917 as the erstwhile Dinajpur district was bifurcated into West Dinajpur and East Dinajpur. East Dinajpur became a part of Pakistan while West Dinajpur was subsequently divided into North Dinajpur and South Dinajpur. Balurghat in South Dinajpur lies only a few kilometres away from Hilly border post on the India-Bangladesh boundary. The check post is only a strategic point on the map. In reality, the boundary has literally cut through the area, so on both sides of the border, the town continues to be called Hilli, without any specific national reference to either India or Bangladesh. The Hilli border check post in is located on the border between India and Bangladesh and it serves as a strategic point in cross-border trade between India and Bangladesh. Moreover, as with other border districts, South Dinajpur is a security concern given the illegal smuggling of cattle, and agricultural products like cumin

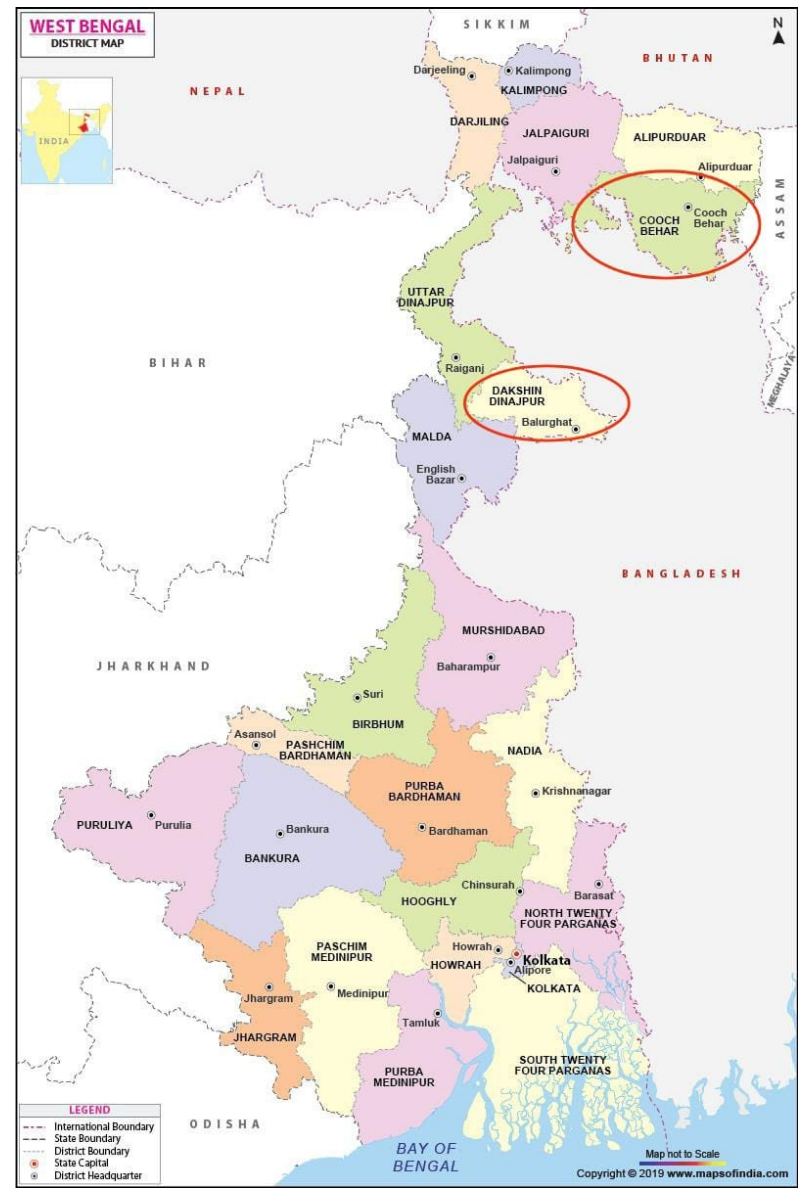

Figure 1. District map of West Bengal, India highlighting districts of South Dinajpur and Cooch Behar.

Source: infoandopinion.com (red ellipses added). 
seeds, and some drugs that are banned in Bangladesh, for example, a particular cough syrups (Press Trust of India 2020). There is also a notoriously high trend of sex trafficking which is often carried out through this district and therefore there is a very high surveillance alert all over the area ("Prostitution Corridor on Bangladesh Border: How Human Traffickers Buy Land and Smuggle Women" 2017). During the study in Cooch Behar, the researcher interacted with approximately eighty people who were earlier residents in the Masaldanga enclave, relocated to the enclave resettlement camp in Mekhliganj sub-division of the Cooch Behar district. The spatial characterization of border and its implications reflected itself in how the communities living in the border districts of West Bengal experience it on an everyday basis. In the South Dinajpur border district that runs along almost fifty percent of the boundary between India and Bangladesh, the invisible border continues to cut across families, livelihoods, homes, and properties.

There are almost 70 homes near the Radcliffe line in the whole district of South Dinajpur, which ideally should not be inhabited by any kind of settlements, strategically referred to as no man's yard. But almost three quarters of the district falls into Bangladesh territory, resulting in a scenario where peoples' homes are situated right in the middle of the border. Even the most ordinary livelihood or social practices are in danger of being directly or indirectly facing security threat. This situation has come to mean that peoples' lives here are highly monitored and regulated, disrupting the flow of living and presenting difficult socio-economic conditions.

People in Balurghat have seem to mostly come to terms with the fact that their lives are permanently disrupted by existence of the international boundary (informal interviews with several town residents, March 22, 2017). Most people have their homes so closely located to the Radcliffe line that having two rooms of the house on two different sides of the border is not uncommon. Border here is perceived to the extent of being even invisible, given its historical context and highly porous nature. Residents stated that it is extremely common for them to cross over the boundary and visit the market for grocery shopping on the other side (interview with Sima Das [alias], age 43, March, 2017). 'Crossing' an international boundary for them does not quite hold extraordinary significance since the border was imposed on them. It is extremely crucial to note how the notion of 'crossing' a border differs vastly from the perspective of state and the communities respectively. Residents have complained that the only school in the town had closed down, compelling children to cross over to Bangladeshi territory. The state would consider this movement illegal, but in reality, this movement lacks criminal intent.

The border districts between West Bengal and Bangladesh, due to their highly porous nature, are considered a hub of cross-border drug and sex trafficking. This has resulted in extremely high level of surveillance, disrupting regular life in the area. The BSF guard on duty pointed out that at times approximately 42 kilometres of the Radcliffe Line passes along Hilly Check point, and out of that only about 18 or 19 kilometres are fenced (interview with on-duty BSF patrol guard, March 2017). The unfenced area does not act as any less of a boundary, but the lack of fence makes it difficult to monitor. There were almost 20 homes that had the Zero line through them. This means that not only border shapes the lives here, but even mundane daily routines carried out by the people living here are significantly impacted by the nature and functioning of the border. The residents are required to deposit their identity cards at the gates that run along the Radcliffe line while crossing over to Bangladesh, but given that the gates are only open at certain times, there was an echoing sentiment of frustration and resentment in being bound in their own homes. Most of the residents complained that it is extremely difficult when there is an emergency, and they would have to wait for a senior official to allow them to pass through. Some of the residents confessed to having dual identity cards, issued by both governments for emergency purposes (informal communication with members of local community on condition of confidentiality).

Most of the BSF guards were in agreement that daily life indeed becomes difficult under constant surveillance, and they at times choose to opt for co-existence, allowing some of the known faces to cross over even without an identity card. They stated that in a region as porous as this, it is important to maintain good terms with the local people. The border patrol guards from both sides seemed to happily engage in friendly conversations from time to time. The fluidity of such exchanges between local people, as well as the security forces reflect the idea that borders are no more rigid geographical markers for separation. The boundary between India and Bangladesh is almost over 4000 kilometres long with similar ethnic population on both the sides. The porous nature of Radcliffe Line allows exchanges and movements to take place, and the states cannot enforce overly rigid norms to prevent such exchanges. However, in Cooch Behar at the Tinbigha border post, the high-ranking officials clearly reflected staunch state-centric mentalities where they perceive border strictly in terms of protecting national security and border management is means for them to prevent foreign intrusion into the sovereign territory (open-ended interview with BSF officer-in-charge, March 12, 2017).

The senior government officials at the borderlands receive orders directly from the political and administrative authorities within the central government. The senior government officials at the borderlands strictly follow the security discourse as expressed by the political and bureaucratic sections, and in doing that, they discount the socio-economic motivations or intent of those entering or exiting the territory, making it more difficult for the borderland communities for whom crossing the border is mostly for the purpose of trade and livelihood. Even while the official is aware that not all of them are involved 
in illegal activities, they insisted that regulations are uniform for all. On the other hand, the guards in charge of patrolling the border appeared more empathetic towards the common people and their livelihood problems. Most of them maintained that the situation compels most of the locals to adopt illegal means of crossing the border, and the legal boundary indeed overlooked the social and economic practices that have been going on in the region before the boundary was created. They also indicated that regular patrolling guards interact with the locals on a daily basis, and hence their paramount focus is to avoid unnecessary violence and confrontation (conversations with several patrolling guards on both sides of the border, March 2017).

The enclave re-settlement camp in the Mekhliganj subdivision in the Cooch Bihar district of West Bengal houses close to 200 people who are either Indian citizens who chose to have crossed over from Bangladesh or Bangladeshi citizens who chose to stay back in India. Entry in the camp is not allowed without authorized permission from the officials. The residents, when asked about their perception of borders, were of the opinion that the border is something decided upon, and controlled by the political leaders in the interest of the state. In their daily lives, the border only served as a barrier. Their situation was all the more complex given that they were separated from their 'homeland', resulting in estrangement from their families, relatives, and means of livelihood that could have provided them better socio-economic circumstances (informal interviews conducted in the enclave resettlement camp in Mekhliganj, Cooch Behar, February 2017).

Even during the final exchange process, the residents complained that some of them were tactfully held back from joining their choice of country, by means of delaying the distribution of forms or withholding of information. The census survey conducted before the final exchange had also faced a lot of resentment from the residents who were of the opinion that the survey was hastily done and contained incorrect data, in the sense that people who were not present during the survey, even for the day, were not allowed to opt for joining India or Bangladesh as per their choice (interviews with former residents of the Masaldanga enclave, March 2017). Most of the older people considered themselves Bangladeshi, and not Indian. That in turn results in a feeling of abandonment as they confessed how they had never been able to conjure the sense of belonging even after living the better part of their lives in the enclave. The border forced them to stay alienated from their 'homeland' (conversation with seven people aged between 60-65 years, including four males and three females, on condition of confidentiality). The former enclave residents revealed that although they identified themselves as Bengali, as in the ethnic basis of identification.

The camp residents mostly agreed that without the conscious sponsorship of the state that carries itself through the notion of national identity, a common ethnic identity is not enough to bring people together. Things were even more difficult in enclaves as they defy the regular notions of territoriality, sovereignty, and citizenship. The residents were of the opinion that, even though the community right outside the enclave were not much different in terms of everyday lifestyle nor did they project any sense of hostility or unwillingness to engage with them simply on the account of the enclave dwellers being Bangladeshi on paper, the absent tag of Indian citizenship had always been an invisible barrier, always a reminder that they are foreigners on Indian soil (open-ended interviews conducted with former Masaldanga enclave dwellers, February 2017). However, it is interesting to note that almost a majority of them were of the opinion that the act of simple existence is too difficult for them to actually ponder over where they belong to, or what their identity is. The enclave residents seem to have become a category in themselves, defined not by state or ethnicity but their unique circumstances and the struggle of survival in an age where everything is controlled by the approval of state, which also happened to be the one thing they lack. However, the younger generations appeared divided on the question of identity. They questioned the utility of having an ethnic identity without having a national identity to back it up in practice. Those who had grown up in the enclaves did not seem too keen on being identified as Bangladeshis, although they seemed to be consciously refraining from identifying with the state of India. The younger generation seemed to have accepted the sense of alienation from their home country, and offered sincere acknowledgments for the services and amenities offered by India as the host country (conersation with group of 12 people aged between 23 to 35 ).

The enclave residents are Bangladeshi citizens confined within the territory of India, and in order to conduct even their basic everyday activities for survival and sustenance, they were constantly under scrutiny. As literature widely acknowledges (Paasi 1998; Ackleson 1999; Tripathi 2015), bordering is a process that is shaped by the activities that go on in the border regions, and state borders often do not leave the space for the long-existent social, cultural, or economic practices to be conducted freely, rendering them 'illegal' (Shewly 2013; Jones 2012). As a result, the enclave residents were compelled to resort to illegal means of cross border movement. Respondents said the Indian villages around the enclave boundaries had allowed them to farm on their lands, or graze cattle, or take up other household jobs in order to earn money since the enclave residents lacked the official documents, such as identification documents, required to apply for jobs on Indian territory.

The camp residents seemed in agreement that the exchange treaty had not resulted in a higher quality of life in the camp and the living conditions are in some ways worse than what they faced earlier. They stated that the ration they receive from the government on a monthly basis is nearly not enough for even two weeks. The residents have 
little to no cash, and almost no jobs. The government has not offered them any livelihood options or any vocational training that would enable them to find jobs on their own. The younger residents sneak out of the camp to find jobs that do not require official documentations or educational qualifications, but of course those jobs do not pay much. The residents also protested the governments' decision to move the camp from its current location (Singh 2019).

The Mekhliganj Enclave Settlement Camp is set up just a few metres away from the main road, the local market and the bus stop. However, the Government of India has been contemplating to shift the camp to another location a little more interior. The camp residents told the researcher that, the shift would possibly result in further difficulties for them since they have no means of transportation. Mekhliganj, where the camp is located, is only a small town that has the bare essential facilities. The camp residents have no bicycle/motorcycles for transportation purposes. Shifting to an interior location of what is already a small town would mean that they would have to walk to whatever the destination is, regardless of the distance, even for emergency purposes.

\section{Conclusions}

The everyday lives and narratives of people in borderlands, therefore, are a critical site to examine and understand how discourses of nationalism, identity, and security, as well as securitization and administrative border management practices, affect the day-to-day lives of people located in fluid social spaces. This paper has made an attempt to understand these tensions through ethnographic studies in two districts in the West Bengal state of India adjoining the India-Bangladesh border. The dominant security and identity discourses reflected in the practices of security and administrative institutions namely, the BSF, the police, and other security agencies, and district administration. This is revealed in how the fluid social space and lives of people situated within such spaces are overlooked or looked at as a security threat. For the people residing in these spaces, it is the question of life and livelihood, and most of the times it is these legitimate intentions that lead them to 'violate' rules while crossing the border. As discussed above, even security and administrative officials do acknowledge at times that most people cross the border and 'violate' rules out of sheer necessity of livelihood. But what is ignored and overlooked is that it is the dominant security and identity discourses that shape security practices within these institutions and processes in border regions, and hence, the empathy and sensitivity to the fluidity of social spaces of borders is disregarded by administrative agencies and security forces.

The rigid security centric policies and administrative rules and institutions that regulate borders, however, cause problems that can be solved if there is sensitivity that is often illusive to states in peripheral regions. While legitimate security threats exist in the form of human, drug, and cattle trafficking, the security and administrative officials and agencies deal with social processes that are 'normal' for people in the borderland regions. Hence, the tensions between security-centric policies and dynamic social spaces in the borderland emerge. These tensions are a characteristic feature of the daily lives of people living right at the border with their house divided into two national territories, trying to earn a livelihood, without a sense of belonging. It is these aspects of everyday lives that make the quotidian an important site to understand and think about borders. This paper, therefore, has made an attempt to understand how everyday lives of people come into tension with border management by administrative and security agencies.

\section{Works Cited}

All hyperlinks last accessed December 2021 unless specified.

Ackleson, Jason M. 1999. "Discourses of identity and territoriality on the US-Mexico border" Geopolitics 4(2): 155-179. http://dx.doi.org/10.1080/14650049908407645

Agnew, J. 1994. "The Territorial Trap: The Geographical Assumptions of International Relations Theory" Review of International Political Economy 1(1): 53-80. https://doi. Org/10.1080/09692299408434268

Anderson, Benedict. 2016. Imagined Communities. London: Verso Books.

Banerjee, Sreeparna, Anasua Basu Ray Chaudhury, and Ambalika Guha. 2017. "The 2015 India Bangladesh Land Boundary Agreement: Identifying Constraints And Exploring Possibilities In Cooch Behar" ORF Occasional Paper. Observer Research Foundation. https://www.orfonline.org/research/ the-2015-india-bangladesh-land-boundary-agreement-identifying-constraints-and-exploring-possibilities-in-cooch-behar/

Baruah, Sanjib. 1999. India against Itself: Assam and the Politics of Nationality. New Delhi: Oxford University Press.

Bhattacharya, Snigdhendu. 2015. "History At Midnight: India, Bangladesh Exchange Enclaves" Hindustan Times (August 1). https://www.hindustantimes.com/india/history-at-midnight-india-bangladesh-exchange-enclaves/story-gLtjOSQWFhbnCFsROS1Ral.html

Brenner, Neil, Stuart Elden, and Gerald Moore. 2009. "Introduction: State, Space, World: Lefebvre and the Survival of Capitalism" in State, Space, World: Selected Essays, edited by Neil Brenner and Stuart Elden, 1-48. Minnesota: University of Minnesota Press.

Carter, D. B. and Goemans, H. E. 2011. "The Making of the Territorial Order: New Borders and the Emergence of Interstate Conflict" International Organization 65(2): 275-309. https://doi.org/10.1017/S0020818311000051

Chandran, D. Suba and P.G. Rajamohan. 2007. "Soft, Porous or Rigid? Towards Stable Borders in South Asia" South Asian Survey 14(1): 117-128. https://doi. org/10.1177/097152310701400109

Chatterjee, Partha. 1993. "Whose Imagined Community?" in The Nation and Its Fragments: Colonial and Postcolonial Histories, 3-13. New Jersey: Princeton University Press.

Chatterji, Joya. 2002. Bengal Divided: Hindu Communalism And Partition, 1932-1947. Cambridge: Cambridge University Press. 
Chaturvedi, Vinayak (ed.) 2000. Mapping Subaltern Studies and the Postcolonial. London: Verso.

Cons, Jason, and Romola Sanyal. 2013. "Geographies at the Margins: Borders in South Asia-An Introduction" Political Geography 35: 5-13. https://doi.org/10.1016/j. polgeo.2013.06.001

Donnan, Hastings and Thomas Wilson. 1999. Borders: Frontiers of Identity, Nation and State. London, Routledge.

Elden, Stuart. 2013. The Birth of Territory. Chicago: Chicago University Press.

Emerson, R. 1960. From Empire to Nation: The Rise of SelfAssertion of Asian and African Peoples. Cambridge: Harvard University Press.

Forsberg, Tuomas. 2003. "The Ground without Foundation: Territory as a Social Construct" Geopolitics 8(2): 7-24. https://doi.org/10.1080/714001038

Gellner, David N. (ed.). 2013. Borderland Lives in Northern South Asia, Durham \& London: Duke University Press.

Ghosh, Partha S. 2016. Migrants, Refugees and the Stateless in South Asia. New Delhi: Sage.

Gilpin, Robert. 1981. War and Change in World Politics. Cambridge: Cambridge University Press.

Herz, John H. 1957. "Rise and Demise of The Territorial State" World Politics 9(4): 473-493. https://doi.org/10.2307/2009421

Houtum, Henk van, Olivier Thomas Kramsch, and Wolfgang Zierhofer. 2016. B/Ordering Space. London: Routledge.

Iwashita, Akihiro, and Edward Boyle. 2015. "State Borders in Asia" in Introduction to Border Studies. Dalnauka: Vladivostov.

Jones, Reece. 2012. "Spaces of Refusal: Rethinking Sovereign Power and Resistance at the Border" Annals of the Association of American Geographers 102(3): 685-699. http://dx.doi.org/10.1080/00045608.2011.600193

Kaplan, David H. and Guntram H. Herb. 2011. "How Geography Shapes National Identities" National Identities 13(4): 349-360. http://dx.doi.org/10.1080/14608944.2011.629424

Krishna, Sankaran. 1994. "Cartographic Anxiety: Mapping the Body Politic in India" Alternatives: Global, Local, Political 19(4): 507-521. https://doi. org/10.1177/030437549401900404

Laine, Jussi P. 2015. "A Historical View on the Study of Borders," In Introduction to Border Studies, edited by Sergei V. Sevastianov, Jussi P. Laine, and Anton A. Kireev, 12-33. Dalnauka Vladivostok.

Massey, Doreen. 1994. Space, Place, and Gender. Minnesota: University of Minnesota Press.

Ministry of External Affairs, Government of India. 2015. IndiaBangladesh Land Boundary Agreement. https://www. mea.gov.in/Uploads/PublicationDocs/24529_LBA_MEA_ Booklet_final.pdf

Misra, Sanghamitra. 2014. Becoming a Borderland: The Politics Of Space And Identity In Colonial Northeastern India. Delhi: Routledge.

Newman, David. 2011. "Contemporary Research Agendas in Border Studies: An Overview" in The Routledge Research Companion To Border Studies, edited by Doris Wastl-Walter, 33-49. London: Routledge.

Newman, David. 2006. "Borders and bordering: Towards an Interdisciplinary Dialogue" European JournalofSocialTheory 9(2): 171-180. https://doi.org/10.1177/1368431006063331
Paasi, Anssi. 1998. "Boundaries as Social Processes: Territoriality In The World Of Flows" Geopolitics 3(1): 69-88. https://doi. org/10.1080/14650049808407608

Paasi, Anssi. 2005. "The changing Discourses on Political Boundaries: Mapping the Backgrounds, Contexts and Contents" in B/ordering Space, edited by. Houtum et al., 17-31. England: Ashgate.

Penrose, Jan. 2002. "Nations, States and Homelands: Territory And Territoriality In Nationalist Thought" Nations and Nationalism 8(3): 277-297. https://doi. org/10.1111/1469-8219.00051

Press Trust of India. 2020. " 6 Held With Huge Consignments Of Banned Cough Syrup Near Bangladesh Border" Outlook India. https://www.outlookindia.com/newsscroll/6-heldwith-huge-consignments-of-banned-cough-syrup-nearbangladesh-border/1904739.

Reuters. 2017. "Prostitution Corridor On Bangladesh Border: How Human Traffickers Buy Land And Smuggle Women" India Today (June 23). https://www.indiatoday.in/india/ story/human-traffickers-fake-documents-india-bangladesh-border-984411-2017-06-23

Riggsby, Andrew. 2021. "Space" in The Cambridge Companion to the Roman Historians, edited by Adrew Feldherr, 152-165. New Jersey: Cambridge University Press.

Rosenthal, Caroline. 2012. New York and Toronto Novels After Postmodernism. Cambridge: Cambridge University Press.

Ruggie, John. 1993. "Territoriality and beyond: Problematizing modernity in international relations" International Organization 47(1): 139-174. https://doi.org/10.1017/ S0020818300004732

Schendel, Van Willem. 2002. "Stateless in South Asia: The Making of the India-Bangladesh Enclaves" The Association for Asian Studies 61(2 February): 115-47.

Schendel, Willem van. 2005. The Bengal Borderland: Beyond State and Nation in South Asia. London: Anthem Press.

Scott, James C. 1998. Seeing Like A State: How Certain Schemes To Improve The Human Condition Have Failed. New Haven: Yale University Press.

Shewly, Hosna J. 2013. "Abandoned spaces and bare life in the enclaves of the India-Bangladesh border" Political Geography 32: 23-31. https://doi.org/10.1016/j. polgeo.2012.10.007.

Singh, Shiv Sahay. 2019. "Life After Citizenship In West Bengal's Cooch Behar" The Hindu. https://www.thehindu.com/news/ national/other-states/life-after-citizenship/article26155766. ece

Smith, A. 1991. National Identity. Reno: University of Nevada Press.

Soja, Edward. 1971. The Political Organization of Space. Washington: Association of American Geographers, Commission on College Geography.

Suan, Kham Khan Hausing. 2009. "Hils-Valley divide as a site of Conflict: Emerging Dialogue Space in Manipur" in Beyond Counter-Insurgency: Breaking the Impasse in Northeast India, edited by Sanjib Baruah, 263-289. New Delhi: Oxford University Press.

Sur, Malini. 2021. Jungle Passports: Fences, Mobility, and Citizenship at the Northeast India-Bangladesh Border. Pennsylvania: University of Pennsylvania Press.

Tripathi, Dhananjay, and Sanjay Chaturvedi. 2020. "South Asia: Boundaries, Borders and Beyond" Journal of Borderlands 
Borders in Globalization Review | Volume 3 | Issue 1 | Fall/Winter 2021 Bhaumik, "Everyday Lives in Peripheral Spaces: A Case of Bengal Borderlands"

Studies 35(2): 173-181. https://doi.org/10.1080/08865655.2 019.1669483

Tripathi, Dhananjay. 2015. "Interrogating Linkages Between Borders, Regions, and Border Studies" Journal of Borderlands Studies 30(2): 189-201. https://doi.org/10.1080/ 08865655.2015 .1042010

Vaughan-Williams, Nick. 2012. Border Politics: The Limits of Sovereign Power. Edinburg: Edinburg University Press.
Verdery, Katherine. 1993. 'Whither 'Nation' and "Nationalism'?" Daedalus 122(3): 37-46. http://www. jstor.org/stable/20027181

Vladivostok, Dalnauka, and Doris Wastl-Walter (eds.) 2011. The Ashgate Research Companion to Border Studies. London, Ashgate Publishing. 


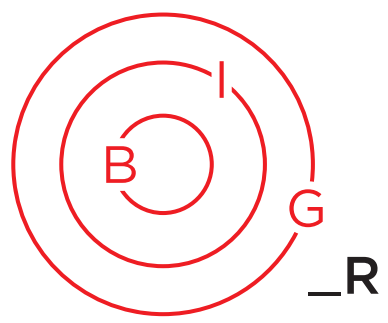

ARTICLE SPECIAL SECTION

\title{
Identity, Religion and Difference in the Borderland District of Poonch, Jammu and Kashmir
}

\author{
Malvika Sharma *
}

This article (part of a special section on South Asian border studies) is an exploration of a multi-religious ethnic group in the borderland district of Poonch in Jammu and Kashmir, India. The work focuses on the Pahari ethnicity and looks at how prominent religious identities within this group have been continuously aligning themselves along religious lines in the post-partition era. Partition of the Indian subcontinent in 1947 acted as a major disruption in the construction of identities. The evolution of national and ethnic identities went hand in hand with the evolution of religious identities, with the latter being more pronounced than the former. Such a fixation along religious lines in the socio-cultural and political sphere led to changes in everyday inter-community relations. Through oral histories and other accounts, this ethnography understands the new set of interactions that emerged in Poonch which have been shaping identities, while also analysing identity construction and its impact on the social organisation of space and neighbourhoods in general in the post-partition era.

Key Words: Borderland, Border, Boundaries, Community, Communalism, Difference, Ethnicity, Identity, Inter-community interaction, Nation, Nation-State, Othering, Religion

\section{Introduction}

In August 1947, the Indian subcontinent witnessed one of the bloodiest partitions along religious-lines in recent history, which led to the territorial division of the subcontinent into the nation-states of India and Pakistan. Though the event took place in August, it struck Jammu and Kashmir (then a princely state) in October 1947, two months after it hit the provinces of Punjab and Bengal. Poonch, the borderland that is the focus of this study, existed as an erstwhile fiefdom/principality in the princely state when the partition bisected it into two halves, each now existing as a borderland along two sides of the same boundary in Jammu and Kashmir. This work explores the role that the 1947 partition played in transforming both the socio-cultural and political nature of the 'space' of the fiefdom of Poonch in the pre-partition era and the hostile borderland that it has become in the post-partition period, thereby understanding partition as a rupture that stands in between the being and becoming of this borderland. ${ }^{1}$

The 1947 partition and the events that unfolded as a result of it in Jammu and Kashmir, particularly in the fiefdom of Poonch, form a major line of inquiry in this research that further informs the change in interactions between communities in the post-partition scenario. In fact, partition acts as a base-year/event for this research as any kind of religious-reassertion explored in this work has its origins in the turn of events in 1947 when partition

\footnotetext{
* Malvika Sharma, PhD Candidate, Sociology, Centre for the Study of Social Systems, School of Social Sciences, Jawaharlal Nehru University, New Delhi, India. Email: malvikasharma58@gmail.com
} 
first occurred. Due to a lack of secondary material on this topic, this research relies heavily on first-hand accounts, oral-histories, narratives, and memory as tools of research. My on-going work in the borderland of Poonch is perhaps first of its kind in the sociological and social-anthropological study of this region. Most of the narratives I collected, as shall be shown below, are deeply connected with the events of 1947. The narratives of contemporary life are intertwined with narratives of partition and have, in fact, shaped the social/political life in Poonch by transforming it into a borderland. Thus, the establishment of the borderland of Poonch lies in the unbecoming of the ethno-scape it was, with this transformation resting heavily on the 1947 partition as an event/a disruption/a rupture in the social-political and cultural history of this region. ${ }^{2}$

Poonch emerged as a borderland in the post-1947 era where a tragic set of events divided the territory of Poonch that existed as a jagir/fiefdom/principality under the monarchy of the princely state of Jammu and Kashmir into two halves. The infamous Pukhtoon-tribal-raid aimed at capturing the city of Srinagar, ${ }^{3}$ struck Poonch in late October 1947, and unleased targeted carnage and violence that continued for months thereafter. The first Indo-Pak war of 1947-48 lasted for more than a year and ended, due to UN-intervention, in the declaration of a ceasefire where both the states agreed to a ceasefire line (now known as the line-of-control or the LoC) that was laid across the points held as of January 1, 1949 by troops of both the nation-states. ${ }^{4}$ It was this cease-fire line formed at the culmination of the first Indo-Pak war that divided the fiefdom of Poonch into two parts, with one part lying on the side of the line in India and the other part in what came to be known as Azad Jammu and Kashmir, contested by India as a disputed territory. ${ }^{5}$

Borderlands are lived-habitable spaces where the implications of there being a strategic-cartographical boundary running through them cannot overlook the processes and inter-personal exchanges that shape the communities who inhabit these hostile contours. Once these regions along boundaries such as LoC are recognized as also regions with life, then the narrative changes, something that has been referred to in the works of Paasi (1998), Newman (2004), and Gellner (2013). Hence, diversified works in the social sciences take up where conventional political science and international-relations leave off. Sociology and social anthropology study borders as borderlands wherein they take into account the lived experiences of communities that inhabit them. Following these lines, this paper looks at the inter-communitarian interactions (between Muslims and non-Muslims largely) that constitute these lived habitable spaces thereby making borderlands living zones, much more than their perception of being cartographical-zones dividing sovereign nation-states. Poonch, as a borderland, has been made and unmade through various changes that the communities that constitute Poonch as Poonchies (the people of Poonch) have witnessed since 1947. These evolutions involve key changes to the interactions between communities. Another important point here is to see how borderlands in the north-western periphery along the LoC in Jammu and Kashmir have been least explored sociologically and anthropologically. A few of the good ethnographic accounts in the scholarship around this zone have come from Ladakh and Kargil, in an undivided state of Jammu and Kashmir, before its division into two union territories of Ladakh and, Jammu and Kashmir respectively after the recent abrogation of special status under article 370 in the Indian constitution on August 5, 2019 (Aggarwal 2004; Gupta 2013). The reasons for the lack of good sociological and anthropological studies are many, key among them are: these borderlands being one of the most hostile and violent zones of high risk; security and surveillance with issues of accessibility and mobility; and the marginal peripheral ethnicities that reside here, which are different from dominant identities of Dogra, Kashmiri and Ladakhi. 6

The Pahari-Poonchies are a community of ethnic relevance. Belonging to Pahari ethnicity, they are a linguistic group speaking the Pahari-pothowari dialect, 7 residing in a common territory with shared values and cultures (Oommen 1997; Smith 1986). They are a multi-religious ethnic group with a predominantly Muslim population, and with a substantial minority Hindu and Sikh presence. ${ }^{8}$ Besides shared ethnicity, the community as a Poonchi-Pahari community has a shared past that traversed the turbulent pre- and post-partition eras. All three communities bore the brunt of the post-partition carnage including the other ethnicities that also reside in the region such as Koshur and Gujjars and Bakerwals. However, the violence played a major role in changing the demographic composition of the area - as will be elaborated in the following sections. The tribal-raid and the partition-violence in 1947 onwards did act as a major disruption in the ethno-history of the Poonchies, where this disruption had the potential to unleash waves leading to assertive religious identities threatening the mutually shared ethnic-ties and bonds.

The drift in the intra-ethnic-ties however did not occur abruptly. The partition led division of Poonch acted as a disruption that triggered responses which played a major role in identity building based on religious affiliations in line with the larger nation-state identity constructions in India, Pakistan and in Kashmir. This paper brings into focus the transformed identities where identities became closed, aligning more along religious lines and thus threatening inter-community interactions within an ethnic-group. From changed neighbourhoods to changed cultural exchanges, identities have been more expressive along religious lines, bringing to a social-anthropologist a new set of readings which constructs ethnicity on a hostile ground where religious identity construction seems to threaten the ethnic bonds of solidarity. Therefore the questions that this paper explores are: Does the alignment of identities within an ethnic-group render 
shared ethnicity a myth? How do the interactions in a multi-religious ethnic-group change with assertive religious identities living with the memory of a violent partition? What does this tell us about the nature of multireligious-ethnicity, plurality and co-existence? Shail Mayaram (1997) raised that being bi-religious or multireligious has been the major mode of religious being in Asia and is distinct from being singularly religious. If so, what are the new challenges to such older forms of diversity and pluralism that can be explored while studying this particular ethnic-group? This research paper taps into these challenges emanating from an already hostile geographical space, a borderland, and puts them in the larger Asian and South-Asian perspective of belonging to a community where identities are driven by religion within a nation-state.

Change in spatiality and neighbourhood patterns across the religious communities in this borderland is something that this work relies upon in order to understand identities and their assertion along religious lines. The work infers how the organisation of neighbourhoods along religious lines is a two-way process. One is where religion had shaped neighbourhoods in the town of Poonch (the site of my study) in the immediate post-partition scenario, where the huge displacement and influx of minority non-Muslim population into the town of Poonch pushed out the local Muslims; and the other where newly formed neighbourhoods have come up in contemporary times, largely organised along religious lines thereby encouraging assertion through spatial construction and its use.

\section{Boundaries Generating Difference}

This borderland ethnic community is internally segmented through 'boundaries' (social, cultural, and political) that have escalated the drift between the primary religious identities, that is, the Muslims, the Sikhs, the Hindus, and the growing population of Christians in Poonch. Boundaries generating difference here have been studied by categorizing the interactions between these religious communities as those between the Muslims and the non-Muslims largely. Michele Lamont's (2002) work on symbolic and social boundaries inspires an understanding of these boundaries that have been responsible for categorization of identities into separate units within the community. Lamont's differentiation of symbolic and social boundaries is such that he calls symbolic boundaries 'intersubjective conceptual boundaries that precede the manifestation of social boundaries' (Lamont \& Molnar 2002, 169). Before social boundaries generate evident social differences like inequality and hierarchy, which further translate into an identifiable pattern of social exclusion, it is the invisible abstract presence of symbolic boundaries that is effectively at play causing psychological difference and othering (Lamont \& Molnar 2002). The subjective individualistic and mental presence of symbolic boundaries have the ability to segregate individuals, however, it is these same boundaries that also organise individuals into groups based on various metrics of commonness, we-feeling, and compatibility. This associational and dissociational trait of symbolic boundaries makes them an interesting study for mapping exclusion and inclusion patterns, how groups in a community segregate or come together, and the forces that lead to such fluctuating changes. Lamont (2002) puts it wonderfully when he says, "How do individuals think of themselves as equivalent and similar to, or compatible with others, and how do they perform their differences and similarities in day to day lives?" Lamont's work on boundaries is an interesting prism of looking at community-relations in Poonch and seeing how boundaries work in social relationships as elaborated through empirical findings in this work ahead.

Coming to an understanding of ethnicity and religious identities, a review of Harjot Oberoi's construction of religious boundaries is useful for an understanding of conceptual categories like culture, religion, and diversity in this work. This is further substantiated by reading Oberoi's (1994) understanding of religious identities along with Smith's (1986) ethnic and national identities, Varshney's (2001) ethnicity and inter-ethnic engagement, and Nandy's (2020) understanding of religion as faith-systems.

Ashutosh Varshney's understanding of ethnic identities in a way has informed an understanding of ethnic-identities present in this borderland district. His engagement with the informal and formal networks in a community, where he differentiates the everyday informal quotidian networks between families, individuals, and neighbourhoods from the formal civil ties that are generated through formal institutions like police, bureaucracy, and civil societies is vivid. After reading through primordial, perennial, and modern constructs of nation and ethnicity (Smith 1986), Varshney's understanding of ethnicity provides fresh insight into understanding the every-day lived ethnic-life such as in the borderland of Poonch. He calls inter- and intra-ethnic ties within a community or between two or more communities 'networks of engagement', and adds that it is upon these networks of engagement that vulnerability of an ethnic group to ethnic-conflict depends (Varshney 2001). These networks of engagement decide how integrated and disintegrated a community is on ethnic-lines. According to him, formal associations play a larger role in the integration of a community, because formal associations are regulated by institutions with power unlike the quotidian associations that are successful in integrating neighbourhoods and smaller regional affiliations. But in the times of a threat it is the formal civic-ties regulated by state backed mechanizations that defer chances of a conflict and hence negate the chances of larger ethnic-violence taking place. Varshney's take on ethnic-conflict, everyday interaction, violence, riots, and pogroms, and how they all differ from each other in a way informs communal understanding of religious diverse ethnic community of Poonch as elaborated below. 


\section{Displacement Led Migration: Understanding the Transformed-Neighbourhoods}

Before understanding the shift in identities, and looking at what is causing identities to perpetually organise themselves on religious-lines in an otherwise multi-religious Pahari community of Poonch, this paper would like to first discuss how the post-partition turn of events acted as a severe disruption, changing the spatial demographic organisation of the region, especially in the town area. My ongoing fieldwork in Poonch gave me an opportunity to interact with four survivors of the October 1947 carnage, all of them nonagenarian. Their detailed first-hand accounts are a subject matter of a separate paper and demand an exclusive piece on their oral-narratives, however the narratives collected cite incidents that matched each other so well, hence validating the events that took place in 1947-48.9 These narratives also helped in locating the prime source of spatial-reorganisation based on religious identity affiliation. Before this, when I started to map the town ${ }^{10}$ and understand the construction of various neighbourhoods, it did become clear that most of the peripheral spaces in the town are largely occupied by Muslim households, with Sikhs and Hindus being located towards the centre and the core. The reasons for this are both historical and rooted in contemporary pattern of migration in and out of the town.

I started to map the town quantitatively, having decided to take fifty respondents from each community, that is, Muslims, Sikhs, and Hindus based on random sampling. Having done so, I did not get satisfactory results that might have been the required representational sample of the town. There were two reasons for this; one, because in a random sampling in every household chosen, the probability of finding people in the age bracket above sixty years was bleak (as this was the age-group that I was particularly interested in as their narrations were crucial in grasping the social-history of the region) and two, the demarcation between neighbourhoods was not always sharp particularly in the semi-peripheries where neighbourhoods were with a mixed population. Moreover the entire exercise seemed like an institutional survey that could not satisfy my desire to study this community through narratives. I purposely chose to snowball through my contacts and acquaintances and visited people across religions who fell in the right age-group and who could speak about the events in fifties and sixties in an immediate post-partition phase. It is here where I obtained the narratives of four men above eighty years of age who narrated for me the events dating as far back as the pre-partition past of Poonch. Also, when I started triangulating, weaving one method into another, I realised this community (please see that my site of ethnography is the town-area primarily) could only be understood once I stopped trying to find the slots for the number of respondents. I needed to instead find people who could shine light on the social history, before taking into account views of the young strata. As such, memory and oral-narratives formed the key methods that shaped my study. I realised only when I use memory as tool and studied the memory of both the space and the people along with the oral narratives that I have been fortunate to collect would I be able to deconstruct Poonch and understand its decadal transformation. It was thus that the life-histories of a few octogenarian and nonagenarian men helped me understand how Poonch changed in spatiality and demographics.

I begin my analysis with a discussion of the narratives provided by these men (the details of their narrations with a brief account on their life-histories have been included in detail in my work (2020) on Sikhs in Poonch). All four men that I approached were Sikhs and them being Sikhs was not a targeted choice but a coincidental one that made me look at the town in concentric circles rather than a space that is to be mapped through sampling. ${ }^{11}$ Why circles? Because these narratives explained how the events of 1947-48 turned the Poonch town into a camp, where people of only a particular religious affiliation could enter, barring others who belonged to a different religion. The narratives, as collected, weave the story that goes like this:

'The tribals reached Muzaffarabad somewhere around October 22 to 24, 1947. They took the RawalakoteMuzaffarabad route. At Muzaffarabad, as they were waiting for the final orders to attack Srinagar through Baramulla, as there was a delay in the orders from their chiefs, they exploited the opportunity and plundered the nearby regions. The areas falling in the fiefdom of Poonch such as tehsil(sub-district centre of administration and governance) Bagh, Sudhnoti, Haveli, Mehndhar etc had multireligious inhabitations and in fact most of the villages had substantial Hindu-Sikh families. The raid and plunder had already taken a communal colour and so the minority Hindus and Sikhs who were around $4 \%$ of the total population of Poonch were their main targets. The minority Sikhs and Hindus were thus driven out of the area that later fell on the other side of the LoC in Pakistan Occupied Kashmir. One of the tehsils of Poonch, tehsil Haveli (that constitute the present day district headquarter) was a well inhabited town with the seat of power residing within the town inside the well-guarded Poonch-Fort, from where the Raja of Poonch fiefdom exercised his suzerainty.

Two tehsils of the fiefdom that is, tehsil Bagh and tehsil Sudhnoti fell completely, and half of the territory of tehsil Haveli and a major part of tehsil Mehndhar were taken over by the raiders as well. It is only the remaining portion of the erstwhile tehsils Haveli and Mehndhar that remained on the Indian side at the time of ceasefire. As majority of the fiefdom fell, the fief-headquarters that is Haveli (the present day Poonch town, and the site of my study) became the only place of refuge for those who ran for their lives from the areas of those tehsils that fell. Sardar Kirpal Singh Sudan, Sardar Tara Singh Sudan, Sardar Dalip Singh all of them narrated this is how the present day Poonch town turned into a refugee-camp overnight, and remained so for years to come up to 1952 when the policies of refugee rehabilitation and resettlement gathered pace. 
The impact of this communal carnage was such that all the minorities from across the fiefdom took refuge in the town. The kafilas kept pouring in, some even arrived deep in the winter of December and January, fleeing their homes, leaving everything behind. From a town with a mixed population, Haveli headquarters turned into a town sheltering the last Hindu-Sikh alive across the entire region of Poonch principality. The results of these sudden turn of events were obvious: as the town area turned into a safe-haven for the minority-Sikhs and Hindus, the Muslims who resided in the town were pushed out in revenge for the wrongs that the minorities had been facing outside the town. Hence, the town lost its Muslim population completely, and it is in this context that we need to understand the present day spatial- organization in the town.' (narratives collected from the field by the author during various phases of her fieldwork conducted through 2018-2020).

It is this spatial reorganization and, its evolution and transformation over the decades since the communal-carnage led displacement and migration in 1947-48, that plays a major role in understanding the interactions between communities that further shape the neighbourhoods that exist today [Figure 1].

\section{Spatial Reification and Migratory Patterns in Poonch: The Rise of New-Neighbourhoods}

The demographic-imbalance caused by the communal carnage of 1947-48 has had its repercussions on how the neighbourhoods were constructed in the Poonch town that fell on the Indian-side post-cease-fire line demarcation of territories. In the initial phases of my fieldwork I did come across the neighbourhoods being organised on communitarian basis. Religion was the major tool that formed and organised neighbourhoods. However, it was the above mentioned narratives of post-partition that explained why a particular community was situated heavily on the peripheries and the others towards the core.

As the town sheltered the battered Hindus and Sikhs, all the Muslims had to leave as most of the non-Muslim victims occupied the ghostly homes left behind by the Muslims. With the UN-intervention and the ceasefire-line, the tensions fizzled out and the administrative machinery gathered pace after 1950. Various relief, rehabilitation, and resettlement programmes were launched catering to the needs of the displaced who, by then, were inducted into the new category of 'refugee'. Although, they had been internally-displaced as they arrived from one part

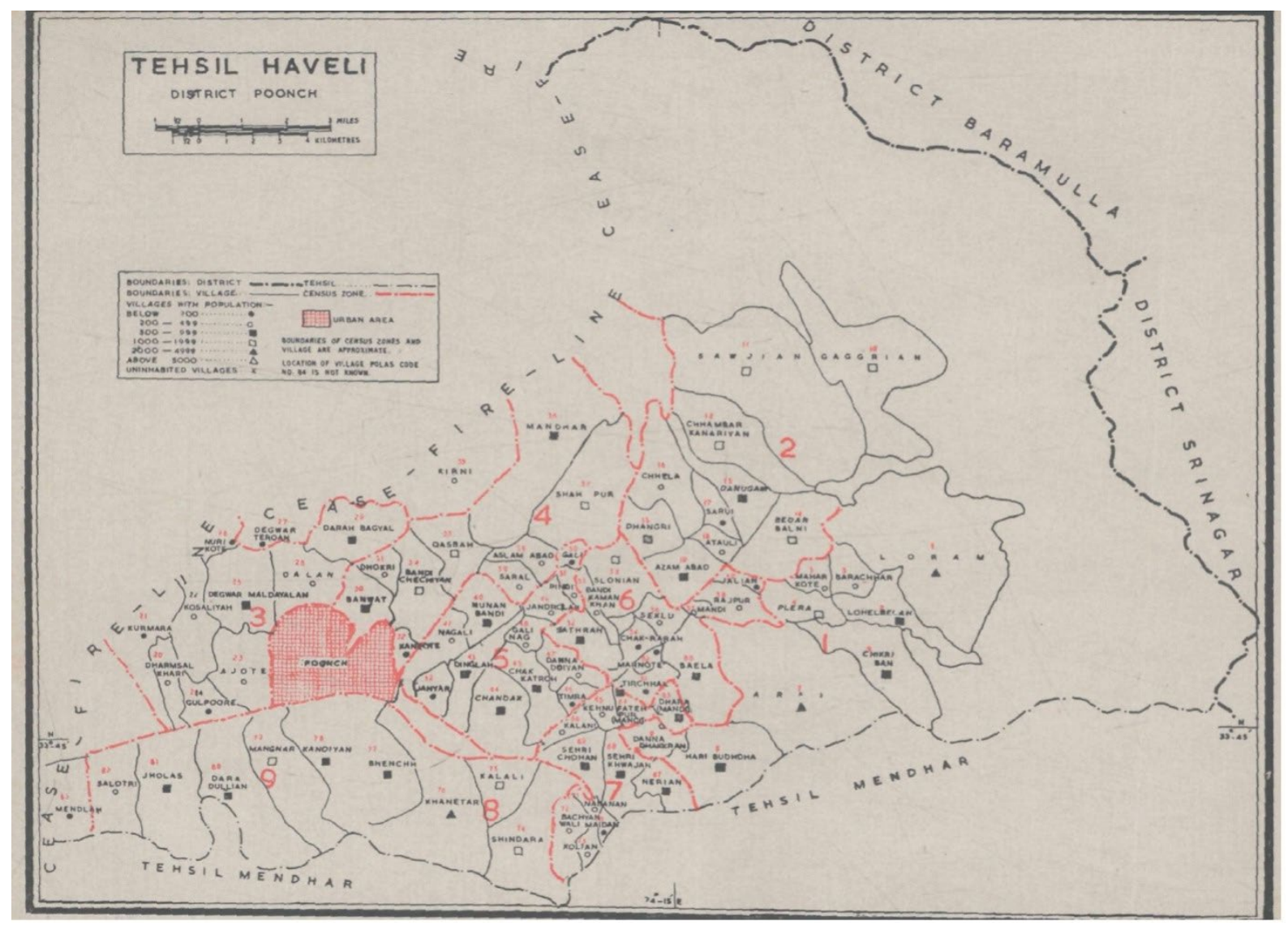

Figure 1. Map of Tehsil-Haveli, in district Poonch, showing the Poonch-town and the cease-fire line passing through it North-western side. The map also show the frontier villages of Jhullas (Jholas) and Khari-Karmara (refered to as Dharamsal Khari-Kurmara in the map) mentioned in this work, at its extreme western front. Source: Census 1961, 373. http://Isi.gov. in:8081/jspui/bitstream/123456789/5865/1/24735_1961_POO.pdf 
of the erstwhile Poonch-fief into another, but because of the UN-intervention and the ceasefire-line in January 1949 they now belonged to the Indian part of Poonch as 'Refugees', as the other part of Poonch on the other side of the LoC by then was a contested territory for India belonging to Azad Jammu and Kashmir. The new occupants and settlers in the town (the minority natives besides the refugees who were also natives of Poonch but from a few-kilometre across the line) formed the vast majority occupying almost all the space in the town until 1952. These refugees are essentially the 'Pakistan Occupied Jammu and Kashmir Dis-placed Persons', the category that exist in papers of the state. They are known as refugees locally because of the familiarity of the term in the local languages along these borderlands. However, the official state category for them is 'displaced-persons' (Sharma 2020; 2021). With the rehabilitation process, these refugees were allotted lands with a scale of 48 acres given to each family head based on a notary Alpha/ Alaf form which had the name of the head who was allotted the land.

The land however was not allotted equally to each refugee family because of the obvious loopholes in the administrative and disbursement mechanisms. As the people on the ground add that the land was allotted based on who had the agency and the power to reach the gates of the disbursement mechanism first. Most of the refugees added that the elderly in their households were ignorant and could not complete the required paperwork on time. Thus those who were swift enough have around 48 acres today, and others have no more than 20 acres. To note here also is the point that these lands allotted were located both within the town area and outside in the neighbouring villages as well. The suffocating town-space thus had a breather when refugees and especially the native minorities who also had to take refuge in the town began spreading in the villages around the town.

With the rehabilitation of the non-Muslim minority refugees, the reinstatement of the Muslims who had to flee from the town and the neighbouring villages also took place. However not all Muslims who chose to come back were reinstated in their original property as some of their property was considered to be evacuee property and was allotted or taken over by the Hindus and Sikh refugees between 1947 and 1952. Thus, the only lands left for them were in the periphery of the town or in the villages where such a population explosion had not happened.12 Thus the present day spatial occupation scenario has its roots in the post-1947 turn of events, where the periphery was occupied by the Muslims who resettled in and around Poonch post the rehabilitation and administrative changes after the first ceasefire-agreement between India and Pakistan.

Adding to such origins of rebuilding a town-space after the partition-disruption are the migration-patterns that have been a major force behind organisation of neighbourhoods in the town space. Understanding these patterns that are more active in the contemporary times than in the past few decades is the core concern of my present phase of research, but suffice it to say here is the peculiar process through which Poonchies have been migrating to larger cities. Particularly the migration to Jammu is an outmigration trend that is seen more among the minority Pahari Hindus and Sikhs with that of Muslims now on the rise. A layer of reasons exist but to write that I have coherently traced these migratory changes would be quite insufficient at this point of time. Although, as of now based on the ground-narratives and observation, I can deduce that the migration is hefty on the side of the Hindus and the Sikhs. The following section on identities shall explain how one cannot anymore write of Hindus and Sikhs as a non-Muslim minority mix community that suffered together, as one ethnicity until 1950s. The Hindu and Sikh identities have bifurcated and solidified as much as a Muslim identity in the past few decades. Bifurcated because the minority Pahari Hindus and Sikhs of Poonch had a culture of mix-families, where two brothers in the same family lived with two different faiths, one a Sikh and the other a Hindu. Hindu and Sikh families had this shared faith system within the same family, but over the years with the hardening of identities, the same brothers today have much less religious exchange and have gradually begun asserting a Hindu and a Sikh identity respectively. This has been explored in great details in my work on Sikhs (Sharma 2020).

The heavy Hindu-Sikh migration (who constituted a mere 4-6\% of the total population of Poonch) to cities like Jammu and elsewhere has led to the selling of the lands to Muslims. Over the last decade, Muslims from around the villages have been settling in the town in large numbers. One wave of migration in nineties, between 1990-1998 affected Muslims, Hindus, and Sikhs equally, where Hindus and Sikhs out-migrated to cities like Jammu, and Muslims in-migrated into the town of Poonch. This migration was driven by the chaotic times during which terrorism was at its peak. Migration within and outside Poonch has been taking place due to three main reasons: Terrorism, the survival necessities of being a borderlander, and the obvious socio-economic push and pull factors. Terrorism during the 1990s affected all the communities belonging to different religious and ethnicities in this borderland.

The Hindus and Sikhs who have migrated to Jammu usually have one reason in common which is that Poonch is a border ilaqa (region), with majority Muslim population. Besides the territorial backwardness, the threat that one day if situation turns sore again then there is no chance of survival being a meagre $6 \%$ minority (hinting at the scars of communal carnage of 1947 being still ripe and the denial of such an event occurring again is less likely to be heard among the minorities today) is also a driving force behind such a migration. Muslims who have suffered at the hands of terrorists in the villages had this opportunity as the new buyers and town settlers when the minority Hindus and Sikhs were/are selling off their lands. Hence, the periphery of the town gradually became 
a majority Muslim settlement with dispersed Hindus and Sikh households. The following narratives from the field shall shine sufficient light on how these migratory patterns among all the three main communities changed interactions and widened the communal gap between them.

Poonchies, from all ethnicities have formed colonies in the peripheral regions of the Jammu city (the next big city outside the town) and they look out for land that lies in the vicinity of the lands already purchased by another Poonchi family, thus catering to the concept of a colony. Having a land or a house in Jammu is considered an asset, which has connotations that go beyond the economics of buying a property and hints at the prime reason for migration particularly among the non-Muslims here (which is that they are looking for safe-havens or a place they can look up to in times of urgency). The fears behind this urgency are both external (violence and other cons of living at a borderland, especially a violent zone of conflict like this one) and internal (intra-ethnic differences which can take up a communal form).

\section{Shift in Identities: Narratives from the ground}

The interactions in this community are not the same everywhere. The dynamics are so layered that identities often overlap and blur the boundaries, sometimes leaving no clear space to differentiate at all. On the extreme north-western side of Poonch touching the Line of Control lies village Khari-Karmara. The village is the last territory on this side of LoC in India. We find a single Hindu family living in an all Muslim dominated village, refusing to leave and migrate to the town. The frames are thus, not all hostile. Ethnic solidarities do overcome other divisive forces. Similarly, the house of Rammohan (name changed), who has two daughters and a son, resides at such a place in the Jhullas village where 6 o'clock in the evening is night and it lasts till seven in the morning. The lone Hindu house, situated at a trek of one hour on foot from the village centre of Jhullas (the last village at the border, a new road now has come up that connects habitations such as Rammohan's with the village centre), this house is the space of a hundred details. It is situated in a deep dark gorge with only a few Muslim neighbours. This land was allotted to Rammohan's ancestors when they migrated from a part of Poonch across the LoC and hence he too is a refugee, an officially displaced person in the eyes of the state. He has two adult daughters who trek daily up and down and one of them works in the village health centre as a nurse. He refuses to leave, and more than him it's his Muslim neighbours who deny him the permission to leave. They threaten to migrate along in case he did. Though for 'unfortunate times' he has built a house in the town in which he has never resided, but I wonder what more did he mean by 'unfortunate-times', when he has survived through the violent nineties along with all the major wars between India and Pakistan. More than militancy and encounters, he has ghost stories to tell and as we were taking leave of him, he guided us through a safer path which as he says has been sanitized with rituals (one can see Hindu ritualistic threads and vermin along with chadars from Peers' courtyards placed all over). It was a path meant and known earlier only to those four households, one Hindu and three Muslim with the neighbourhood having expanded in the recent years. The family of Rammohan has lived like a family with their Muslim neighbours, but with other precautionary havens built elsewhere, such as the one he owns in the town.

Pahari-Poonchies are thus also a 'plural' community, with all four main religions cohabiting as an ethnie-most of them connected through ancestral ties, kinship, culture, and traditions. Besides ethnic makers like language, traditions, and food, the Paharis of Poonch have also been reasserting their identity as a community together for reservation. Since the 1990s, the entire community has been mobilising support within the state and have organized themselves under several platforms such as the Jammu and Kashmir Pahari People's Forum. The state in 1989 forwarded a list of minorities that should be considered for the grant of scheduled tribe status. Among them, Gujjars and Bakerwals were chosen but Paharis were left out after a committee was established by the Centre for scrutinizing the list provided by the state of Jammu and Kashmir. Ever since then, their struggle for minority status has continued, ${ }^{13}$ which has also led to ethnic-conflict and other fault-lines between these two ethnicities (the Gujjars-Bakerwals and the Paharis), a topic that needs to be explored further (Chaudhary 2011). At the same time this conflict has solidified ethnic-ties and bond within the multi-religious Pahari ethnicity.

The fixation on identities has happened gradually without any explicit communal overtone. It is the fixation and multiplication of these identities in recent times that carries a threat to ethnic-unity here which had not been the case previously. The identities also do not get fixed as communal identities alone. By fixation and reified identities I mean identities that cause difference and othering, which are ultimately an anathema to ethnic-homogeneity and syncretism and plurality. The othering had led to differences that have divisive tendencies. The case of the assertive Hindu-Sikh identities within the same family with shared faith-systems quoted above and elaborated in a separate research paper, explains this (Sharma 2020). Such an intangible symbolic-cultural boundary may not directly lead to sharp polarisation, it does lead to irrevocable 'difference' that carries the potential to create new assertive identities out of a pool of diverse ones. Two incidents in the past few years from this site of ethnography hint at the dissociation between communities that has otherwise not been found in the decades after the partition carnage.

For any outsider, Poonch appears to be a flagrant multi-religious town on the very first evening of their arrival. The cacophonous loudspeakers start simultaneously from Temples, Mosques, and Gurudwaras both at the fall of the 
dusk and at the arrival of the dawn, but more than noise they are a tradition that no district administration has been able to do away with not even under the provision of controlling noise-pollution. Locals add on a lighter note that every morning and evening the loudspeakers from the three main religious sites of worship actually compete with each other as to who shall continue louder and longer. On paying a visit to a Hindu household one evening (it was one of those few non-Muslim households in an all Muslim neighbourhood in the periphery of the town), one of the female inhabitants reacted unhappily at the sound coming from a mosque in the neighbourhood. Her resentment clearly was something that was new and unfound as sounds from the mosque were one of the biggest elements of the 'sounds of religion' that fill the towns in the mornings and in the evenings. Any Poonchi, irrespective of ethnicities, who has been a part of this ethnic borderland can hardly complain over such a sound emanating from any religious place primarily because, being a Poonchi, they ought to have lived such a plural life. My astonishment was short-lived as after a few minutes into the conversation, it was revealed it was because the woman had been affiliated to the right-wing political party in the town and had served as one of its workers.

Another incident involving sounds and noises on a religious front had to do with the annual Budda Amaranth pilgrimage that the town proudly receives around the festival of Rakshabandan. The legend relates this pilgrimage with the other pilgrimage, that is, the Amarnath-Pilgrimage near Srinagar which is also one of the biggest pilgrimages of Hindus across the country. This pilgrimage in Poonch goes by the name BuddaAmarnath, or baba-chattaani (a stone shiva-linga) as compared to baba-barfani (the famous snow shiva-linga) in Srinagar. Pilgrims in large numbers arrive every year in a span of around 10 days and visit Budda-Amarnath in tehsil Mandi of district Poonch. Tehsil Mandi is located 30 kilometres from the town and is a majority Muslim tehsil with a prominently Kashmiri-population. ${ }^{14}$ On the eve of Rakshabandhan, a procession called Chadi-yatra leaves the Poonch town on foot for the Budda-Amarnath Shrine in Mandi. The procession is received wholeheartedly by the Muslim traders association at Mandi with meethasharbat (sweet drinks) marking the age old custom of fraternity and brotherhood in the district. However, in the year 2018, this tradition that stood as an ideal for religious tolerance and harmony took a wrong turn.

The narrative, as told, was that when the procession entered Mandi tehsil, a group of men started shouting slogans such as, 'Mandi main rehna hoga toh Ram naam kehna hoga, one who resides in Mandi has to bow to Lord Ram which did not align with the ethno-religious environment of the area they were passing through. With Mandi being a majority Muslim region that has welcomed this pilgrimage with open arms thereby understanding religion beyond a monolithic-identity and as an ethnogeographic category (see Harjot Oberoi's work and my work on Sikhs in Poonch), the religious plurality in Poonch was consequently scarred in the 2018 procession. Narratives from the ground have corroborated that the situation got way too out of control. Though it did not lead to a riot of any sort, it did teach Poonch and its ethno-geographic religions a lesson. The trauma of the memory of this exchange shall take years to die. One should also take into account that these communal forces are well at play under the influence of external agencies that own a communal political tone. The intra-ethnic gap and rise in tensions such as these multiply in the times when political parties with a conservative bend run the affairs of the state from a centre stage. These forces should take into consideration that communal politics will lead pockets like Poonch to a stage where it may not take long for religion as a regional ethno-geographic construct to transform into religion as a monolith, an identity that breeds difference and othering. ${ }^{15}$

I have been writing most of this paper in the post-370 context in Poonch, where various regions of the erstwhile state have been put under restrictions of all sorts for the past three months. I was in the field when the decision was declared on August 5, 2019, abrogating article-370 and along with it ending the special status given to Jammu and Kashmir under the Indian constitution. A few days into the communication-blockade where we had no connectivity at all with the world outside Poonch, I met this elderly Muslim Gujjar who worked as a land-labourer on a field owned by a Hindu. He was visiting his employer's household when I happen to be there too. A labourer by occupation, he said something that, in a way, highlights the nature of ethnic and religious tolerance among communities in this borderland.. He said, 'bas bhaichara bana rehna chahiye, baaki siyasi masalaat toh chalti rahegi, hum border ke rehne wale hain, sarkarrein yeh sabh badlaav laati rehti hain/ we should remain united as we have always been, for we are borderlanders and such a unity matters to us more than the politics that is bent on dividing us. It is in the nature of politics to bring changes such as the abrogation of article 370. Nothing should disrupt our unity again.'

Paul Brass (2003), in his work 'The Production of Hindu-Muslim Violence in Contemporary India', takes on Varshney's analysis that understands a riot situation as something that is reached due to the breakdown or an absence in civic-ties between and across communities. Brass states that a riot situation is reached not only due to the breakdown of inter-community civic ties but also due to 'institutions of riot' that are well established and planned riot-inducing establishments led by those with a larger political purpose in mind (such as electoral gains). While Varshney (2008) understands 'civic-ties' as the everyday 'networks of engagement' between and within communities, neighbourhoods, Brass (2003) understands riots and hence, communal violence, as 'socio-political networks' led by specialists in riot production. These specialists can operate at any level, and through his empirical findings vis-à-vis the city of Aligarh, 
Brass (2003) shows how 'specific neighbourhoods' in a city witness more violence and therefore, are more volatile because they are intentionally kept so in a way that keeps tensions simmering and the divide between religious communities grows every day. Seasoned riot specialists are always active in these localities and one of the premises that Brass uses to draw this inference is 'the changing neighbourhood patterns'. These patterns go hand in hand with local rivalries over economic resources, space, and religious hatred. Varshney also classifies neighbourhoods according to close-networks of engagements with strong civic ties, and loose-networks of engagement with weak civic ties. The chances of communal tension and hence, violence is greater in the latter. Nandy (2020) in 'The Politics of Secularism and the Recovery of Religious Tolerance' bisects religion into faith and ideology. Faith, he writes, 'means religion as a way of life, a tradition that is definitionally non-monolithic and operationally plural.' Ideology, he writes, 'means religion as a sub-national, national, cross-national identifier of populations...protecting non-religious, usually political or socio economic interests...this religion as an ideology gets identified with one or more texts, which rather than the ways of life of the believers, then become the final identifiers of the pure form of religions' (p.322).

Going by this, the changing neighbourhood patterns in the town of Poonch over the years in a post-partition context have been leading to loose networks of engagement with weak civic ties, but important here is to see that the identities have not been completely polarised. Anecdotes shared in this paper from lone Hindu-Sikh households residing in absolute harmony with their Muslim neighbours in the frontier villages outside town show this. Identities have been evolving and changing with prominent religious assertion, but a study of this borderland shows how it is the mother ethnic-identity of being a Pahari that has been binding the communities together through a simultaneous assertion for reservation and solidarities built through the collective memories of past (partition and survival as borderlanders among others).

\section{Conclusion}

Ethnicity as an identity fails to wane in the contemporary cosmopolitan world. Ethnic-solidarity existing in peripheral geographies such as in the borderland of Poonch relies on the territorial-proximity, common language as a medium of communication, shared cultural bonds, and collective histories and memories, to flourish. Communities such as Pahari-Poonchies dwell together and affiliate through shared cultures and traditions which they derive from a particular ethnic-lineage. This very nature of ethnic-solidarity has been undergoing changes with the gradual assertion of identities along multiple lines-spatiality and the construction of neighbourhoods along religious lines being one of them. This shift in the nature of identities in a post-partition context is not without the scars of the partition where the migration and displacement along religious-lines that took place during partition are living histories and memories with key influence on social-cultural life in a post-partition phase. It may take several forms, as in addition to the shift along religious lines, identities also can also start being assertive along caste, class, and gender lines. At Poonch, this gradual transformation and fixation of identities within the same ethnicity is also driven by another identity that has a huge impact on social life, that is, the identity of being a borderlander, an important aspect of identity that needs to be taken up as a separate research project. Besides the processes through which identities emerge and evolve in a community, the dynamics of borderland construction and its gradual transformation play an equal role in shaping identities. Apart from the physical political borders, the fluctuating social-boundaries that divide identities and create difference, have a complex relation with the process of 'survival' as a borderlander. This works by tapping into the inter-community engagement in micro-settings as small as a neighbourhood and analysing the intersection where religiously assertive identity within an ethnic-group produces a complex reality thereby deciding the nature of everyday socio-cultural life. Hence, this work has a scope of looking at ethnic-identities and their transformation in a newer light, especially in South-Asia, where not only the social, cultural, and political processes change them, but the geographical location of such an ethnic-community (such as a borderland with histories of partition) strongly influence identity construction and formation.

\section{Appendix 1. The Site of Ethnography: The Borderland Community of Poonch}

Poonch; a border-district on the Indian side in JammuKashmir, infamous for making headlines because of incessant cease-fire violations across the Indo-Pak border, has had a bitter past just like other regions in the area, some of which are still gasping for a breath of normalcy. However, unlike the widely known conflict-ridden Kashmir dispute, Poonch, or the similar lesser known territorial-belts of Jammu and Kashmir though have been the products of partition that rendered the state disputed and fractured in 1947-1948, such regions also have emerged as isolated pockets fighting separate struggles, ostensibly overshadowed by the gigantic discourse on Kashmir-dispute (Bouzas 2016; Lamb, 1991; Zutshi 2010). An erstwhile fief under the monarch of the princely state of Jammu and Kashmir and administered under the trustworthy kith and kin of the Maharaja of Kashmir, Poonch remained a land/territory that was situated at a certain distance from the monarchical centres in the cities of Jammu and Srinagar. However, this does not mean that it was loosely connected to the monarchy. The rajas of Kashmir held their firm grip on Poonch through the extended administration. Going back to late nineteenth and early twentieth century when the command of Poonch was taken over by the Dogra-rulers in 1840 , the raja of Poonch established this very town by bringing in skilled men and traders from outside Jammu and Kashmir apart from the locals. He incentivised them with land and service, and encouraged them to settle down 
in the otherwise dispersedly populated lands of Poonch, hence marking the beginning of the administrative centre in Poonch, (as recorded by Muhammad-ud-din Fouq in his social history, Tariq-e-aqwaam poonch, a project he completed under the patronage of the raja of poonch in 1931, making it a contested history). The grant of the Radcliffe award in 1947 that partitioned the provinces of Punjab and Bengal, also later partitioned Jammu and Kashmir as well as frontier regions like Poonch. Poonch was a fief at the western margins of the princely state of Kashmir located at a distance of 100 kilometers from one of the biggest cities of erstwhile united Punjab: Rawalpindi. In October 1947, two months into the partition of the country while the monarch of Kashmir was still deciding on whether to accede the princely state to India or to the state of Pakistan, he was shaken from his indecisiveness by a pukhtoon(pathan) tribal raid aimed at conquering Srinagar by force which was also infamous for the support and encouragement that newly formed Pakistan administration provided it (Lamb 1991; Snedden 2013). The raiders (majorly pathans from NWFP) took the route along the north-eastern regions of west-Punjab that ran parallel to Mirpur, Poonch, and Muzaffarabad of the Jammu and Kashmir State. It was under these circumstances that Jammu and Kashmir acceded to India under the widely known instrument of accession with Indian soldiers fighting this marauding army out of Jammu and Kashmir which by then had been strengthened by the reinforcements from Pakistani army (Lamb 1991; Whitehead 2007). This is also how India and Pakistan waged their first war, the war of 1947-49.

There is another important point to take into account here, which is that certain scholars like Christopher Snedden (2013) have written about the support these raiders got from people in Poonch (largely Muslims) who had been supporting the cause for an Azad Jammu and Kashmir. The men of Poonch were known to have served in British army so most of them were ex-servicemen who had rifles and other weapons. They were also frustrated under the heavy tax-regimes and other oppressive tendencies of the monarch of Jammu and Kashmir and have arisen in revolt a few times before finally supporting the raiders in their attempt at over-throwing the monarchy by violent means (Snedden, 2013). This took a flagrant communal colour as it was mostly the Muslims who took up arms and joined the raiders. The marauding raiders did not hesitate in persecuting the Hindu and Sikh Poonchies who had to run for their lives and seek shelter. Their abandoned homes across the border became part of what came to be known as the Pakistan administered territories of Azad Jammu and Kashmir, contested by India as a disputed territory. It is these Hindus and Sikhs that today form the majority refugee population on the Indian side of the town of district Poonch.

Important here is to look at the fact that these Poonchies (Hindus and Sikhs) left their homes in Poonch that now lie across the LoC in what India referes to as Pakistan Occupied Jammu and Kashmir territories and took refuge only a few miles inside the LoC in India. Another major repercussion of these events was that when the 1984 ceasefire that ended the war between India and Pakistan, it ended with a substantial modification of the geography of the erstwhile princely state. The fief was divided into two parts by the ceasefire line that, after 1972, was known as the line of control, with 855 square kilometre today lying on the other side of line of control, hence dividing the population of Poonchies into two nationalities with differing loyalties that gradually evolved as Indian and Pakistani Poonchies.

\section{Notes}

1 See Appendix 1 for more details on how the situation during 1947-48 transformed the principality of Poonch into the borderland district of Poonch.

2 For an understanding of ethnic-homelands transformed into borderlands along the line-of-control in a post-partition phase, one can refer to my work on another ethnic-group situated in a different borderland here, Nodes of Marginality: Identity, Displacement and Migration in the Post-Partition Borderlands of Kashmir, (Sharma 2021).

3 Which led to events ending in the signing of Instrument of Accession, between Maharaja Hari Singh, the Ruler of Kashmir, and India, leading to accession of Jammu and Kashmir with India.

4 The Pakistani army later took over the war officially (Lamb 1991; Whitehead 2007).

5 The district on the Indian side has an area of $1674 \mathrm{sq} . \mathrm{km}$, with a total population of 476,835 , forming $3.80 \%$ of the total population of Jammu and Kashmir State. Hindus are $5.20 \%$ of the Population, Muslims 91.93\%, Sikhs 2.76\%, and rest forming the remaining $0.37 \%$ (Census, 2011).

6 For an understanding of how these ethnicities form an outer-rim of non-dominant ethnicities along the northwestern boundary at the line-of-control see, https:// thewire.in/society/kashmiri-language-dogri-hindi-pahari

7 A sub-group of the Indo-Aryan group of languages spoken around undivided Punjab, Sindh, and the North-western Frontier Province in Pakistan today.

8 There is a fourth religious presence that has been growing within the Pahari-ethnicity here, which is the Dalit-Christians, a small minority of Dalits who have been converting to Christianity in the past few decades. My paper, In search of a religion: Making of a Dalit-Identity in Jammu and Kashmir, India (forthcoming) takes up this particular religious-caste identity in detail.

9 For a detailed account on the narratives collected see, Remaking of ethnic-boundaries: identity and religion among Sikhs in the borderland of Poonch, Jammu and Kashmir, Asian Ethnicity, (Sharma 2020)

10 The town sits on the Pir-Panjal foothills on a river bed. The Poonch river flows north-westwards into Pakistan Occupied Kashmir and the town of Poonch is situated on the northern bank of the river. The line of control divides Poonch on the north-western side, and acts as the volatile border between India and Pakistan, which is a highly disturbed zone.

11 Their accounts form the primary source of the narration included here. Though it is also important to mention that these elderly men and their accounts corroborated what oral-narratives prevalent among the middle-aged and the young were already hinting at. Hence, the account on partition is the living memory among the people here, and constitute key oral-accounts crucial for a researcher. I was lucky to have found a few persons who could still speak from their lives as and when partition in later 1940s took place and the repercussions it had on the social-cultural life of Poonchies in its immediate aftermath.

12 Please see that most of the villages falling in the border-zone of district Poonch were emptied out, as the coercion and aggression between the forces took place around the town in these village spaces (Sharma 2020). 
Borders in Globalization Review | Volume 3 | Issue 1 | Fall/Winter 2021

Sharma, "Identity, Religion and Difference in the Borderland District of Poonch, Jammu and Kashmir"

13 Paharis that assert their identity together for reservation are also found in other parts of the state. Their concentration is the highest in Poonch-Rajouri and Kishtawar, apart from Doda, Baramullah and a few other segregated clusters.

14 The Kashmiri speaking population of Poonch is restricted to a few locations and is the most widespread in Mandi Tehsil. Kashmiri here however does not denote the ethnic affiliation with Kashmiries of the valley as the Kashmirispeaking population of Poonch are the Pahari-Kashmiris that have migrated from places like Muzaffarabad and some from the valley a few centuries ago and have become assimilated with the Pahari culture such that their accent and tonality of Kashmiri language also differs from the one that is spoken in the valley. Also, Kashmiris of Mandi are one of the oldest khandans (clans) who have contributed to economy, culture and social exchange of Poonch fief, as written by Foug in his Tariq-e-aqwaam Poonch in 1931. Fouq's was one of the earliest and perhaps the only attempt at writing a people's history of Poonch under the patronage of the Raja of Poonch.

15 See Nandy's "Time warps: Time travel to a possible self, (2002), Varshney's concept of 'networks of engagement' (2008) and Shail Mayaram's Work (1997) for an elaborate understating on this.

\section{Works Cited}

All hyperlinks last accessed December 2021 unless specified.

Aggarwal, Ravina. 2004. Beyond Lines of Control: Performing Borders in Ladakh, India. Durham, NC: Duke University Press.

Bouzas, Antia M. 2016. "The Kashmir Space: Bordering and Belonging Across the Line of Control" Revista Electronica De Estudios Internacionales. https://doi.org/10.17103/ reei.31.13

Brass, Paul. 2003. The Production of Hindu Muslim Violence in Contemporary India. New Delhi: Oxford University Press.

Choudhary, Zafar. 2011. Understanding the Gujjar Pahari Faultline in J\&K, A Gujjar Perspective. IPCS Special Report 106. IPCS Conflict Alert.

Gellner, David (ed.). 2013. Borderland Lives in Northern South Asia. Duke University Press.

Gupta, Radhika. 2013. "Allegiance and alienation: border dynamics in Kargil" in Borderland Lives in Northern South Asia, edited by David Gellner, 47-71. Duke University Press.

Lamb, Alastair. 1991. Kashmir: A Disputed Legacy 1846-1990. Oxford University Press.
Lamont, Michele, and Virag Molnar. 2002. "The Study of Boundaries in the Social Sciences" Annual Sociological Review 28: 167-195.

Mayaram, Shail. 1997. Resisting Regimes: Myth, Memory and Shaping of a Muslim Identity. Oxford University Press.

Nandy, Ashis. 2020. "The Politics of Secularism and the Recovery of Religious Tolerance" in Secularism and Its Critics, edited by Rajeev Bhargava. 321-344.

2002. Time Warps: Silent and Evasive Pasts in Indian Politics and Religion. C. Hurst and Co. Publishers.

Newman, David. 1998. "Creating the fences of territorial separation: the discourse of Israeli- Palestinian conflict resolution" Geopolitics and International Boundaries 2: 1-35.

_. 2003. "On borders and power: a theoretical framework" Journal of Borderlands Studies 18, 13-24. https://doi.org/10 .1080/08865655.2003.9695598

Newman, David, and Anssi Paasi. 1998. "Fences and neighbours in the post-modern world: boundary narratives in political geography" Progress in Human Geography 22: 186-207.

Oberoi, Harjot. 1994. The Construction of Religious Boundaries: Culture, Identity and Diversity in the Sikh Tradition. The University of Chicago Press.

Oommen, T.K. 1997. Citizenship, Nationality and Ethnicity; Reconciling Competing Identities. Cambridge Polity Press.80

Paasi, Anssi. 1998. "Boundaries as social processes: territoriality in the world of flows" Boundaries, Territory and Postmodernity. Ed. D. Newman. 69-88, London: Frank Cass.

Sharma, Malvika. 2020. "Remaking of ethnic boundaries: Identity and religion among Sikhs in the borderland of Poonch, Jammu and Kashmir" Asian Ethnicity. https://doi. org/10.1080/14631369.2020.1811951

__., 2021. "Nodes of Marginality: Identity, Displacement and Migration in the Post-Partition Borderlands of Kashmir" Journal of Immigrant and Refugee Studies. https://doi.org/ 10.1080/15562948.2021.1949656

Smith, Anthony D. 1986. Ethnic Origins of Nations. Blackwell Publishing House

Snedden, Christopher. 2013. Kashmir: The Unwritten History. HarperCollins Publishers India.

Varshney, Ashutosh. 2008. Ethnic Conflict and Civic Life: Hindus and Muslims in India. Yale University Press.

Whitehead, Andrew. 2007. A Mission in Kashmir. Penguin, New Delhi.

Zutshi, Chitralekha. 2010. "Rethinking Kashmir's history from a borderlands perspective" History Compass 8(7): 594-608. https://doi.org/10.1111/j.1478-0542.2010.00692.x 


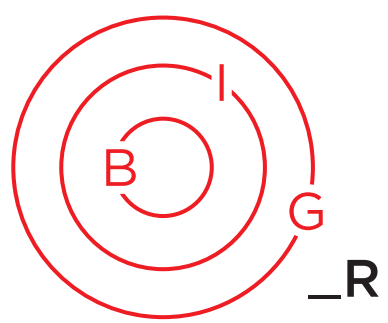

ARTICLE SPECIAL SECTION

\title{
Rohingya Refugees in South Asia: An Exploration of Social Borders and the Margins
}

\author{
Rachel Irene D’Silva *
}

By reviewing the case of the Rohingya, a marginalized community in the postcolonial state of Myanmar, this article (as part of a special section on South Asian border studies) explores the perspective of Rohingya refugees and conceptualizes social borders from the voices of the refugees. Juxtaposing postcolonial borders with narrations of Rohingya in India brings out the politics of the marginalized communities in the country's borderlands. The article shows how borderscapes are shaped for refugees that articulate ideas of social justice and recognition. Building on international studies of the Rohingya, I conducted fieldwork into the situation of the Rohingya in India. The resulting interviews add to our understanding of Rohingya refugees and address a scarcity of literature on the Rohingya in border studies. Through the analysis, I discover the history of the Rohingya identity in Myanmar, which contextualizes their statelessness. Social borders and state legislation reinforce barriers to citizenship and sharpen the exclusion of migrants, refugees, and other stateless peoples in South Asia.

Keywords: South Asia, Refugees, Rohingya, post-colonial states, boundaries, borders, margins, Southeast Asia, marginal communities.

\section{Introduction:}

As an ethnic, religious, and linguistic minority in Myanmar, the Rohingya have been stateless for almost four decades (since 1982). The Myanmar state discriminates against them and imposes severe restrictions on their activities. They are denied the right to nationality and citizenship by Myanmar and, therefore, they are forced into statelessness. Their lives in Myanmar depend on the legal status of temporary papers. In 2017, they were forced out of their villages and towns through violence. They face severe restrictions on movement, culture, everyday life, and access to education by the state. The 1982 law on citizenship excludes them as national people. Throughout history, they were repeatedly displaced into neighbouring Bangladesh by the state. Since the late 1990s, there has been a massive exodus of Rohingya to Bangladesh as a result of persecution, torture, and killing in Myanmar. In the host country, they are yet to gain access to refugee recognition and resettlement rights. In November of 2021, hundreds of refugees were relocated to an island in the Bay of Bengal by Bangladesh (AP 2021).

Migrants and refugees in India, such as Rohingya who are considered illegal by the state, have been understudied in border studies. They face statelessness and lack sufficient protections. In the context of forced migration, this paper asks: what types of borders confront Rohingya refugees? First, the introductory section summarizes the international plight of Rohingya refugees in the context of border studies and

\footnotetext{
* Rachel Irene D’Silva MA in Politics, PhD candidate in Social Management, Central University of Gujarat, India. Email: rchldsilva@gmail.com
} 
borderscapes in particular. The second section outlines the methodology of the study. The third section highlights the current situation of Rohingya in India. Section four expands on the history of the Rohingya and explains borders of identity and belonging through the voices of Rohingya refugees as they discuss the threat they face in Myanmar. Section five shows the processes of marginalization, as demonstrated in accounts of exclusion from citizenship and violations of human rights. Section six explains bordering processes based on national law, which have led to restrictions and curbing of religious freedom and even mass attrocities. Finally, section seven highlights the borderlines of the marginalized Rohingya refugees in the state of exceptionality and subjectivity. This entire exploration of marginalization shows that the situation faced by Rohingua refugees arrises from their condition of forced migration.

Marginality in South Asia can be studied by linking borders to spaces and processes at the margins of the community (Cons \& Sanyal, 2013). Narratives of marginalization are not just about borders but are also essential to forging and asserting the community, a sense of belonging, and internal boundaries (Cons \& Sanyal 2013; Cons 2013). Margins conceptualized here are the lived margins by Rohingya refugees in the internal boundaries. Rohingya refugees face discrimination due to identity politics. This experience of discrimination is manifested in dire poverty among refugees, poor living arrangements, shortfalls in protections, standards, and humanitarian assistance that are internationally prescribed.

The word 'borderscape' typically refers to borders that are formed by a collection of regulations, semantics, and other practices and discourses that constitute the border itself. In the social sciences the word 'borderscape' means the geopolitical interactions of exchanges between different (affirmative and subversive) practices of border control and various types of social or cultural formations, discursive processes, and individual identity policies (University of Luxembourg 2005). The conceptualization of borderscapes also includes what is permitted, culturally and socially prohibited, and artistically justifiable, as well as the borders of artworks, buildings, or concepts, and the borders given by individuals and language (University of Luxembourg 2015).

Borders as marginal spaces at the edge of a nation continue to be both problematic and central to national and state politics throughout the region (Cons 2013). Borders are situated in dialogue with other kinds of spaces and practices as well as with centres. Processes of bordering are replicated in the margins that are away from the borders. Borders are articulated in how forms of state recognition are not only central to the formation of identity, but also in how states co-opt these forms of 'grey spacing' through flexible forms of 'border citizenship' (Cons \& Sanyal 2013). The literature on margins and borders is often from the perspective of state sovereignty. Internal borders are made from experiencing belonging and unbelonging, making and un-making, and the illegalization in everyday life for refugees in sanctuary cities (Fakhrashrafi et al. 2019). In this context, there is limited literature on the making of social borders, or borders within society.

\section{Methodology}

This research is a pilot study based on fieldwork completed as part of my $\mathrm{PhD}$ research. From news reports, it was evident that the Rohingya refugees were very vulnerable. For example the Indian Express carried a feature on Rohingya refugees living in India (Express News Service 2018). However there was lack of information on refugee protection and status for Rohingya aimed at dealing with such vulnerability. The report on Rohingya refugees described the settlements, access to education and livelihoods in Mewat and Hyderabad (Fields et al. 2019). As part of a study on urban refugee livelihoods the Women's Refugee Commission did a field assessment of the economic coping strategies where they interviewed key stakeholders from service providers, donors, and refugee communities. Their findings reflect the many voices and perspectives gleaned through the interviews, project sites, visits, focus group discussions (Women's Refugee Commission 2011).

From the pilot study, I learned about the identity and statelessness of the Rohingya peoples (including not being duly recognized by the host government). Samaddar states,

Therefore the post-colonial commentaries on statelessness are studies of permanent incompleteness-a reality that always seems to fall short of a hyper-reality, and therefore the ideal reality, of citizenship, entitlements, legal protection, full proof identity, solemn recognitions by courts of law, and the avowals by the state $(2016,102)$.

I visited Hyderabad-a city in south central India where a sizeable Rohingya settlement is found today. This led me to explore how Burma Rohingya refugees arrived and settled here.

During the pilot study, with the support of a local guide, I interviewed refugees and care workers. Information was sought on the legal protections of Rohingya refugees and on the role of other stakeholders. Interviewees were asked about how they felt in the city, and they generally responded positively on living conditions compared to the situation they faced back home. Also, they expressed comfort that their children were being supported in education by NGOs, government schools, and madrassas. We asked care workers why they came to Hyderabad as refugees. They said that growing urbanization, in particular the outskirt region where the Rohingya have settled, were factors in why they migrated 
here. Overall, we learned how their statelessness impacts their protection in the country. This study presents the voices of six of the refugees who gave interviews.

\section{Rohingya Refugees in India: Presumed Illegality and Associated Risks}

In interviews conducted in June 2019, Noor Mohammed, Abdul Alam, Zakir Hussain (Rohingya refugees in Delhi) expressed their stories and discussed their situations as follows. Noor Mohammed was in Saharanpur, in Uttar Pradesh for 25 years. His family consists of eight people: two children in school, two auto rickshaw drivers, and two are looking for jobs. He got a UNHCR refugee card in 2013 and works as a vegetable vendor where he buys vegetable from Okhla Mandi (wholesale market) and sells them locally. Abdul Alam works as construction labourer or daily wager. Zakir Hussain sells fish purchased from Ghazipur mandi to people and refugees in Faridabad and Kanchan Kunj. The average income earned by the three men is 6000 to 8000 rupees.

They are currently put up at Shaheen Baug extension in the settlement known as Shram Vihar where they live among 25 to 30 Indian families. The landlord sold off the land. Some people purchased plots and rented them out to refugees on the land. Currently, they pay 2000 rupees in which three families live together in about 300 square meters. Previous rates have been as low as 500 rupees for 100 square meters. Sanitation infrastructure is non-existent and the toilet is the sewer. They have one toilet for 95 refugee families. They cannot build concrete structures on the land and the land officers do not permit concrete construction. Part of the land belongs to Delhi Development Authority and part to Uttar Pradesh irrigation department. They are inhabitants in an enclave.

This community is served by UNHCR which supplies one female volunteer, a youth club, a stitching centre, and a medical clinic service provider. An additional stitching centre is run by an NGO. Children do rag-picking occasionally. There are two disabled persons. They have one sick person. They need a good place to stay. A report on the experiences of Rohingya found that Rohingya families face sudden evictions and non-renewal of informal leases (Brenner 2019). The Rohingya also face food scarcity due to inadequate income (Brenner 2019). The Rohingyas work as 'ragpickers, collect scrap, work in wholesale vegetable and fruit mandis, shops and even local industrial estates in Jammu city and its outskirts' (Express News Service 2018). To the Indian government, the Rohingya living in India are "illegal". The Supreme Court recently issued notice to the Centre and to states providing aid to all refugees and asylum seekers (Jain 2021). The Court allowed nearly 150 Rohingyas detained in the holding centres in Jammu to be deportated to their parent country, as per the procedure of law (Live Law News Network 2021).
The Human Rights Law Network (HRLN) posted a YouTube video of the massive fire in the Rohingya settlements of Madanpur, Khadar in Delhi in June 2021 that burnt down 54 shanties making 250 refugee families homeless (Abdali 2021). The following is a brief summary of the video footage on the "Continuing Exodus of Rohingya to India" by Human Rights Law Network (HRLN) describing the incident. The commentator explains that the refugees come from Myanmar. They went to India to save their lives and seek refugee protection by registering with the UNHCR as refugees. The fire destroyed basic necessities. Families lacked food, water, and clothing. Women and children were on the road all night, shocked and helpless. In 2013, HRLN, conducted a fact-finding operation and found that Rohingya settlements in Delhi and Haryana were "sub-human conditions". They had no food, no water to drink, no access to education, and no access to healthcare services. Since 2018, they have noticed that fires have broken out eight times in different settlements in Delhi, Haryana, and Jammu. Destruction is always preceded by threats before colonies are burned down. These refugees are under threat and culprits are responsible for the fires. A Twitter handle claimed, "Yes we did and we do again. Hashtag rohingyaquitindia". This indicates the severity of the risk they face.

\subsection{Life in Exile}

Rohingya voices: Zakir Mohammed, head of Camp N. 1 Balapur, Hyderabad, India:

The name of the camp is Bismillah settlement, a new camp that came into existence in 2018. There are 22 Camps in Balapur. Camp 1 includes 64 families and 230 members. We have camps big and small. An individual named Assim Bhai gave them the land. He takes charge of the place. They pay 20,000 rupees to rent some land in Balapur.

\section{The Making of Social Borders}

Politics of borders are linked to geographical, social, and spatial margins in South Asia (Cons \& Sanyal 2013). In Myanmar, the state has publicly restricted the use of the word 'Rohingya' since it means inhabitants of Rohang, an early name for Arakan. The official position is that this community is from Bangladesh and therefore must be called Bengali. The Rakhine Buddhist are the ethnic majority in Arakan and speak a dialect of Burmese. The regions of Chittagong of South-eastern Bangladesh and Arakan saw an influx of Muslim Arab merchants in 9th century. Rohingyas claim descendancy from the first Muslim Bengalis, Muslims, Persians, Moghuls, Turks, and Pathans (Lewa 2008). According to Zarni, despite Aung Sang Syu Kyi's professed commitment to democracy and human rights, she has practiced the same policy of chauvinistic nationalism that alienated 
minorities (as cited in IMPRI Impact and Policy Research Institute 2021). In international law, a stateless person is a person who is not considered a national by any state under operation of its law. As such, the Rohingya are considered a stateless people.

In order to understand how residents of border zones navigate and negotiate risk, it is necessary to be rooted in the histories, complexities, and contexts which are not formed in isolation, but rather are relative to a broader system of marginalized and marginalizing spaces, processes, and patterns (Cons \& Sanyal 2013). The macro boundaries within the histories of the post-colonial state are understood by analysing the literature on the Rohingya based on the histories of the colonial period. This paper uses the optics of internal boundaries to explain borders. The "stateless Rohingya" needs to be viewed through the lens of histories where nation-state politics creates the problem. The Rohingya are denied rightful national membership or citizenship as an indigenous race, but the histories and colonial boundaries bring out the politics of negotiating with state and the non-state actors in Myanmar.

\subsection{Politics of Identity of the Rohingyas}

The colonial systems and their implications influence politics of identity and ethnicity. The politics of identity of the Rohingyas also affects the formation of internal borders which are based on ethnicity. The term "Rohingya" is based on their belief as the inhabitants of the Arakan region. ${ }^{1}$ Those who identify by this term Rohingya mean they are 'native' to Arakan region. The claim of Rohingya lies in the Arakan country, history, identity, culture, religion, communities and geography. But the Rohingya are contested due to the fact that they claim independence and the right to representation of ethnic minorities in the political affairs of Myanmar. The notion of citizenship in the Burma/Myanmar state based on indigeneity is tied to the politics of ethnicity and political representation, and the Burma/Myanmar state has strong claims against the Rohingya identity (Thawnghmung 2016).

Rohingya self-identify with "Ruaingga" (Leider 2014). "Rohingya" in the popular language is the name of 'Arakan'. The nomenclature, Rohingya is cultural. The Arakan region has a rich history of cultural exchanges among religions. It also served as the seat of Buddhism and syncretism, a culture of Vaishnavism and Persian. The Arakan region was ruled by various dynasties. The colonial conquest of Rakhine and Burma changed the demographic of the region. After the Burmese took over the Arakan people, they fled to Chittagong. This has also caused conflict as a result of demographic changes and resource control. When the census conducted in the 1930s in Burma categorized people into different groups based on ethnicity there were riots amongst the people.
Rohingya are native to the Rakhine State of Myanmar. Their origins can be traced to the present-day territory prior to British annexation of Burma in 1824. This issue has been the subject of many discussions on the part of the elites in Myanmar and a number of historians have contributed to this debate. Historian Kei Nomoto discussed the presence of the Rohingya in Rakhine since the 8th century which might help to establish their claim to a Rakhine State. That view is challenged by historian Aye Chan. The 'Development of a Muslim Enclave' in Rakhine the State of Burma (Myanmar), Chan discusses the various events throughout the history of the region-particularly the events of colonial Burma including the mass migration of people from the neighbouring Bengal region under the British rule. His key argument is that the 'Muslim identity' in Rakhine is a historical development constructed by migration under the various regimes (i.e. Burmese, British) that held power primarily during the 18th and 19th centuries. This sheds light on Chittagong's migration to the region and the development of community violence across ethnic lines. Chan notes that those who call themselves Rohingyas reside at the Mayu border, in the townships of Maugdaw and Butitaung, which are descendants of Chittagonian immigrants and that they are different from other Muslim communities in Arakan who live in other townships. It provides evidence to demonstrate how the people of the Mayu border were referred to the Chittagonians in British colonial records. His viewpoint could be complemented by Leider's analysis on the Rohingya in Myanmar. Leider mentions that a certain section of the people from the northern region of Arakan began to identify as 'Rohingya' which then led to the movement of ethnic identification of the Rohingya (Leider 2014).

Historical records also mention that the 15th century kingdom of Marak $U$ extended to the ancient Indian subcontinent. The descendants of the Muslim communities of Arakan during the time of Marak $U$ lived in the Marak $U$ and Kyauktaw Townships from 1430 to 1784. Another periodic reference to a Muslim presence is the retinues of the Sultan of Bengal who were the earliest Muslim settlers in the region, dating back from 1430 to 1784 . Histories showed how the term Rohingya becomes politicized by the 1950's movement to create an autonomous Muslim zone in Rakhine State. Similarly, the creation of the Jamiyyat al ulama of the Rohingya in 1936 under British domination is proof of the emergence of a Muslim movement in Arakan. The origins of the mujahideen movement in Rakhine bears witness to the disappointment of Muslims who tried to integrate the cantons of Buthidaung, Maugdaw, and Ratheedaung in Pakistan and ended up in revolt. The rebels who declared holy war on the new Republic called themselves Mujahedin (Chan 2005). In the case of the Rakhine State People's Council, the testimony of the inability to resettle in the villages after fleeing the Japanese occupation led to the Mujahideen rebellion. 
Muslims made several attempts to gain entry into the political affairs of the state of Burma as a Muslim ethnic nationality and legal status to be given to the Mujahid party. In the 1960s, under Burmese Prime Minister $U$ $\mathrm{Nu}$, Muslims called for establishing the Rohingya state. Efforts have been made to obtain recognition of their ethnic identity in the Union of Burma and to obtain the equality of status enjoyed by other ethnic groups. They firmly insisted on their identity as Rohingyas after the Bangladesh gained independence as Dhaka followed the policy of disowning the Chittagonians who were in favour of West Pakistan (Chan 2005).

While there are debates as to whether or not Rohingya originated in Burma before the British annexation, census records of Burma show the formation of 'ethnicity' as a social and political construct that was established under colonial rule. In particular, an Indian ethnicity (referred to as Ko La in historical records and scholarly articles on Arakan) was recorded by the British in the Arakan region after the arrival of slaves from Bengal (Chan 2005).

The development of economic frontiers in Arakan under the British annexation policy encouraged agriculturalists who were said to be residents of Bengal to come from areas around the Arakan, a development that shifted the social boundaries in Burma's society. Another racial division began to develop on the lines of ethnic difference with Chittagonian immigrants becoming ethnically dominant in number in the Mayu border under British rule. The report on the settlement operation in Akyab District mentions the comparative tension between the Bengali and the Arakanese race. The racial classifications established by the British census (including categories such as Mahommedean, Burmese, Arakanese, Shan, Hill Tribes, and Others) are proof of the emergence of racial identities in this time period. After the census in 1921 that classified Indian as separate group of people, the first Anti-Indian riots took place in Burma. Chan (2005) states that all Chittagonians and Muslims were recorded as Mohammedan under column of 'Race' in several census reports of 1871, 1901 and 1911.

Categorizing populations under British religion and ethnicites created limits that determined people's ability to access resources in society. These ethnic divisions still have an impact on Myanmar's society. For instance, in 2016 and 2017, ethnic cleansing operations by the state in an attempt to drive Rohingya people out were reported. Despite the national challenge to the identity of the Rohingya, we cannot deny them in Myanmar. The "South Asian ethnicity", as defined in the British records, referred to the Chittagonians of Bengali until the 1990s thus registering them as Muslims and considering them persons of Indian ancestry.

The case of the Rohingya indicates that the politics of identity of the Rohingya was built in a socio-spatial context. Through the various powers and rules it has undergone alterations. The second part of this section highlights politically mediated identity formation of Rohingya under post-colonial state regimes-starting during the early democratic rule of Independent Burma and tracing through the military coup and the military run democratic government in Myanmar. It was in this post-colonial period that army General Ne Win's Burma Citizenship Law effectively rendered the Rohingyas stateless. He excluded generations that regarded themselves as a Rohingya people although he was viewed differently by military leaders. They became stateless and their community identity was adversely affected by the law (Farzana 2017).

\subsection{Rohingya Refugees voices: Threat to Identity}

Rohingya voices: Akhtar, 24 (Rohingya interpreter at UNHCR, female):

The village is called Nayan Chaw. Since we have lived there, we have lived under a lot of restrictions. The government is creating restrictions, as far as Musalman is concerned. After studying and after finishing class ten, there are difficulties to go to college. We have no right to go to university. There is a pass which we cannot obtain. To go from one village to the other too we must take permission. If a girl wants to see her dad, she needs permission. She can stay no longer than a day. We have to pay 500, 600, 1000 to have permission. We had to deal with that type of restriction in Burma. As we were born there, in that place, we continued to live there for our love for the country. People feel a different way about their country. They kept us like a bunch of animals. For cutting timber we need permission, for cutting bamboo we need permission. We have to get permission to farm on our own land. There are mostly famers there.

\subsection{Rohingya Statelessness and Post-coloniality}

Samaddar (quoted in IWM Vienna 2019) states that the surge in de facto statelessness in Myanmar is due to nationality issues that have been more "ethnicized" and "securitized". He argues that international conventions on statelessness do not acknowledge the problem of statelessness in this manner. The British practice of colonial labour in different countries created statelessness for plantation labours in Sri Lanka. The same was true of the Rohingya. Samaddar (2019) observes that the nearly a million tea plantation workers that were taken from the southern part of India ended as disenfranchised. The issue of Sri Lankan Tamil ethnicity in Sri Lanka started with Tamil plantations labour of Indian origin. He contends that post-colonialism created the problem of statelessness not addressed by the 1954 Convention. Critical postcolonial approaches to forced migration analyse contemporary forced migration using concepts such as "borders". According to Samaddar (2016) postcolonial perspective of forced migration includes 
the combined exceptionality of the events of forced migration with the structure and the daily experiences of colonialism, decolonisation, and the post-colonial realities of society and politics. According to Samaddar (2016) post-colonial perspective of forced migration includes the combined exceptionality of the events of forced migration with the structure and the daily experiences of colonialism, decolonisation, and the post-colonial realities of society and politics. In South Asia, post-coloniality has shaped borders around belonging and citizenship.

\section{Migrant Historicity}

The continuous movement of Bengali-speaking Muslims from Bengal, particularly Chittagong, to Rakhine (Burma or Myanmar) contributed to the statelessness of the Rohingya whose Muslim origins were noted in Rakhine in 16th through 18th centuries, as per Dutch and British sources (Gosh 2016, 25-26). The descendants of Bengali slaves were there among many of them. Bengali and local were not distinct, though the Bengali would have retained their mother tongue. Additionally, during the British occupation of Rakhine in 1825 and the signing of the Yandabo Treaty the following year, Rakhines returned home as well. As such, new Chittagongians who were attracted by the commercialization of rice cultivation and by the opportunities to work could have entered Rakhine. The development of Akyab port by the British for a century or more under the British until Burma was separated from the Indian Empire in 1937 in the future provided additional opportunities as well (Gosh 2016, 26; Leider 2013).

The Indian partition event may have added another dimension to the immigration issue as a large number of Bengalis, most of whom had been in Rakhine province, demanded either political status as part of Pakistan or demanded an independent nation (Gosh 2016). Gosh notes that Pakistan's vision did not bear fruit as the political leaders Jinnah and Aung Sang of Burma had entered into an agreement before partition in July 1947 through which they chose to not alter their international border at the Naf River (Gosh 2016, 26; Leider 2013).

In 2014, the Government of Myanmar continued the census exercise established in 1983 and kept the Rohingyas outside its scope because the government insisted they should identify as 'Bengalis' (an ascribed group identity) and not 'Rohingyas' (a term that historically defined them). The term 'Bengalis' is more linguistic in nature while the term 'Rohingyas' may hold a more religious connotation. The political situation of the Buddhist-Muslim conflict in the country makes the "religious" identity an important cause of exclusion (Gosh 2016, 27).

\subsection{Citizenship and human rights?}

Rohingya voices: Samira (interpreter at UNHCR, woman):

We don't have an ID. They kept us temporarily there. Children from all denominations study in the classroom. There is bias towards Buddhist study within the school. If we do something, they take us to the police station.

Here, children are allowed to study. We cannot remain in Burma as we do here. There is no contact with the local population. We came out of fear. We had to go through the mountain when the violence started in Akyab. I was involved with an UNHCR BMLRC in Burma. Violence broke out in Sittwe. People at the mosque were murdered. I have already lived in Bangladesh for 2 months. We are not allowed to make the appeal of prayer (Azaan) and are not allowed to pray (Namaaz). They beat up two people praying they nearly died. They're taking people to a police station.

We have no documents. My mother brought us up with so much difficulty. My mum used to work with UNHCR. We have temporary papers. We have a temporary I.D. There are those who don't have a husband or children, who live alone and are old. Some young children with no one with them also commit suicide. To give a single prayer call, it is very difficult. Even to follow the true religion, that's hard. You have an identification card. We don't have an ID. We live as temporary individuals. We still live the way they want us to live because where else should we go. Where should we go from here? Yet they commit so many atrocities against us.

On crossing the border:

It took four hours to cross that border. At some side there is 1 hour road, another side there is two or three hour road and some side have two days road to the border. I belong to Maungdaw of Khamung. I arrived June 12, 2013. I came by boat to the border. I came to Balughat and took a bus to the Indian border, then train to India. We had to come with no food.

\section{Ethno-religious boundaries of Myanmar}

Refugees were often termed by States as "economic migrants" or "illegal settlers". The politics of sub-nationalism, nationalism, and nationhood as decolonizing processes produced postcolonial borders and boundaries in the states. In South Asia states, postcoloniality impacted the implementation of citizenship and belonging for groups of refugees and migrants.

In Myanmar's ethnoreligious politics, the Rohingya are identified as Bengali immigrants by Rakhine Buddhists. The presence of East Bengali/ Chittagonian/ Rohingya refugees means one thing in the international political 
context. However, being seen as Rohingya is different, something which the politically active section of the Rohingya community wants to be acknowledged as. Furthermore, in Buddhist-Rohingya politics Buddhists claim the Rohingya to be Bengali-speaking immigrants who have to return to where they came from, which is Bangladesh. The Rohingya assert themselves as an ethnic community in this context and seek regional autonomy. They demand cessation from Myanmar through the creation of a Rohingya state (Gosh 2016, 119-121).

\subsection{Politics of nationalism of Burma/Myanmar}

In the Burmese State, the Rohingya face oppression for their identity. Each exodus of Muslims corresponds to changing regimes. In 1978, during the Tatmadaw (Burmese Army) operation known as Nagamin about 220,000 Muslim refugees fled to Bangladesh. This operation was conducted in order to verify and determine 'nationality' and was carried out against possibly illegal Bengali migrants. As the newspapers said at the time, the atrocities in Arakan were against the "armed bands of Bengalis", "wild Muslim extremists", "rampaging Bengali mobs" ransacking indigenous Buddhist villages", and perceptions towards Muslims in the region were aggravated with incidents of violence and tyranny by the Burmese state and army (Grundy-Warr \& Wong 1997). Ever since the military came to power nationality has become significant to the citizenship and inclusion of the Rohingya. The Citizenship Law initiated by Burmese Social Programme Party (BSPP) in 1982 changes the citizenship regime to jus sanguinus. The government claimed that the National Register of Citizens (NRC) was not effective in proving citizenship and the residents in Burma would have to undergo a citizenship determination to verify nationality (Farzana 2017).

Citizenship was for the taingyin tha people and the non-taingyin tha. People considered indigenous to Myanmar, Thai-gyin-tha (citizenship at birth), nyan ngaing tha (for the non taingyin tha) or associated citizenship for those who were guest citizens or those who were allowed to be naturalised citizens, and those who were already citizens in 1982. These categories were applied by the state for granting citizenship. Identity became instrumental to how the state deprived the Rohingya of citizenship. Laws on citizenship by the state in 1980s alienated people through their documentation of identity. This affected the first exodus of Rohingya for most of the refugees had fled and were repatriated. The ruling Burmese Socialist Programme Party and popular opinion believed that aliens from China and East Pakistan were the cause of the operation (Kyaw 2017).

\subsection{Laws are passed against the freedom of minorities}

The 1982 Citizenship Law was brought in by the Burmese military rulers and denied citizenship to most people of Indian and Chinese decent. The law is different from the preceding Citizenship Act and it is based on the principle of jus sanguinis and identifies categories of citizens as full, associate, and naturalised. The Rohingyas do not appear in the list of 135 national races to whom full citizenship is given. The government of Myanmar does not recognise 'Rohingya' and the citizenship law does not recognise them as nationals belonging to the state. The associate citizenship category was granted to those whose application for citizenship was pending on the day the 1948 Citizenship Act came into force. The Naturalised citizenship could be given to those who provided "conclusive evidence" of entry and residence before Burma's independence on 4 January 1948, who could speak national languages well, and whose children were born in Burma. Few Rohingyas could fulfil all these requirements. The power to decide matters pertaining to citizenship was assigned to the government controlled 'Central Body' which resulted in Rohingya entitlements to citizenship not being recognised (Lewa 2009).

Discrimination also occurred through actions such as the severe restrictions imposed on movement, the banning of Rohingyas from civil service employment (including the education and health sectors), and the 1990 decision that made official marriage authorisation compulsory. Eventually, the authorities even stopped issuing Rohingya children birth certificates. Infringement of these rules can result in long prison sentences. Additionally, forced labour, arbitrary taxation, and confiscation of land, which are practiced elsewhere in Burma, are imposed on Rohingya in disproportionate manner (Lewa 2009).

Life, liberty, and the rights of the Rohingya people in Burma have become highly securitised with the freedom of movement being heavily restricted for Rohingya people. Some of the restrictions they face include being confined to villages. They have to apply for travel passes even to visit the neighbouring villages first exodus and they have to pay for the pass. Travel is restricted to North Arakan and even Sittwe, the capital of Myanmar, is declared off limits for them. The lack of mobility has had devastating consequences on their access the markets, employment opportunities, health facilities, and higher education. Those who over stay their travel pass are prevented from returning to their villages and names are deleted from family list. They are then obliterated administratively and compelled to leave Burma. Some Rohingyas have been prosecuted under national security legislation for travelling without permission. Rohingyas are forbidden to travel to Bangladesh, though some are able to do so using clandestine methods which has proven easier than going to the state capital. However, those who are caught could face a jail sentence there for their illegal entry. Many people who went to Bangladesh as patients seeking medical treatment were unable to return home and during their absence their names were removed from their family list. Once outside Burma, Rohingya are denied the right to return to their own country (Lewa 2009). 
State practices relating to registration and documentation since 1978 have also played a significant part. Such practices include the confiscation, destruction, nullification, and targeted non-issuance of identity documents (Brinham 2019). National verification is a process that showed the evidence of crimes against Rohingya. These "registration processes [have become] increasingly repressive, coercive and abusive since the mid-1990s, making survival for Rohingya in Myanmar more and more difficult" (Lewa 2009, 11).

\subsection{Atrocities and local discrimination}

Rohingya voices: Minister Shakir Alam:

\begin{abstract}
Coming here made me poor. He came right from Kolkatta to Hyderabad. Earlier, I had studied in Deoband Madrasa in India. When I came to Bangladesh I thought I would stay in Bangladesh or come to India. The police at Kolkatta gave me 2000 rupees seeing the children with me. All of India is good. This Government is good here.

Our government has committed numerous atrocities against our people, killed a lot of people in our village and raped a lot of people. We feel angry. If I have the good fortune to meet the Suu Kyi, I will tell how many atrocities have been committed. I am very angry. It might be better to die. We still have no card and we were given a home. It is a gift of the government on humanitarian grounds. They have given us help to live. Religious ministers face a great deal of atrocities. My village has been confronted with many atrocities. We have a temporary I.D.
\end{abstract}

\subsection{Sectarianism}

State laws in Myanmar go against the freedom of religion. The laws passed are the Religious Conversion Bill and the Monogamy Bill, or the so-called "race and religion" laws which came into force on August 21, 2015 (Human Rights Watch 2015). The religious conversion bill gives the state the provision to regulate religious professions and conversions. The Monogamy Bill prohibits a married person from entering into a second marriage or "unofficially" living with another person while still married. The 1982 Law of Citizenship privileges members of "national races" considered as indigenous by the state into three categories they are: (full) "citizen," "associate citizen" and "naturalized citizen." Meanwhile, the Buddhist Women's Special Marriage Law's purpose is "to enable the enjoyment of equal rights by Myanmar Buddhist Women and non-Buddhist men with respect to marriage, divorce, partition and guardianship of children and to give [them] effective protection" (International Commission of Jurists 2019). The race and religion laws are hostile to Rohingya culture as they allow the Rohingya to be singled out for citizenship based discrimination, religious profession and conversion discrimination, and restirctions on the freedom to marry and interracial marriages. These legislations form the social borders.

\subsection{Restrictions on freedom}

Rohingya voices: Farook (Interpreter with the UNHCR, Male):

That's because they say we don't belong there. We don't belong to Burma. Some years ago our ancestors had emigrated from Bangladesh, so we should not have Burmese citizenship. Yes, as well as the government. That was not just in 2012. This has been happening for 30 to 40 years. Slowly and slowly... one restriction and a second restriction. In 2012, it came in a big way. We were originally stripped of our citizenship in 1962. Before this we were citizens. We would be regarded as citizens by the government. As after this the restrictions that were brought upon us were like if you need to go to another city like for example if from Hyderabad you need to go to go to Secunderabad it falls in the same district you have to take permission. On paper, we have to take permission that we need to stay for a couple of days. We must take permission. This government has imposed restrictions on marriage. You can't just marry freely. To get married, we must submit a large application and after verification, they approve it. In the mosque no more than five people can come together and say their payors. We expected the situation to improve in 2013 and 2014. But that didn't happen. Because our country and our land are home to us. If we go to Bangladesh, they say that you are from Burma, if we go to India, they say that you are from Burma. Day after day, things went from bad to worse.

\section{State of Exceptionality for Rohingya refugees}

Jones (2009a) talks about the sovereign power of the state over the targeting of few individuals for exception, which occurs in particular places more than others. The task of understanding the state of exception is to identify the agents, targets, and spaces where sovereign power practices occur. In border enclaves the connections between bordering practices and sovereignty claims of India demonstrate the social benefits the sovereign state system has brought through the establishment of law and order and the devastating consequences it has caused by territorializing those basic social protections (Jones, 2009b). Rajaram and Grundy-Warr's (2007) work on "borderscapes" examines the structures of justice, security, and belonging that result from sovereignty, moral frameworks, and insurrectionary politics of belonging and un-belonging. This section outlines the discursive borders for Rohingya. The undocumented nature of the migration of stateless Rohingyas brings them into contact with the policies against them. These emerging conditions are shaping the impending anxiety of migration in South Asia. Newspapers reported that in 2019, 31 Rohingya families were stuck in No-Man's lands between the IndoBangladeshi borders (Aseanplus News 2019). In this event the two sovereign states had to choose who was 
responsible for the stateless people. People who have crossed the border can either be recognized or barred. This is an intermittent dilemma between sovereign countries over border-crossing refugees in a regional context where the refugee regime is weak.

The stigma of disease and exclusion during epidemics also affect Rohingya. The Rohingya refugees are affected by a disinformation campaign surrounding the COVID-19 pandemic (Bose 2020). They face the constant threat of eviction from the lands they are living on thus making the nature of shelter precarious for the Rohingya living in the Delhi settlement.

These groups of refugees have marginalized identities. The politics of identity overlapped with access to basic rights. With statelessness they are undocumented in terms of state recognition of their individual identity. These refugees are made dependant on refugee cards. The boundaries and borders of belonging and citizenship for the Rohingya refugees made them subject to control through securitisation regulations, rules in settlements, restricted work opportunities, limited access to education, and camp like life in settlements as well as other local restrictions. These social borders, boundaries, marginalizations, and marginalities have impacted on their daily lives.

The global protection regime across states in South and South East Asia and the global North have obstructed the effective protection of refugees and the development of sustainable solutions to the refugee problem, especially in regards to burden sharing through naturalisation or resettlement. Refugees face social exclusion and marginalization in the context of the robust institutional responses to the "urban refugees" in the cities of Delhi and Hyderabad which has had an adverse impact on refugee rights and well-being. The migration control on territories and people through securitization policies practices and actions has also had an impact on the human rights of the Rohingya refugees under globalization and flows which has resulted in the infringement of their citizenship and rights. As a result of the exercise of state sovereignty, pre-existing borders and extreme marginalities led to the further marginalization of refugees in the context of India. Do to their statelessness, the Rohingya rights to life are endangered by the implementation of deportation laws. Here in the margins, the state exercises to declare or treat person as unbelonging or illegal is failure to protect refugees and vulnerable groups at the society's margins.

\subsection{Boundaries and subjectivity}

They are subject to boundaries as refugees. Therefore they reside temporarily and without access to basic needs, particularly shelter and decent living conditions, their rights as refugees are violated. In the absence of a refugee regime they encounter the state with fears of deportation.

Inequalities give rise to socio-economic challenges. They form challenges that refugees are subjected to because of their legal status. They have to pay rent and rebuild the houses from time to time when they are asked to shift or move out. The challenges mainly exist because, under current circumstances of non-recognition, Rohingya refugees cannot survive freely.

The challenges of finding suitable work and earnings are meagre. The refugees face multiple challenges such as making an agreement with the employers for getting a job. Though work is informal they have no permanent informal employer-employee relationship because of their identity, their choices, and their preferences. They prefer to live in mobile way and go to find work whenever they get the opportunity. However, they are left with the choice of performing work at the bottom of the hierarchy where they must compromise on many aspects of the employer-employee relationship such as negotiating for longer terms with the employer, building a formal employer employee relationship, and obtaining more stable, continuous, and persistent form of work.

\subsection{Communal discourses on refugees}

The politics over the alleged immigration from Bangladesh led to the National Register of Citizens in the Indian State of Assam which excluded 19 lakh people after spending four years and billions of rupees (Choudhary 2021). The political bordering over "illegal immigrants" in Assam led to the building of detention camps to check alleged illegal immigration from Bangladesh and an NRC exclusion exercise resulted in massive human rights violations. Such ethnic politics and practices caused many people to become stateless. This is the outcome the ethno-national state that promotes a certain view of the mainstream based on politics of ethnicity and distinction. These are additional social borders that lead to the creation of marginalized groups and communities.

For the Rohingya, crossing the border means fearing ethnic violence and discrimination against 'Bengali immigrants' in their countries of origin. They have legitimate and substantive issues. In one incident, a Rohingya boy reported that he had to wait overnight in an isolated place to cross the border with India. He was told to run without looking back, even if someone throws a flashlight at him. The road of the border was muddy and full of grass and is 60 to 70 miles wide. In addition to large populated border areas and without personnel to find security, they also much navigate through additional legal obstacles. Social borders provide obstacles for the Rohingya who are fleeing to Bangladesh from Myanmar as immigrants face such communal campaigns. 


\section{Conclusion}

In a discussion about "cascades of violence", Braithwaite and D'costa (2018) examine a proposition stating that, "refugee and IDP flows further cascade violence... refugee camps become nodes of hopelessness and resentment for those whom they trap. This makes them ideal recruiting grounds for those with weapons and cash to enrol bereft young refugees into armed groups. In turn, these recruitment practices inside refugee camps make camps targets for atrocity by enemies of the recruiters" (138). On the other hand for Rohingya no country has been willing to resettle them in their own territory except for Bangladesh's plans to settle some of the refugees in the Bhasan Char, an isolated island in the Bay of Bengal. The official UN resettlement policy is for one percent of the people from the entire refugee group to be resettled in all areas of India. While some from the Rohingya look for their own means to resettle to the third country, a majority of Rohingya depend on the benefits of the government. Therefore, among the Rohingya they look for access to better educational, individual, and community development solutions in order to sustain their lives as refugees. Refugee protection is implemented in practice by the UN through the institutional mechanism of NGOs and civil society groups in Delhi and other places. There is limited funding and access from the UN for managing the refugees in Delhi and many of these aid organizations are unable to meet all the needs and concerns including the cost of shelter, health, education, other basic needs and day to day sustenance in a local level. State control has an impact on local integration. The Rohingya also have limited scope to work in restricted regions, sectors, and types of work.

The treatment of Rohingya refugees and marginalized groups in India is as if they are 'unauthorized'. The Rohingya are displaced people. The UNHCR assistance is based on humanitarianism. It is inadequate to meet challenges for dignified living conditions, right to development, and sustainable livelihoods due to which there are organizations that reach out to them. But the problem is that an outcome of politics and oppression, these humanitarian organizations consider the treatment of Rohingya as 'unauthorized' by state. Therefore these organizations are functioning within these established social barriers. Since they are stateless, the refugees are criminalized because they do not belong to anywhere. No nation or country says they are theirs. They have temporary IDs and no documentation with any government. They are forced to become either refugees or victims of traffickers.

This paper is on borders and the margins of Rohingya refugees. The marginal experience recounted by Rohingya refugees in India highlights the politics of social borders. The narratives and politics of the migrant or the immigrant are the borderscapes that affect the Rohingya refugees. The immigrant is being culturally and socially constructed based on politics of differentiation, oppression, subjugation, ill-treatment, and non-identification, as well as other parameters or stereotypes under the state. There are overarching political borders and actual concerns by the state about immigrants and the porous borders of states. The massive influx of Rohingyas refugees in Bangladesh is a burden to the local society. The vulnerability of the refugees and concerns over fostering terrorism affect national and international politics in the states. The attempts at securitization, detention, and confinement to the camps are the borderscapes for Rohingyas shaping state concerns regarding territorial integrity and sovereignty over population.

\section{Acknowledgement}

The author is grateful to a friend for accompanying her at the time of interviewing refugees for this paper.

\section{Note}

1 Rakhine State was geographically situated between Indian subcontinent and South East Asia. The Arakan region was a coastal kingdom of South East Asia. Arakan was ruled by different rulers in pre-colonial era such as the Marak $U$ kingdom in the 15th century. The Burmese rulers invaded Arakan from 1784 to 1824, the British ruled Arakan region after conquest of Burma in 1824.

\section{Works Cited}

All hyperlinks last accessed December 2021 unless specified.

Abdali, F. 2021. "The Continuous Exodus of Rohingyas in India" (Video). YouTube (July 8). https://www.youtube.com/ watch?v=BWrw9yu5ruw

AP. 2021. "Bangladesh sends hundreds more Rohingya refugees to island" The Times of India (November 25). https://timesofindia.indiatimes.com/world/south-asia/ bangladesh-sends-hundreds-more-rohingya-refugees-to-island/articleshow/87911155.cms

Aseanplus News. 2019. "Rohingya stuck in no man's land'” The StaR (January 22) https://www.thestar.com.my/news/ regional/2019/01/22/rohingya-stuck-in-no-mans-land

Bose, T. 2000. "COVID-19: Rohingya Refugees in India Are Battling Islamophobia and Starvation" The Wire (May).

Brenner, Y. 2019. "Rohingya migration to India: Patterns, drivers and experiences" Mixed Migration Centre. https:// mixedmigration.org/resource/rohingya-migration-to-india/

Brinham, N. 2019. "When Identity Documents and Registration Produce Exclusion: Lessons from Rohingya Experiences in Myanmar" LSE Blog. (May 10). https://blogs.Ise.ac.uk/ mec/2019/05/10/when-identity-documents-and-registration-produce-exclusion-lessons-from-rohingya-experiences-in-myanmar/

Chan, A. 2005. "The Development of a Muslim Enclave in Arakan (Rakhine) State of Burma (Myanmar)" SOAS Bulletin of Burma Research 3(2). 
Choudhary, S. 2021. "Borders Shift and People Move. So Who Are 'Illegal Immigrants', Really?" The Wire. (November 26). https://thewire.in/rights/ assam-border-bangladesh-illegal-immigrants

Cons, J. 2013. "Narrating boundaries: Framing and contesting suffering, community, and belonging in enclaves along the India-Bangladesh border" Political Geography 35: 37-46. https://doi.org/10.1016/j.polgeo.2012.06.004

Cons, J., \& R. Sanyal. 2013. "Geographies at the margins: Borders in South Asia-an introduction" Political Geography 35: 5-13. https://doi.org/10.1016/j.polgeo.2013.06.001

Dcosta, B., \& Braithwaite, J. 2018. Cascades of Violence: War, Crime and Peacebuilding Across South Asia. ANU Press.

Express News Service. 2018. "The Most Unwanted: A gripping account of Rohingya refugees living in India" The Indian Express. https://indianexpress.com/article/india/the-mostunwanted-a-gripping-account-of-rohingya-refugees-livingin-india-4464103/

Fakhrashrafi, M., J. P. Kirk, and E. Gilbert. 2019. "Sanctuary Inter/rupted: Borders, illegalization, and unbelonging" The Canadian Geographer / Le Géographe Canadien 63(1): 84-99. https://doi.org/10.1111/cag.12510

Farzana, K. F. 2017. Memories of Burmese Rohingya Refugees Contested Identity and Belonging. Palgrace Macmillan.

Fields, J., D. Bapat, S. Surbhi, I. Mohammed, S. K, R., and S. Jerath. 2019. "Understanding Contours of Refugee Resilience: Rohingya Refugees in Mewat in Haryana and Hyderabad in Telangana" Actionaid.

Gosh, P. 2016. Migrants, Refugees and Stateless in South Asia. SAGE Publications Pvt. Ltd.

Grundy-Warr, C., and E. Wong. 1997. "Sanctuary Under a Plastic Sheet-The Unresolved Problem of Rohingya Refugees" IBRU Boundary and Security Bulletin.

Human Rights Watch. 2015. "Burma: Discriminatory Laws Could Stoke Communal Tensions" (August 25). https:// www.hrw.org/news/2015/08/23/burma-discriminatory-laws-could-stoke-communal-tensions

IMPRI Impact and Policy Research Institute. 2021. "Special Lecture | Muang Zarni | Myanmar's Coup, Rohingya Genocide and Failed Democratization" (video). Youtube (May 5). https://www.youtube.com/watch?v=rfqELxwzgjg

IWM Vienna. 2019. "Ranabir Samaddar: Statelessness in South Asia” (Video). Youtube (March 12). https://www.youtube.

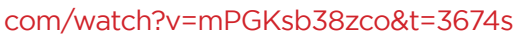

Jain, M. 2021. "Supreme Court Issues Notice On PIL Seeking To Ensure Food Security For Refugees \& Asylum Seekers" LiveLaw (November 29). https://www.livelaw.in/top-stories/ supreme-court-pil-issues-notice-food-security-refugeesasylum-seekers-186549

Jones, R. 2009a. "Agents of exception: Border security and the marginalization of Muslims in India" Environment and Planning D: Society and Space 27(5): 879-898. https://doi. org/10.1068/d10108

Jones, R. 2009b. "Sovereignty and statelessness in the border enclaves of India and Bangladesh" Political Geography 28(6): 373-381. https://doi.org/10.1016/j.polgeo.2009.09.006

Kyaw, N. N. 2017. "Unpacking the Presumed Statelessness of Rohingyas" Journal of Immigrant \& Refugee Studies 15(3): 269-286. https://doi.org/10.1080/15562948.2017.1330981

Leider, J. P. 2013. "Rohingya The name. The movement. The quest for Identity" in Nation Building in Myanmar. Yangon: Myanmar EGRESS/Myanmar Peace Center.

Lewa, C. 2008. "The Rohingya: Forced Migration and Statelessness" in Forced Migration in the South Asian Region: Displacement, Human Rights and Conflict Resolution, edited by O. Mishra. Manak Publications.

Lewa, C. 2009. "North Arakan: An open prison for the Rohingya in Burma" Forced Migration Review 32(Special Issue: Statelessness): 11-13. https://www.fmreview.org/sites/ fmr/files/FMRdownloads/en/FMRpdfs/FMR32/FMR32.pdf

Live Law News Network. 2021. "Supreme Court Allows Deportation Of Rohingyas To Myanmar As Per Procedure Prescribed" (April 21). https://www.livelaw.in/top-stories/ supreme-court-allows-deportation-of-rohingya-refugees-to-myanmar-as-per-procedure-prescribed-172302

Rajaram, P. K., and C. Grundy-Warr. 2007. BorderscapesHidden Geographies and Politics at Territory's Edge. University of Minnesota Press.

Samaddar, R. 2016. "Forced migration situations as exceptions in history?" International Journal of Migration and Border Studies 2(2): 99-118. https://doi.org/10.1504/ IJMBS.2016.075579

Thawnghmung, A. M. 2016. "The politics of indigeneity in Myanmar: Competing narratives in Rakhine state" Asian Ethnicity 17(4): 527-547. https://doi.org/10.1080/14631369. 2016.1179096

University of Luxembourg. 2015. Borderscape as an Interdisciplinary Concept, Call for Papers Symposium. Luxembourg.

Women's Refugee Commission. 2011. Bright Lights, Big City Urban Refugees Struggle to Make a Living in New Delhi. Women's Refugee Commission. https://reliefweb.int/ report/india/bright-lights-big-city-urban-refugees-struggle-make-living-new-delhi 


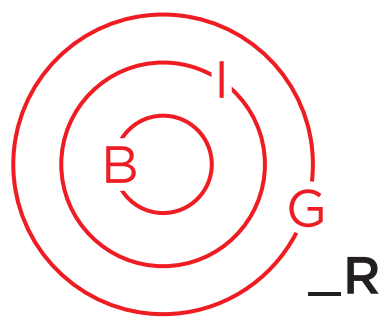

ARTICLE SPECIAL SECTION

\title{
Rohingya Refugee Movement in Bangladesh: Insiders and Outsiders in Strengthening and Weakening of Borders
}

\author{
Sariful Islam *
}

This paper examines the role insiders and outsiders play directly and indirectly in strengthening both territorial and psychological borders. At the same time, it also investigates how they undermine the existing boundaries of difference; in other words, how they weaken borders. This study understands 'borders' as both physical and cultural boundaries or visible and invisible boundaries of (re)producing and (re)ordering "us" versus "them" or insiders and outsiders. The conceptual framework developed by Azmeary Ferdoush (2017) has been employed to investigate the role of insiders and outsiders in strengthening and weakening borders. The Rohingya movement to Bangladesh case study is used to examine the paradoxical affects that both insiders and outsiders have on borders. This study aims to contribute the existing literature by explaining how borders are (re)produced and (re)shaped with the interaction of both the insiders and outsiders, with a specific focus on the implications of the refugee movement on border-making.

Key Words: Border, Refugee Movement, Rohingya Refugee, Bangladesh.

\section{Introduction}

Borders are intended to keep aliens or foreigners out or to restrict their movement. It is traditionally thought that insiders, particularly the state actors, play the main role of border making and bordering. With the emergence of critical perspectives, the concept of the border gets widened, which includes both the physical and psychological borders. Critical scholarship has also pointed out the role the people of a country play in border-making (Rumford 2006; 2008). However, literature on the role of "others" remains scant despite the indispensable role they play in making, strengthening, and weakening the borders. This paper explains how insiders and outsiders play both direct and indirect roles in strengthening territorial and mental borders. At the same time, it also investigates how they undermine the existing boundaries of difference; in other words, how they weaken the borders.

This study aims to contribute the existing literature by explaining how the borders are (re)produced and (re)shaped with the interaction of both the insiders and outsiders. It also provides an empirical analysis of the role of both insiders and outsiders in (re)making the borders, with a specific reference to the Rohingya refugee movement. The 'insiders' in this paper are the state actors and the local people while the refugees are the outsiders. The borders are in a constant process of (re)making with the movement of the refugees.

* Sariful Islam, Doctoral Candidate at the Department of International Relations, South Asian University, New Delhi, India. Email: sarifmcjdu@gmail.com 
This paper brings the case of the Rohingya refugee movement and argues that the borders are not static but dynamic, and the borders are made by the actions and perceptions of relevant actors.

This paper has four sections. The first section discusses the conceptual framework and research methodology. The conceptual framework draws insights from border studies literature in general but mainly uses the conceptual approach developed by Azmeary Ferdoush (2017). As the paper is about understanding the role of the insiders and the outsiders in (re)shaping the borders, Ferdoush's approach of "seeing borders through the lens of structuration" (Ferdoush 2017) helps us to understand the constitutive role of structure and agent in (re)making the border. This section also briefly deals with the concept of agency by drawing insights from critical scholarship (Chatterjee 2013; Scott 1985, 2009; Stern, Hellberg \& Hansson 2015). It concludes by briefly discussing the data sources for this research. The second section traces Bangladesh's colonial legacy of ordering foreigners through bordering mechanisms and new developments. This discussion is required to understand the trajectory of border-making between Bangladesh and Burma/Myanmar and the implication of the Rohingya issue on border management. The third section examines how both the insiders and outsiders play a role in strengthening and weakening these borders. Both hard and soft measures are at the hand of the insiders. Meanwhile, everyday survival mechanisms make the Rohingya refugees choose between sometimes following the border-making strategies and policies of Bangladesh and sometimes avoiding and resisting the same strategies and policies. The fourth section presents the concluding remark.

\section{Section I: Theoretical and Methodological Framework}

This study recognizes that borders are constitutively constructed and that both territorial and psychological borders are constructed and performed by relevant actors. The concept of a border is no longer an easy one to define. With the expansion of scholarship on borders and boundaries, the understanding of borders has now become vague, obscured (Johnson and Jones 2011), and more complex (Johnson \& Jones 2011; Paasi 2009). While in a traditional geographical sense, borders used to be denoted territorial boundaries that differentiated one state from another. The concept of a border is no longer attached with the geographical demarcation alone (Sendhardt 2014). Borders are now increasingly conceptualized as "discourses and practices" (Pfoser 2020, 2). The constructivist perspective focuses "beyond the visible, material, and seemingly objective manifestations of borders" (Sendhart 2014) while considering borders as a "dynamic cultural process" (Sendhart 2014, 26, quoting Paasi 2003). This perspective does not deny the concrete form of the border but centres on "social practices and discourses" in understanding the borders. To constructivist scholars, borders are a "dynamic cultural process" as they are produced and reproduced through everyday practices, policies, and discourses. According to Newman and Paasi (1998), borders are dynamic as they rise and fall, or the construction and deconstruction of boundaries go with the progress of human civilization and social transformation (193).

As our understanding of borders expands, we understand that borders exist both inside and outside of a country in various forms and modes. Borders now exist at the "edges" of territories as well as through innumerable "societal practices and discourses" (Allen 2011, 287, quoting Paasi 2009). According to Balibar, "borders are everywhere" (as cited in Johnson \& Jones 2011, 61). Boundaries might exist visibly or invisibly, in their physical or symbolic form, or as both; sometimes the material forms can be visible while sometimes the symbolic or both can be simultaneously (Newman \& Paasi 1998, 194). To David Newman and Anssi Paasi (1998), "state boundaries [border] are equally social, political and discursive constructs, not just static naturalized categories located between states" (187).

In alignment with the constructivist perspective, the border is also seen as an act of performance. Johnson and Jones (2011) suggest, "Borders are enacted, materialized, and performed in a variety of ways" (61). Drawing on the work of Judith Butler, Mark Salter suggests that border is performative. The performance embodies the articulation and re-articulation of something through "stylized repetition of acts" (Salter 2011, 66). The border is performed through formal policies of demarcation, practical exercising of including and excluding, and discursively articulating and rearticulating the meaning of border in popular realm. Different actors such as governments, citizens, and other agents perform the border in various ways (Salter 2011, 66).

Since this study understands borders as both physical and cultural boundaries, or visible and invisible boundaries of (re)producing and (re)orderning "us" versus "them" or insiders and outsiders, the conceptual framework developed by Azmeary Ferdoush would be appropriate to adopt to investigate the role of the insiders and outsiders in strengthening and weakening the borders. Ferdoush (2017) has developed the conceptual approach of "seeing borders through the lens of structuration" by drawing Anthony Giddens' theory of structuration. He sees borders as the "edges of structure" and the state as the "structure" (Ferdoush 2017, 8).

Ferdoush's approach does not privilege either the structure (state) nor the agents (individual actors) solely; instead, he accords their significance in equal measure in (re)producing, (re)shaping, and influencing borders and bordering practices (Ferdoush 2017, 2). Both citizens and non-citizens are agents in addition to the state actors that play a role on the border (Ferdous 2017, 5). According 
to Ferdoush (2017), as borders are in a "constant state of becoming," emphasis should be given both to the state and people (4). Ferdoush's makes the conceptual framework easy to understand by breaking the argument down into four:

1. structural factors play a role in determining the characteristics of a particular border;

2. actors, including the borderlanders, border crossers, border guards, and so on are reflexive human beings who reflect upon these structural factors based on their socio-political status, economic condition and positionality, and cultural background;

3. this reflection influences the way actors choose to interact with a given border within the limits of the rules and resources to which s/he is entitled;

4. these rules, resources, actors, and structural factors with their constant (inter)action give birth to localized totalities with the greatest time-space expansion become institutionalised and supply the rules and resources for further interaction between the structure and the actor (Ferdoush 2017, 5).

The first two points accord agency to both the state (as structure) and to non-state actors (as agents). Along with an emphasis on the state actors, the focus on the non-state actors, in other words, the ordinary people, including citizens and non-citizens, play their part in making and remaking the border. Chris Rumford (2008) conceptualizes the role of the people in making and remaking the border as "borderwork" (2). Rumford (2006) notes that "debordering and rebordering accompany each other" and borders do not remain the same or fixed (157). Bordering, debordering, and rebordering, according to Rumford, are no longer the exclusive business of the state. The ordinary people, the citizens, are also in the business along with the state actors. Similarly, VaughanWilliams also notes down the role of citizens in working as deputies of state actors in borderwork (as cited in Johnson and Jones 2014, 5). Johnson and Jones (2014) termed the actors that are not state actors but play their part in border making and strengthening the border as "non-traditional actors" (6). These actors (re)produce border through their everyday life experiences. Borders exists through everyday interactions with the "other." However, the non-traditional actors or the local actors, mainly the people, might not always be on equal terms with the central government or state actors. As Ferdoush suggests, some factors, namely cultural or ethnic factors, religious ties, and cross-border ties, sometimes play a positive or negative role between the local populations and the refugees, the "outsiders."

It is required to note that there exists a difference of power and resources between the state and the people. Traditionally, since the state avails more resources, it might have more power to influence and make a difference in producing and reproducing the borders and borderwork. The second point in Ferdous's argument highlights the everyday activities of the actors who work within and sometimes outside of the already settled rules and policies and (re)produce or (re)shape the border. Actors' perception of the border and their action is determined by three significant factors: socio-political characteristics, economic conditions, and cultural background (Ferdous 2017, 9). Ferdous (2017) terms these actors as "reflexive actors" as the combination of these three factors influence their perception and actions while their day-to-day actions influence the bordering process (9). According to his approach, neither the state (structure) nor the agents are static; instead, they are dynamic, evolving, and interactional. As this is so, the border and bordering process could be understood as constitutive. The insiders and outsiders are part and parcel of the production of borders. In the words of Nick Vaughan Williams (2009), "Indeed, borders are perhaps even constitutive of political life. Borders are inherent to logics of inside and outside, practices of inclusion and exclusion, and questions about identity and difference" (1). The existence of a border is realized and materialized with the acceptance of the notion of the border as a line of demarcation-both territorial and psychological-and the everyday exercise of the border. With their acceptance and resistance, both the insiders and the outsiders (re)produce and (re)shape borders. It is not that the border only excludes or permits foreigners. Through the border, state actors and citizens maintain relations to the foreigners. The existence of insiders and outsiders is relational, and the one cannot exist without the other.

The insiders in this paper are the Bangladesh's state actors and the local people while the outsiders are the Rohingya refugees. It is now pertinent to unpack the concept of agency and delineate its usage for this paper. It is generally presumed that agency is "the capability" of the subjects/actors of "doing things" (Ferdoush 2017, 8). However, the term agency "means and does different things" from one scholar to another (Stern, Hellberg \& Hansson 2015, 11). While it is, for some scholars, the capability or doing the actions, it is, for others, the resistance of the governed subjects to the actions taken by the rulers or the dominant group. It could also mean the wilful inaction of some actors. Even "carefully selected strategies of silence and muted voice" are considered agency (Thomson 2013, 589).

Political anthropologist James C. Scott (1985) observes that the people at the margin of the hierarchical structure manipulate the existing status quo for their interest. It is not that they are not aware about their position in the society or the exploitation they are going through; it is their way of compromising and demanding from the powerful class within the existing system. In his early work Scott (1985) notes how the "everyday resistance" in which the subordinate group neither go for "outright collective defiance nor rebellion" (27). In his more recent work Scott (2009) discusses the resistance to the state apparatus by fleeing from the reach of the state while noting the adaptive strategies "to take advantage of favourable developments at the political center and to shield themselves from the worst effects of turmoil" 
(332). Political theorist Partha Chatterjee (2013) observes how some marginal groups demand their rights within the existing state structure, with some groups succeeding and some not. The marginal group might need to go for bending or stretching the rules (Chatterjee 2013, 66). We can draw from both Scott and Chatterjee that the marginal groups act everyday accordingly to their survival interest and contextual manner. Their cognizance of following the rules, norms, and policies of the dominant actor or group in the society or the state varies from context to context and situation to situation. The resistance to the dominant rules and norms that are discriminatory to them remains mostly latent and symbolic but spark out when the limit of toleration is crossed. In a similar line, even in a more clearly articulated way and also keeping the room for understanding the agency in broad way, Stina Hansson and Sofie Hellberg (2015) include "both the refusal and the acceptance of the rules of governing" in defining agency (29).

In this study, the capability of doing as per the pursuance of state is agency for the state apparatus of Bangladesh. The agency for the people of Bangladesh is their wilful action and the cultural production against as well as in sympathizing with the Rohingya refugees. The Rohingya refugees are considered the marginal group and hence, their agency is understood in a vague way. Their resistance to Bangladesh's action and policies, as well as their acceptance and the adaptation to the same, are understood as agency. The agency for the Rohingya refugees is part of their everyday survival strategy whereas the agency of the Bangladeshi state apparatus is to act upon the outsiders. It is thus the state actors have much leverage than the outsiders, i.e., the Rohingya refugees, in (re)making and (re)shaping the borders.

\section{Research Methodology}

The Rohingya movement to Bangladesh is the case study for examining the paradoxical characteristics of the strengthening and weakening of the borders through the actions of both "insiders" and "outsiders". The data for this research is primarily collected from secondary sources. Besides consulting related academic books, articles, and Bangladesh's government's policy reports, an archival study of newspapers was also done to collect data for this study.

\section{Section II: Rohingya Issue and Bangladesh- Myanmar Border-A Brief Note on Colonial Legacies of Border making to Present Time}

As many other South Asian countries inherited the British mode of governance, so did Bangladesh, though the latter was borne out of a second partition in 1971 from Pakistan which was created in 1947 by a tragic partition of British India. British rule converted frontiers to borderlands, and the 1947 partition changed them to borders (Banerjee 2010, xxxiv). The borders during the British rule were largely unprotected, unguarded, and unfenced. It was the state's coercive machinery inside the controlled territories that worked to find out the outsiders (Banerjee 2010). To make the drawn border alive, British rulers initiated and invented some measures. Through legislative Acts such as the Foreigners Act of 1864, Aliens Restriction Acts of 1914 and 1919, and the Passport Act of 1920, as well as administrative practices such as population census, the British rule enrooted the practice of "othering" and thus ordering the movement of the people, not to mention foreigners, was governmentalized. However, it was judicious towards the categories of alien/foreign and deported them (Banerjee 2010). It is also notable that the British allowed the Arakanese refugees to integrate with the local society. In some cases, the British rulers even sponsored their resettlement. For example, Hiram Cox, a mid-ranked government official, was appointed to supervise the resettlement of the Arakanese refugees in Cox's Bazar area in the 1780s (Chakraborty 1984).

The dissecting of British India into different parts had split a community into two parts and undermined the cultural, ethnic, language commonalities. The countries that emerged with the abolition of British rule still bear the scars of dissection. Though post-colonial South Asian countries have been carrying out nation-building projects forward over time, it does not get away from the cross-border ethnic or cultural connectivity among the people or the people's movement across borders. Post-colonial South Asian countries inherited some of the governance technologies from their colonial rulers; nonetheless, the nature of the border and border management strategies are qualitatively different from the British rule. The border demarcation with the neighbouring countries during the British rule was a result of either war, diplomatic negotiation, or both (Tripathi \& Chaturvedi 2020). During British rule, borders were loosely demarcated but were not decorated with the high presence of border guards and fences. The current India-Nepal border came into existence after the 1814-1816 war and subsequent agreement between British India and the Kingdom of Nepal is an example of identifying the borders but keeping flexible. The policing at the borders and fencing up are getting to new levels as time passes. For instance, the highly securitized fencing and the presence of border security forces along borders of Bangladesh and Pakistan by India informs qualitative changes in border management in post-coIonial South Asia. Moreover, there has been a rise of hard measure border management strategies in South Asia in recent decades. India has already erected fences along 3123 kilometers out of 4096 kilometers land border with Bangladesh (GOI 2021). The government of India has adopted a multi-pronged approach which includes the construction of fences, uninterrupted surveillance, and the installation of Hi-Tech surveillance equipment along the Bangladesh border (Business Standard March 25, 2021). 
Bangladesh inherited its borders from Pakistan when the former achieved liberation after a bloody war in 1971. As Bangladesh inherited a governance system from Britain and Pakistan, it does also inherit some cross-border issues with neighboring countries. Amongst many, the movement of the Rohingya is one. Under British rule, the flow of people, including the Arakanese Muslims to eastern part of Bengal (present-day Bangladesh ${ }^{\mathbf{1}}$ ), was not a bone of contention as both the territories were ruled by the British. However, prior to the British's conquering of Arakan (Rakhine) and subsequently Burma, eastern Bengal (present-day Bangladesh) used to a place for the Arakanenese refugees to take shelter in order to escape the oppression of Burmese rulers (Chakraborty 1984). During the British rule, people from both sides crossed borders for various purposes including employment. Sometimes, the administration resettled people as per their interests of governance, cultivation and development projects (Akhanda 2018; Chakraborty 1984). During World War II, due to the advancement of the Japanese forces, some thousands of Muslims who supported the British crossed over to eastern Bengal (Jilani 1999; Pandey 2017). After the end of colonial rule, the boundary line came into existence between the newly emerged East Pakistan (present-day Bangladesh) and Burma (present-day Myanmar). However, the porousness of the border remained in large extent. The Pakistani government had to deal with the refugees coming from Burma in 1948 and 1958 (Bahar 2012; Pandey 2017). The effort of the Pakistani government of sending back the refugees and Burmese government agreement to take back refugees came in 1958 signified the "otherness" of the refugees in post-colonial South Asian neighbors. Seeing refugees as "others" flowed from the Pakistan era into the independent Bangladesh in a more rigid form. The borders were drawn between present-day Bangladesh and Myanmar by separating the latter (erstwhile Burma) from British India in 1937 based on the India Act of 1935. Bangladesh and Myanmar share both land and maritime borders of a length of 314.20 kilometres. The first large scale Rohingya refugee movement in 1978 initiated the land border issue between Bangladesh and Myanmar and subsequently an agreement was reached to demarcate the land border (The Bangladesh Observer August 2, 1978). After the second wave in 1991-1992, both countries signed the "Demarcation of the Land Section of the Boundary North of the Naaf River" (Uddin 2014, 9). In its part of the land border, Myanmar has already erected barbed wire on almost 80 percent area (Xinhua March 10, 2019). Being an economically developing country and having a lack of willingness, Bangladesh did not follow the path of Myanmar until recently.

The Rohingya refugee movements and other related illegal movements and activities bring border security for discussion time and again. The movement of refugees and the activities that are by-product of the refugee movement such as cross-border drug and arms smuggling and insurgent activities have made Bangladesh and Burma feel the need to demarcate and secure their borders. State centric security scholarship and the government documents contend that the Rohingya refugee issue is hampering the stability and security in bordering areas and impeding the cooperation between two countries (Uddin 2014). The Rohingya refugee crisis has pushed Bangladesh to consider its border security to a greater extent both on the borderline and inside the country.

While the Bangladesh government has been taking measures to maintain the physical borders, the cultural production of borders has also started with the inception of Bangladesh as an independent country. The nation-building project of Bangladesh is primarily based on secular cultural Bengali identity (Bjornberg 2016). Sometimes the nationalism gets an overtone of Muslimness. The oscillation between cultural ethnocentrism and religious identity shifts as the main political parties in power change (Majumder 2016). Like most nation-states, Bangladesh has also been pursuing an exclusionary nationalism that even sometimes pushes the non-Bengali tribal community to the line of exclusion. In the initial days of the newly independent Bangladesh, the indigenous communities of the Chittagong Hill Tracts were asked to change their identity and convert to Bengali (Chakma 2016; Mohsin 1997). For the Rohingya people, the ethnic gap presents itself as a gulf in the imagination of the Bangladeshi Bengalis (Bjornberg 2016; Farzana 2017). The religious similarity plays a subtle role in bringing two communities together but does not stand firm in the territorially confined imagination of a nation-state (Farzana 2017).

The exclusionary nation-building imagination and the practices do not allow the borders to be dismantled but rather they are sustained. However, the borders sometimes are strengthened and weakened. Bangladesh has taken steps combining both violent/ hard and non-violent/soft measures. The measures are hard that make the bodies of the physical border crosser are the sites of imposing both the instrumental and abstract technologies that obstruct the entry or at least force to follow some procedure to enter from one side of the border to another. The hard measures can be violent as well (Jones 2016). The soft measures are the exercises that are culturally produced. It includes the narratives of making "other."

\section{Section III: Agency of Bangladesh-Use of Hard Measures in Strengthening Border}

Bangladesh partially uses coercive and productive power to strengthen the borders and borderwork or embolden the "identity/difference" that makes the Rohingya refugees "outsiders" or "others" (Connolly, 1991). Bangladesh continuously struggles in maintaining 
Borders in Globalization Review | Volume 3 | Issue 1 | Fall/Winter 2021 Islam, "Rohingya Refugee Movement in Bangladesh: Insiders and Outsiders..."

the sanctity of the borders amid the increased inflow of the Rohingya. Both hard and soft borders are in consultation with each other. The Rohingya inflow in Bangladesh has been pushing Bangladesh to strengthen the physical borders and increase the border-making practices in the borderland. The first large scale influx of refugees in 1970 s had pushed Bangladesh to bring the issue of border demarcation at the table of discussion with Burma as discussed above. Stringent action was not in place at that time. However, it is alleged that the repatriation of some 200,000 did not happen without coercive measures. Though the government in Bangladesh-inside and outside of the country-was propagating to provide shelter to the Rohingya refugees as part of the religious obligation as a Muslim country, it was not ready to provide shelter to the refugees permanently (Islam 2022). Since the second major influx in 1991-1992, Bangladesh has been following restrictive border polices and measures in regards to the movement of the Rohingya; the restrictions became more visible from 2009 onward. The policies are multi-faceted: restrictive entry, temporary shelter, and restricted rights (Uddin 2020; Islam 2019). It has increased security on the borders due to the increased movement of the Rohingya refugees.

The movement of the Rohingya has made Bangladesh realize the urgency of building up military forces at the borders and increase surveillance and patrolling. The active military response of Bangladesh to the military build-up of Myanmar during the refugee influxes, particularly in 1991-1992 and 2017, suggests that Bangladesh shows its determination of protecting the borders and, thus, asserts its sovereign authority. With a defensive approach to protecting, Bangladesh actively maintains the status of the existing border. From 2009 onwards, Bangladesh has increased surveillance and patrolling along the borders and adopted a policy of detention and push back of Rohingya. For the first time in 2009, police and the Border Guard Bangladesh (BGB) were "actively involved in rounding up unregistered Rohingya at their workplace, along roads, on buses and in their homes, simultaneously in all sub-districts where Rohingya have settled" (Lewa 2010, 3). Though this policy saw a setback during the 2017 influx, it started to go back to the previous position a few months after the 2017 influx. After each massive influx, Bangladesh upgraded some technologies adopted in previous times and added some new ones in strengthening the borders. The Bangladesh government decided to erect a barbed-wire fence along with the Myanmar border "to prevent illegal migration of Rohingya [M]uslims" (Chowdhury 2013). In regards to this initiative, the first of its kind in Bangladesh since its independence, Bangladesh's Home Minister Mohiuddin Khan Alamgir informed the Parliament in June 2013, "we have approved, in principle, the proposal to construct a barbed-wire [fence] along the Bangladesh-Myanmar border, set up searchlights, build watchtowers and 21 new outposts to improve border surveillance" (Chowdhury 2013). He also informed that his government's enhanced patrolling at the border foiled the attempt by the Rohingya refugees to enter Bangladesh (Chowdhury, 2013). In 2013, for the first time, Bangladesh approved a "Strategy Paper on Addressing the Issue of Myanmar Refugees and Undocumented Myanmar Nationals in Bangladesh" (Abrar 21 June 2014). This strategy paper aimed to: reinforce vigilance along the Bangladesh-Myanmar border in order to stop the intrusion of Rohingya refugees, enlist the undocumented Rohingya refugees, provide basic amenities to the documented individuals, and create international pressure on Myanmar to take its nationals back (RohingyaBlogger).

As the days go on, the Bangladesh government continues to beef up security measures at the borders and take precautionary measures. The government's plan of fencing the border came to light again in 2016. Director-General of BGB Major General Aziz Ahmed said that the government has already approved a project for erecting a 282-kilometer barbed wire fence along both the India and Myanmar border, which will begin with the fencing on the Myanmar border (Bhat 2016; The Economic Times 12 July 2018). According to Bradnock (2016), "The fencing of the borders has been designed to limit both refugee movement and politically motivated infiltration, but the issue remains alive and unresolved" (p.170). After the inauguration of a border outpost (BOP) in Saint Martin's Island on September 24, 2019, BGB chief Shafinul Islam said that the barbed wire fencing along the Myanmar border would start soon. Since the 2017 Rohingya refugee influx, the number of BGB members have been increased along the border with Myanmar has been increased significantly (Zaman January 19, 2019). It is now become a short notice issue for the Bangladesh authority to deploy para-millitary forces at the border if something happens in Myanmar that might force the Rohingya to move out. For instance, just after the coup in Myanmar in the early February 2021, Bangladesh stepped up the security along its border with Myanmar (Business Standard February 4, 2021).

The border is not now confined only to the territorial boundary that demarcates from other countries. Inside a country, through "ordering" and the making of "others", bordering takes place. This makes the border keep the "outsider" out and identify them as "other" inside the country. The presence of outsiders inside the country provides an impetus for a host country to invent or employ technologies, such as documentation, encampment, and legal action, or even the erection of visible and invisible walls separating them as "others". The practice of the encampment of Rohingya refugees has become more normal after each influx and it has become stricter. During the first influx in 1978, the Rohingya refugees were put into 13 makeshift camps, and after repatriation, these camps were dismantled. 
During the second influx, more than 20 camps were set up for the Rohingya. Before the repatriation started, there was less restriction on their movement. The restrictions came stringently after 1994, which was the cut-off year of allowing the Rohingya refugees in Bangladesh, and at that time, the repatriation was in the pick. Bangladesh thought that providing easy entry to the Rohingya refugees might endanger the repatriation campaign. The repatriation continued till 2005 in several phases, overcoming some hurdles. The Rohingya refugees who were not repatriated were encamped in two officially designated refugee camps-Kutupalong in Ukhiya and Nayapara in Teknaf (Uddin, 2019). Refugees staying in these camps face restrictions on the right to movements, works, and education, albeit these are different kinds or restrictions as compared to the same in the Rakhine state of Myanmar (Islam, 2019; Uddin, 2020).

The inflow of Rohingya in 2017 has surpassed all previous instances, and even the number of refugees entered is more than double of first and second influx combined. Bangladesh is now hosting more than one million Rohingya including 740,000 newly-arrived Rohingya. They are kept in 34 newly built temporary camps (Uddin, 2019). The camps that have been set up after the 2017 influx are under more surveillance. The Rohingya refugees are subject to several restrictions regarding their movement, education, and work (both inside and outside of the camps). They can go outside the camps only for health or other emergency reasons, subject to prior permission from government officials. Their movements are strictly regulated and under surveillance. There are para-military and police check posts around the camps (Ashraf 2021; Islam 2019). These restrictions have been implemented on a broader scale than they were previously. The government has found Rohingya scattered in different districts, particularly in the Chittagong Hill Tracts (CHTs), which was not there before the 2017 influx. It was an open secret that the Rohingya were living outside of designated camps, but it was not like it is today where the government wants all the Rohingya to be inside the camps. Providing shelter to the Rohingya outside of the camps is now treated as a punishable offense. In a few cases, shelter providers have been detained (Dhaka Tribune April 28, 2019).

To make surveillance easier and more convenient, the Bangladeshi government has planned to erect a barbed-wire fence around the Rohingya camps to "ensure security inside the camps" and stop them move out to other parts of the country and install watchtowers and CCTV cameras for monitoring the refugees (New Age September 26, 2019). The Bangladeshi government also has a plan to form a special police unit for maintaining law and order in the camps (New Age November 26, 2019). It has recently decided to control mobile phone communication in the refugee camps. Though the government made this decision in September 2017, it came again to light when the Rohingya refugees staged a grand rally that consisted of more than one hundred thousand people marking the two years of their exodus from Myanmar (New Age September 3, 2019; New Age August 25, 2019). According to the government's policy, they can get telecom services through public call offices installed at the camps by TeleTalk, a state-owned mobile phone operator but Rohingya are not officially allowed to use mobile phones (New Age September 3, 2019). Home Minister Asaduzzaman Khan warned that Rohingya would face legal action if they defy the order of not using mobile phones (New Age September 14, 2019). It is reported that snapping the cellular connection in the camps aims to curb crimes in the camps amongst others (New Age September 3, 2019).

An intricate technology related to the encampment of the refugees is documentation/registration. The Rohingya refugees were registered in 1978 and 1991-1992 as "refugees". That time identity cards given to them were a most likely traditional ones. Only 34,000 registered Rohingya have refugee status. Rohingyas that came in before the 2017 influx and are not considered "refugees". They are enlisted as "forcibly displaced Myanmar nationals" (Uddin 2019). The Bangladeshi government has taken the initiative, with a collaboration of UNHCR, to bring the Rohingya staying in Bangladesh under biometric registration. The practice of biometric registration was introduced for the first time in June 2018. Between then and August 2019, more than 500,000 Rohingya had been given biometric identity cards. UNHCR spokesperson Andrej Mahecic says, "this is the first ID, a first proof of identity that they have" (UN News August 9, 2019, para 11). These identity cards are given only to refugees who are over the age of 12 and they "carry unique biometric data that includes fingerprints and iris scans" as well as digital photographs. These cards are not considered "citizenship documents for Myanmar" nor are they permit documents for movement or work in Bangladesh (UN News August 9, 2019, para 11). UN Spokesperson Mahecic clarifies the purpose of giving these smart identity cards saying, "these cards are basically their [Rohingya] registration...They regulate their stay in Bangladesh" (UN News August 9, 2019, para 12).

The refugee community knowingly or unknowingly gives their consent to formalize their "alien" identity. When the majority of Rohingya were registering and accepting bio-metric identity cards, they were categorized as "Myanmar nationals". This data registration is helpful for the host government, as well as national, intergovernmental, and international organizations for providing basic amenities, services, and legal protection. However, it is not out of implication for creating a border. This governmentalized technology needs to be seen as something that creates a psychological border and enhances the existing physical border 
by referring the entrants as "foreigners" or "refugees". The body of the refugees becomes the site of exercising the administrative power of the governments or other organizations working with the governments. Btihaj Ajana rightly defines biometrics as "a technology of biopower whereby the body and life itself are the subject of modalities of control, regimes of truth and techniques of sorting and categorization" (Ajana 2013, 4). It is important to say that the Rohingya staying in Bangladesh that have registered are convinced by the logic of getting basic amenities and shelter. However, the latent purpose of the biometric registration is to identify the "outsiders" and then track and control their movement. They are not only easily identifiable and regulated but also they, by default, become "others" in Bangladesh through the process of registration (Oh 2017). A difference in identity with the host community emerges through such administrative practice. Su-Ann Oh (2017) notes, "Bio-metric registration is another way in which refugee bodies may be classified as other" (3). These registration cards produce an identity of the Rohingya who are only allowed to stay at the designated camp. Along with physical structures of the camps and the security vigilance of the security forces in and out the camps, the documenting process creates a demarcation line for the refugees to stay or not to stay.

Bangladesh has been carrying out such measures without any clear legal framework or legislation relating to the refugees, particularly the Rohingya refugees. In the absence of a particular legal framework to deal with the refugee issues, Bangladesh utilizes its state machinery (such as courts and already existing law) and applies it to foreign nationals. Existing domestic legislation or judicial verdicts are being used to maintain the borderline between the Bangladeshi and the Rohingya. To stop local integration, the High Court of Bangladesh in 2014 banned the intermarriage of local Bengali and Rohingya. The Supreme Court upheld the verdict of the High Court in 2018 making intermarriage a punishable offense (BBC January 8, 2018). It has also banned education in Bangla in the camps while the Rohingya children are not allowed to take formal education in any Bangladeshi school (Mayberry December 13, 2018; HRW 2019).

\section{Agency of Bangladesh: Soft Measures in Strengthening Border}

Besides erecting new borders or strengthening the existing ones, state actors play a significant role in producing psychological borders. The Bangladeshi state and non-state actors produce narratives that make the Rohingya refugees "outsiders" that they need to get rid of. The state actors portray the Rohingyas as "trouble-makers" or a "burden", at best, and "elements for security concerns" at the worst (Ashraf 2021; Islam 2019; Islam 2022; Uddin 2020; Yasmin \& Akhter 2020). The local community also plays its part in the same.
The initial hospitality shown to the Rohingya during the influx fades away and turns to hostility over time (Uddin 2012; Uddin 2020; Yasmin \& Akhter 2020). Sometimes the local community produces narratives and use words that demean the Rohingya community. The fact that inter-ethnic marriage is socially ostracized is a bizarre and racial form of discrimination. Before the Supreme Court decision in 2018, the inter-ethnic marriage would be highly discouraged from the local Bengali. The person who marries a Rohingya used to face discrimination in the family and ostracization in the society (Uddin 2020). The local Bengalis think marital association with a Rohingya "jeopardizes the social status, social prestige, generational continuity of a lineage, and the dignity of identity for traditional Bangladeshi" (Uddin 2012, 86; Uddin 2020, 62). Despite cultural and religious similarities, some locals consider the Rohingya as backward (Chowdhury 2019; Islam, 2019) and as people with "no culture...no social norms and values" (Uddin 2020, 66). To the locals, the Rohingya refugees have been seen as burdens and trouble makers (Rahman 2010; Yasmin \& Akhter 2019). They are blamed for all sorts of crimes and anti-social activities, though their involvement in such activities is not possible with locals' engagement. A negative perception regarding Rohingya among the locals is so strong that some even use derogatory words such as "animal" or "poisonous snake" and "terrorist" to refer to the character of the Rohingya refugees (Islam 2019).

The Rohingya refugees are dealt initially with "hospitality" but it waned over time (Uddin 2012, 2020). The religious affinity turned dim and the demarcation of difference sprouted out between the locals and the refugees. The locals categorize the Rohingya as "others" and treated them accordingly. That is how a psychological border of demarcation played out between the locals and the Rohingya refugees. Uddin (2020) writes, "in fact, mutual co-existence is also a big problem since both groups, despite religious and linguistic homogeneity, are different in their culture, mode of dealings, and philosophy of life" (76).

\section{Agency of the Rohingya in Strengthening the Borders}

The state plays a vital role in demarking the territorial border and producing an identity of the people living in the particular territory. Though the state actor has "absolute authority in determining interstate population movement on the basis of various markers that often make up their identity", foreigners or outsiders play both direct and indirect role in (re)producing the borders (Chowdhory 2018, 1). The Bangladeshi government has been taking the measures discussed in the previous section in reaction to the refugee movement. The refugee movement pushes the government to pursue several restrictive and governmentalized measures on the borders and inside the country. The Rohingya community has also permitted the "identity/difference" construction of Bangladesh by their active engagement 
in the technologies of border making/strengthening (Connolly 1991). Border and identity are two sides of the same coin (Newman \& Paasi 1998, 194). For Bourdieu, it is to create a border to establish or institute something or, in other words, give something a social definition or identity (cited in Newman \& Paasi 1998, 194). A majority of the Rohingya staying in Bangladesh prefer to call themselves Rohingya and claim their origin in the Rakhine state of Myanmar. In this process, they legitimize the identity/difference and allow bordering/ ordering. Through their perception of being "other" in Bangladesh, the Rohingya community draws a line of difference by themselves. In their daily lives, the Rohingya refugees nurture their identity and continue to transmit the identity markers to the next generation (Farzana 2016; Farzana 2017).

A vast number of Rohingya do not want to stay in Bangladesh if they are given proper rights and surety of life security and safety back in their homeland Myanmar (Sengupta 2020). Despite being officially stateless people in Myanmar, the Rohingya feel a strong belonging to the motherland of Myanmar (Sengupta 2020). They do not consider themselves as people who belongs to Bangladesh. They maintain a distance line, a space of difference. Through their claim of belonging to Myanmar and the inter-generational transition of the ethnic Rohingya identity, they enhance the (re)constructing a notion of "we" - the Rohingya - and "they"-Bangladeshi. Thus, their perception of "otherness" works as a complement to the efforts of the Bangladeshi government and the Bangladeshi people who make the distinction. Myanmar's exclusionary state-building project and denial of the existence of the Rohingya ethnicity, and Bangladesh's unwillingness to accommodate the Rohingya refugees as citizens have made the Rohingya identity strong and reasserted (Farzana 2016; Farzana 2017, Mohsin 2019).

The Weakening of the Border(s): All Actors Play Their Part

As Bangladesh's state apparatus, local people and the Rohingya, in their own ways, play their part in strengthening both the territorial and psychological borders. They also sometimes undermine the existing borders and they weaken the borders in several ways. On the part of Bangladesh, it is a section of local people to "local state" to highest political sovereign perform in weakening the border (Uddin 2019, p.880). All three groups sometimes share some common factors. The political leadership primarily considers the domestic sentiments towards the Rohingya, political cost-benefit calculation, and international factors such as the scale of pressure and promise of assistance and international image building when making decisions regarding the weakening or strengthening of borders (Ashraf 2021, Islam 2019, Islam 2022). The visit of heads of government to the Rohingya refugee camps and their urge to the locals to be sympathetic make the rigidness of the border flexible. For instance, during her visit to the refugees at Cox's Bazar in September 2017, Prime Minister Sheikh Hasina equated the persecution against the Rohingya with the oppression of the Bangladeshi in 1971. She also stated that her government is giving shelter to the Rohingya "on humanitarian grounds, as we are human beings" (The Daily Star September 13, 2017, para: 13). The political leadership presented the suffering of the Rohingya as the rationale for providing shelter. The construction of humanitarian narratives thus lessen downs the restriction at the border at a greater scale and allow the Rohingya to enter.

Along with the political leadership, the "local state" also plays a role in weakening the border. When the higher-ups order them to seal off the border, the para-military forces responsible for stopping the entry of the Rohingya sometimes allow them to enter anyway. The inhuman and miserable suffering of the Rohingya people collapses the walls of restriction inside the border forces of Bangladesh. The rigidness of law takes a flexible application when the state agents at the border are driven by emotional impulse. It has happened during all major influxes. During the initial days of the 2017 influx, a border guard is reported to say, "we have been ordered not to allow Rohingya to enter Bangladesh...But how can I deny shelter to this newborn who is dying from cold?" (France24 August 29, 2017, para: 8-9). France24 has published this comment in a report on August 29, 2017. Until then, Dhaka had not decided to allow the Rohingya to come in. The restriction on the entry of the Rohingya was there through until the end of August (The Daily Star August 29, 2017; Roy and Jinnat August 30, 2017). Some groups entered the Bangladesh border without any problems, while others were detained and pushed back (Roy and Jinnat August 31, 2017). Having been aware of the entry of nearly 20,000 Rohingya by the end of August 2017, some local government officials did not want to officially acknowledge their presence. Roy and Jinnat quoted a top official stationed at Cox's Bazar, saying, "people are coming to Bangladesh like floodwater. My estimation based on reports of different agencies is the number of newly arrived Rohingyas will be 20,000 to 25,000 . But I cannot tell the media about it revealing my identity" (August 30, 2017).

Due to the sympathetic feeling of the security forces at the borders, and despite the official stance of barring the Rohingya from entering, in 2012 several thousand Rohingya came to Bangladesh, and in 2016 less than 100,000. Navine Murshid (2018) got to know "the everyday kindness act" of the border forces while interviewing some of them in 2012 and 2015. Murshid (2018) says that the suffering of the Rohingya compels the border forces to be humane. The act of being humane makes the border forces who are deployed to hinder the attempt of the people of another country to come in allow and weaken the border. In this situation, the territorial border becomes a boundary for shelter 
to the Rohingya, not a territorial bifurcation aimed to keep out the "others".

When border security forces allow the Rohingya to enter, defying the higher-ups' order of stopping them, some other members of "local state" help the Rohingya to undermine borders that is drawn by providing legal documents such as identity card or voter registration card. Besides the members of the state apparatus, the local public representatives allegedly helped the Rohingya people intermingle with the local community and switch their identity, at least in the paper, to Bangladeshi. For their political and material benefits, they dodge the legal system and assist the Rohingya to get the necessary documents required for getting National Identity cards, which is proof of holding the citizenship of Bangladesh. Due to their religious affinity and geographical proximity, the local ordinary people were the first to extend their help to the Rohingya during the influx (Uddin 2015; Islam 2019). The sympathetic response of the locals to the Rohingya could be considered the exposure of the disavowing the attitude of seeing Rohingya as "other" but someone of "us". This "us" feeling that arises from religious affinities and geographical contiguousness, specifically, and humanitarianism, in general, subdue the distinction of citizens versus foreigners. The border of identity collapses here, even if it is for a short time.

While the above discussion highlights the active agency of the Bangladesh's state apparatus and the people of Bangladesh, particularly the locals, through it we can also draw an understanding of the agency of the Rohingya people. They actively influence the initiative and response of both the Bangladeshi people and the government. In contrast to weakening the borders, the Bangladesh government has been exercising all available technologies to stop the entry of the Rohingya. However, the continuous attempt of the Rohingya to enter Bangladesh shows the weakening of the borders. They ingeniously keep trying to enter Bangladesh through different routes if they are pushed back once. Since the second influx, several hundred thousand Rohingya have entered Bangladesh secretly. Once they successfully enter the territory of Bangladesh, they communicate with the others waiting at the other side of the borders to follow their path to come to Bangladesh. They exploit the hilly landscape and thick jungles that make the land border porous between Bangladesh and Myanmar. Once they are inside Bangladesh, many of them try to find out how to mingle with the Bangladeshi society or use Bangladeshi documents to go abroad (Uddin 2020). Uddin observes, "Many, particularly who came three decades ago, now hold Bangladeshi passports and own National Identity Card (NID) and have integrated into local society" (Uddin 2020, p.78). Many have also migrated to Gulf countries using Bangladeshi passports (Uddin 2020). Though earlier it was only at the level of claim by Bangladeshi state apparatus, it has recently come to light that some 55,000 Rohingya residing in Saudi Arabia hold Bangladeshi passports and their passports have expired. Saudi Arabia has pressured Bangladesh to issue new Bangladeshi passports to the Rohingya (Sakib, March 12, 2021).

While some disguise their Rohingya identity and take Bangladeshi identity by forging or by availing documents by illegal means, some stay away from being registered as "Myanmar nationals" in Bangladesh. When the biometric registration process started in 2018, a number of Rohingya resisted being registered. They have preferred to stay undocumented. They see registration as the first step of repatriating them without ensuring their rights and security back in the state of Rakhine in Myanmar and also as a tool to restrict their right to livelihood. Though the unregistered Rohingya people face different sorts of exploitation and discrimination, their resistance response poses a challenge to the state's performance in maintaining the borders. Since the second influx, more than 200,000 unregistered Rohingya have been living outside of the designated camps. Some of them have allegedly intruded on Bangladeshi society by disguising their own ethnic identity. A group of Rohingya who came to Bangladesh in the 1970s and 1990s have now intermingled with the Bengali society. The unofficial integration happens when the Rohingya individuals successfully make the arrangement with the local people and the authority (Cheung 2011, 53). Besides the personal arrangement, according to a report in 2000 Human Rights Watch, cultural and linguistic similarities and shared Muslim faith help the Rohingya people to integrate with the local people in a de facto manner (Cheung 2011, 53). Their conscious choice of hiding their identity helps blur the "citizen" versus "alien" identity. It is possible with the willing blindness of the local people and the authority regarding the identity disguise of the Rohingya refugees.

\section{Section IV: Conclusion}

Both physical and psychological borders are created, enacted, and maintained through boundary drawing or map-making, employing military maneuvers or the performance of the security forces at the border, documenting the people staying inside a country or coming to the country, and social practices of the people in finding similarity/difference. As much as the border is produced through paperwork (i.e. borderdrawing or map-making and documentation), it is just as much a performative act by the government officials and people. The case of the Rohingya refugee movement to Bangladesh shows that the strengthening and weakening of the border is the by-product of the refugee movement as well as it causes. Both "insiders" and "outsiders" play their role in strengthening and weakening the borders. It is thus argued that both the strengthening and weakening of the 
borders are constituted. The Bangladesh government apparatus and the common people both play their part in strengthening it as they perceive the Rohingya as "other" from them, as do the Rohingya themselves. The weakening happens when government officials and local citizens consider the Rohingya a fellow human being before a foreigner. However, by their tactful strategies of disguising identity and intruding on mainstream society, the Rohingya also weaken the borders.

However, it needs to be considered that the state apparatus has much more resources and leverage in (re)making and (re)shaping the borders-both physical and psychological. The local people of the host country sometimes work as active agents for the state in strengthening the borders but sometimes they work on weakening the borders. The ground politics and the interests of various sorts implicate the local response in relation to the (re)production of the borders. The drawing of the line of distinction or weakening the border by the outsiders is for their everyday survival and existence. For the Rohingya refugee, the identity claim as Rohingya is related to their existential question. Denying their identity as Rohingya in a foreign land would bring a catastrophic disaster to the group identity, its existence, and their demand to go back to their home country. In such a tricky situation, if some Rohingya refugees escape from the camp and manage to get Bangladeshi documents, it needs to be understood as part of their survival strategy.

\section{Note}

1 The partition of British India created two new states: India and Pakistan. Pakistan had two parts; East and West. The Eastern part is now Bangladesh and West Pakistan is present-day Pakistan

\section{Works Cited}

All hyperlinks last accessed December 2021 unless specified.

Abrar, C. R. 2014. "Government Strategy Paper on Rohingyas: Let Humanitarianism Prevail” The Daily Star (June 21). https://www. thedailystar.net/government-strategy-paper-on-rohingyas-29526

Ajana, Btihaj. 2013. Governing through Biometrics: The Biopolitics of Identity. Hampshire: Palgrave Macmillian.

Akhanda, Mahfuzur Rahman. 2018. Rohingya Somossa O Bangladesh [in Bangla]. Rajshahi: Parilekh.

Allen, John. 2011. “Topological Twists: Power's Shifting Geographies" Dialogues in Human Geography 1(3): 289-298. https://doi.org/10.1177/2043820611421546

Ashraf, A.S.M Ali. 2021. "Humanitarianism, National Security, and the Rohingya Refugee Policy of Bangladesh" Strategic Analysis 45(3): 184-206. https://doi.org/10.1080/09700161.2021.1918953

France24. 2017. "At least 6,000 Rohingya Stranded on Bangladesh Border: Official" (August 29). https://www.france24.com/ en/20170829-least-6000-rohingya-stranded-bangladesh-border-official

Bahar, Abid. 2012. "Burmese Invasion of Arakan and the Rise of Non-Bengali Settlements in Bangladesh: Origin of the Tribes of Chittaging Hill Tract (CHT)-Concluding Part" New Age, (October 23).

Banerjee, Paul. 2010. Borders, Histories, Existence: Gender and Beyond. New Delhi: Sage.

BBC. 2018. "Bangladesh Court Upholds Myanmar Rohingya Marriage Ban" (January 8). https://www.bbc.com/news/ world-asia-42612296

Bhat, Aditya. 2016. "Bangladesh to Construct Fences along India, Myanmar Borders" International Business Times (September 26). https://www.ibtimes.co.in/bangladesh-construct-fences-along-india-myanmar-borders-695355

Bjornberg, Anders. 2016. "Rohingya Territoriality in Myanmar and Bangladesh: Humanitarian Crisis and National Disordering" in Myanmar's Mountain and Maritime Borderscapes: Local Practices, Boundary-Making and Figured Worlds, edited by Su-Ann Oh. Singapore: ISEAS.

Bradnock, Robert W. 2016. The Routledge Atlas of South Asian Affairs. Oxon: Routledge.

Business Standard. 2021. "Bangladesh Ups Security along Myanmar Border to Prevent Influx of Rohingyas" (February 4). https://www.business-standard.com/article/international/ bangladesh-ups-security-along-myanmar-border-to-preventinflux-of-rohingyas-121020302114_1.html

Business Standard. 2021. "Govt to Construct Fence to Stop Infiltration along India-Bangladesh Border" (March 25). https:// www.business-standard.com/article/current-affairs/govt-toconstruct-fence-to-stop-infiltration-along-india-bangladeshborder-121032500286_1.html

Chakma, Bhumitra. 2016. "The CHT and the Peace Process" in Routledge Handbook of Contemporary Bangladesh, edited by Ali Riaz and Sajjadur Rahman. Oxon: Routledge.

Chakraborty, Ratan Lal. 1984. Bangladesh-Burma Relations [in Bangla]. Dhaka: Dhaka University Press.

Chatterjee, Partha. 2013. The Politics of the Governed: Reflections on Popular Politics in Most of the World. Delhi: Permanent Black.

Chowdhory, Nasreen. 2018. Refugees, Citizenship and Belonging in South Asia: Contested Terrains. Singapore: Springer.

Chowdhury, Kamran Reza. 2013. "Dhaka to Build Fence along Myanmar Border" Dhaka Tribune (June 11). https://www. dhakatribune.com/uncategorized/2013/06/11/dhaka-tobuild-fence-along-myanmar-border

Connolly, William E. 1991. Identity/Difference: Democratic Negotiations of Political Paradox. Expanded edition. Minneapolis: University of Minnesota Press.

Dhaka Tribune. 2019. "Over 100 Rohingyas Held across Country in Four Months" (April 28). https://www. dhakatribune.com/bangladesh/rohingya-crisis/2019/04/28/ over-100-rohingyas-held-across-country-in-four-months

Farzana, Kazi Fahmida. 2016. "Life along the Naf Border: Identity Politics of the Rohingya Refugees in Bangladesh" in Myanmar's Mountain and Martime Borderscapes: Local Practices, Boundary-Making and Figured Worlds, edited by Su-Ann Oh. Singapore: ISEAS.

Farzana, Kazi Fahmida. 2017. Memories of Burmese Rohingya Refugees: Contested Identity and Belonging. Singapore: Palgrave Macmillan. 
Borders in Globalization Review | Volume 3 | Issue 1 | Fall/Winter 2021 Islam, "Rohingya Refugee Movement in Bangladesh: Insiders and Outsiders..."

Ferdous, Azmeary. 2017. "Seeing Borders through the Lens of Structuration: A Theoretical Framework" Geopolitics 23(1): 180-200. https://doi.org/10.1080/14650045.2017.1341406

France24. 2017. "At least 6,000 Rohingya Stranded on Bangladesh Border: Official” (August 29). https://www.france24.com/ en/20170829-least-6000-rohingya-stranded-bangladesh-border-official

Government of India-GOI. 2021. "Rajya Sabha: Unstarred Question No.2437" (March 17). https://www.mha.gov.in/MHA1/Par2017/ pdfs/par2021-pdfs/rs-17032021/2437.pdf

Hansson, Stina and Hellberg, Sofie. 2015. "Power, Freedom and the Agency of Being Governed" in Studying the Agency of Being Governed edited by Stina Hansson, Sofie Hellberg and Maria Stern. Oxon: Routledge.

Human Rights Watch (HRW) . 2019. "Bangladesh: Rohingya Refugee Students Expelled" https://www.hrw.org/news/ 2019/04/02/bangladesh-rohingya-refugee-students-expelled

Islam, Sariful. 2019. "Hosting Rohingya Refugees: Explaining the Factors Influencing Bangaldesh's 'Humanitarian' Response" Master of Philosophy Dissertation, South Asian University.

Islam, Sariful. 2022. "Regime's Interests in Hosting Refugees: Bangladesh's Response to the Rohingya" in Rohingya Refugee Crisis in Myanmar: Ethnic Conflict and Resolution, edited by Kudret Bulbul, Md Nazmul Islam and Md Sajid Khan. Singapore: Palgrave Macmillan.

Jilani, AFK. 1999. The Rohingyas of Arakan: Their Quest for Justice. Ahmed Jilani.

Johnson, Corey and Jones, Reece. 2011. "Rethinking "the border" in border studies" in Interventions on Rethinking 'the Border' in Border Studies, edited by Johnson et al. Political Geography 30(2): 61-69.

Jones, Reece. 2016. Violent Borders: Refugees and the Right to Move. London: Verso.

Lewa, Chris. 2010. "Unregistered Rohingya refugees in Bangladesh: Crackdown, forced displacement and hunger" The Arakan Project. http://www.burmalibrary.org/docs08/ Bangladesh-Crackdown.pdf

Majumder, Shantanu. 2016. "Secularism and anti-Secularism" in Routledge Handbook of Contemporary Bangladesh, edited by Ali Riaz and Sajjadur Rahman. Oxon: Routledge.

Mayberry, K. 2018. "Rohingya Facing ‘Lost Generation' of Children Out of School" Al Jazeera (December 13). https://www. aljazeera.com/news/2018/12/rohingya-facing-lost-generation-children-school-181212082048462.html

Mohsin, Amena. 1997. The Politics of Nationalism: The Case of the Chittagong Hill Tracts, Bangladesh. Dhaka: The University Press Limited.

Murshid, Navine. 2018. "Bangladesh copes with the Rohingya crisis by itself" Current History 117(798): 129-134.

Newman, David and Paasi, Anssi. 1998. "Fences and Neighbours in the Postmodern World: Boundary Narratives in Political Geography." Progress in Human Geography 22(2): 186-207.

New Age. 2019. "Rohingas Rally for Rights at Home" (August 25). http://www.newagebd.net/article/82511/ rohingyas-rally-for-rights-at-home

New Age. 2019. "Bangladesh to Snap Telecom Connections of Rohingyas" (September 3). http://www. newagebd.net/article/83348/bangladesh-to-snaptelecom-connections-of-rohingyas

New Age. 2019. "Fences to be Erected around Rohingya Camps:
HM" (September 26). http://www.newagebd.net/article/85763/ fences-to-be-erected-around-rohingya-camps-hm

Oh, Su-Ann. 2017. "Surveillance and Control: The Encampment and Biometric Identification of Rohingya Refugees in Bangladesh" Perspective 93: 1-7. https://www.iseas.edu.sg/wp-content/ uploads/pdfs/ISEAS_Perspective_2017_93.pdf

Paasi, Anssi. 2009. "Bounded $S$ Bounded spaces in a 'borderless world': border studies, power and the anatomy of territory" Journal of Power 2(2): 213-234. https://doi. org/10.1080/17540290903064275

Pandey, Ashutosh. 2017. “Myanmar's Rohingya: A History of Forced Exodues" DW-Deutsche Welle. https://www.dw.com/en/myanmars-rohingya-a-history-of-forced-exoduses/a-40427304

Pfoser, Alena. 2020. "Memory and everyday borderwork: Understanding Border Temporalities" Geopolitics https://doi. org/10.1080/14650045.2020.1801647

RohingyaBlogger. n.d. "Strategy Paper on Addressing the Issue of Myanmar Refugees and Undocumented Myanmar Nationals in Bangladesh". https://pdfcoffee.com/strategy-paper-on-addressing-the-issue-of-myanmar-refugees-and-undocumented-myanmar-nationals-in-bangladesh--pdf-free. html\#rohingyablogger

Roy, Pinaki, and Jinnat, Mohammad Ali. 2017. "Stranded in No Man’s Land: Several Thousand Rohingyas from Myanmar Build Makeshift Shelters There" The Daily Star (August 30). https://www. thedailystar.net/frontpage/stranded-no-mans-land-1456003

Roy, Pinaki, and Mohammad Ali Jinnat. 2017. "They Come in Thousands" The Daily Star (August 31). https://www. thedailystar.net/frontpage/rohingya-refugee-crisis-theycome-thousands-1456507

Rahman, Utpala. 2010. "The Rohingya Refugee: A Security Dilemma for Bangladesh" Journal of Immigrant \& Refugee Studies 8(2): 233-239. https://doi.org/10.1080/15562941003792135

Rumford, Chris. 2006. "Theorizing Borders" European Journal of Social Theory. 9(2): 155-169. DOI: 10.1177/1368431006063330

Rumford, Chris. 2008. "Introduction: Citizens and Borderwork in Europe" Space and Polity 12(1): 1-12. https://doi. org/10.1080/13562570801969333

Sakib, SM Najmus. 2021. "Saudi Arabia Won't Send Rohingya Back to Bangladesh" Anadolu Agency (AA) (March 12). https://www. aa.com.tr/en/middle-east/-saudi-arabia-wont-send-rohingyaback-to-bangladesh/2173654

Salter, Mark. 2011. "Places Everyone! Studying the Performativity of the Border" in Interventions on Rethinking 'the Border' in Border Studies, edited by Corey Johnson, Reece Jones, Anssi Paasi, Louise Amoore, et al. Political Geography 30(2): 61-69.

Scott, James C. 1985. Weapons of the Weak: Everyday Forms of Peasant Resistance. New Haven: Yale University Press.

Scott, James C. 2009. The Art of Not Being Governed: An Anarchist History of Upland Southeast Asia. New Haven: Yale University Press.

Sendhardt, Bastian. 2014. "Border Types and Bordering Processes: A Theoretical Approach to the EU/Polish-Ukrainian Border as a Multi-dimensional Phenomenon" in Borders and Border Regions in Europe: Changes, Challenges and Chances, edited by Arnaud Lechevalier and Jan Wielgohs. Bielefeld: transcript Verlag.

Sengupta, Sucharita. 2020. "Being Stateless and Surviving: The Rohingyas in Camps of Bangladesh" in Citizenship, Nationalism and Refugeehood of Rohingyas in Southern Asia, edited by Nasreen Chowdhory and Biswajit Mohanty. Singapore: Springer. 
Borders in Globalization Review | Volume 3 | Issue 1 | Fall/Winter 2021

Islam, "Rohingya Refugee Movement in Bangladesh: Insiders and Outsiders..."

Stern, Maria., Hellberg, Sofie and Hansson Stina. 2015. "Studying the Agency of Being Governed: An Introduction" in Studying the Agency of Being Governed, edited by Stina Hansson, Sofie Hellberg and Maria Stern. Oxon: Routledge.

The Bangladesh Observer. 1978. "Border Pact with Burma Reached" (August 2).

The Daily Star. 2017. "Provide Shelter, Security to Rohingyas: Khaleda Urges Govt"(August 29). https://www.thedailystar.net/ city/provide-shelter-security-rohingyas-1455655

The Daily Star. 2017. "Take Back All Rohingyas" (September 13). https://www.thedailystar.net/frontpage/ mayanmar-rohingya-refugee-crisis-solution-safe-zone-1460827

The Economic Times. 2018. "Bangladesh to Erect Barbed Wire Fence on Border with India" (July 12). https://economictimes. indiatimes.com/news/defence/bangladesh-to-erect-barbedwire-fence-on-border-with-india/articleshow/54508281. cms?from $=m d r$

Thomson, Susan. 2013. "Agency as Silence and Muted Voice: The Problem-solving Networks of Unaccompanied Young Somali Refugee Women in Eastleigh, Nairobi" Conflict, Security \& Development 13(5): 589-609. https://doi.org/10.1080/1467880 2.2013 .849473

Tripathi, Dhananjay and Chaturvedi, Sanjay. 2020. "South Asia: Boundaries, Borders and Beyond" Journal of Borderlands Studies 35(2): 173-181. https://doi.org/10.1080/08865655.2019.1 669483

Xinhua. 2019. "Myanmar-Bangladesh border fence construction work attacked by ethnic armed group" (March 10). http://www. xinhuanet.com/english/2019-03/10/c_137883675.htm
Uddin, Nasir. 2012. "Of Hosting and Hurting: Crises in Co-existence with Rohingya Refugees in Bangladesh" in To Host or To Hurt: Counter-narratives on Rohingya Refugees Issue in Bangladesh, edited by Nasir Uddin. Dhaka: Institute of Culture \& Development Research

Uddin, Nasir. 2015. "State of Stateless People: The Plight of Rohingya Refugees in Bangladesh" in Slippery Citizenship, edited by Rhoda E. Howard-Hassmann and Margaret WaltonRoberts. Philadelphia: University of Pennsylvania Press.

Uddin, Nasir. 2019. "The State, Vulnerability, and Transborder Movements: The Rohingya People in Myanmar and Bangladesh" in Deterritorialised Identity and Transborder Movement in South Asia, edited by Nasir Uddin and Nasreen Chowdhory. Singapore: Springer.

Uddin, Nasir. 2020. The Rohingya: An Ethnography of 'Subhuman' Life. First edition. New Delhi: Oxford University Press.

Uddin, M Jashim. 2014. "Prospects for Attaining a New Height in Bangladesh-Myanmar Relations: Bangladesh Perspective" BIISS Journal 35(11): 1-22.

UN News. 2019. "More than Half a Million Rohingya in Bangladesh Get ID Cards for First Time: UN Refugee Agency" (August 9). https://news.un.org/en/story/2019/08/1044041

Vaughan-Williams, Nick. 2009. Border Politics: The Limits of Sovereign Power. Edinburgh: Edinburgh University Press.

Yasmin, Lailufar and Akther, Sayeda. 2020. "The Locals and the Rohingyas: Trapped with an Uncertain Future" Asian Journal of Comparative Politics 5(2): 104-120. 


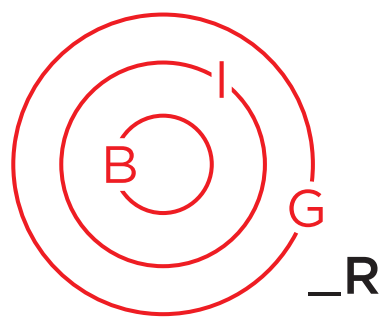

ARTICLE SPECIAL SECTION

\title{
Human Folly and Border Fences: Looking to Non-Human Actors at the Indo-Bangladesh Border
}

\author{
Uddipta Ranjan Boruah *
}

The obsession with inter-state territorial borders and the associated paraphernalia of border management and security makes borders and their management a primarily human-centric discourse. This paper makes an attempt at introducing the agency of rivers as non-human actors-or rather as actants-in shaping and managing international borders. The paper looks specifically at the riverine sector of the Indo-Bangladesh border, where the international boundary has been re-negotiated each year by the transnational rivers, primarily the Brahmaputra (also the Gangadhar), through flooding, erosion, and deposition of sediment. By interrogating the role of rivers in shaping the border and border management strategies, the paper argues that humans, despite persisting as the primary agents in border management, are not the only actors. Drawing on Actor Network Theory (ANT), a case is made to appreciate the general symmetry between humans and non-humans as a-priori equal. Incorporating both in an actor-network may provide insights into border management in complex borderlands.

"The waters flowing under Nihombashi in Edo and the waters in the rivers in China, and Holland are one stream without any barrier" - Japanese Scholar Hayashi Shihei (cited in Smith: 2017, 99)

\section{Introduction}

The study of inter-state borders have mostly been obsessed and confined to the territorial demarcation of the limits of respective sovereign units. Two of the most common concerns associated with inter-state borders have been of border management and security. The continuous attempts at walling and fencing borders have thus, in some way or other remained constants in border discourses. In all of this, the role and agency of the human actor seems to be predominant. The task of defining and delimiting of borders and the designing and implementing of the paraphernalia associated with border management is mostly human centric-either planned and implemented by humans or aimed at checking human movement.

The first section of the paper thus shows the dominance of territorial inter-state borders as the most convincing understanding concerning borders. Coupled with this dominance, the associated paraphernalia of border management through walling or fencing therefore primarily perpetuates a human-centric discourse. The paper then picks up the case of

\footnotetext{
* Uddipta Ranjan Boruah, PhD Candidate, Department of International Relations, South Asian University, New Delhi, India. Twitter: @RanjanUddipta
} 
the India-Bangladesh border fencing project to show how natural phenomena such as flooding and erosion caused by the Brahmaputra fails this human-centred narrative of border walling or management. As an alternative to the human-centric discourse on borders, the next part of the paper analyses the possibility of incorporating the river as a non-human actant in border management. This part draws briefly from Actor Network Theory (ANT) in proposing the possibility of incorporating the non-human into the discourse on border management for a more nuanced understanding of borders.

\section{The Dominance of Inter-State Territorial Borders}

The relevance of territorial borders has been much emphasised in the discourse on international boundaries. This accrues to a great extent to the dominance of the political geographers in the study of borders. The systematic study of borders begun initially as an engagement for the political geographers and focused largely on "descriptive analyses of boundaries, their location and the political and historical processes leading to their demarcation" (Newman 2006a, 145).

Being the fundamental subject matter for the political geographers, borders have traditionally been understood, for examples, "as constituting the physical and highly visible lines of separation between political, social and economic spaces" (Newman 2006a, 144); "Political geographers and political scientists have for a long time perceived boundaries as fixed, stable empirical entities which divide the global space into bounded units that change mainly as a consequence of conflicts" (Paasi 1998, 69); "Very often different from the usual general perception, in the conventional academic phraseology borders are conceptualised as dividing lines between two states" (Tripathi 2015, 1); and "In the traditional sense, borders are considered as a line separating two sovereign territories" (Bhardwaj 2016, 111).

The international system is replete with hard territorial lines and "the current world harbours some 200 states and more than 300 land borders between them, and in addition there are scores of sea boundaries" (Paasi $2011,13)$. With the signing of the Treaty of Westphalia, "the field of politics was formally differentiated into distinct domestic and international spheres, based on internal political hierarchy and external geopolitical anarchy" (Teschke 2009, 3). With the associated model of territorial statehood that came along with the preservation of the Westphalian system, and translating from which, borders came to be seen as sharp dividing lines "between one state unit and its neighbours" has, in a way, become the only model of best territorial practice (Agnew 2007, 398). Others add, "In today's international system, all political units are sovereign territorial states, defined by linear boundaries and with theoretically exclusive claims to authority within those lines" (Branch 2014, 2), and "Since the late 19th century, it has been assumed that regardless of place or context, territories must have linear borders, ideally consisting of precise one-dimensional points on the earth's surface, connected by straight lines" (Goettlich 2018, 2). Therefore, despite considerable expansion in the study of borders in the past decades, territorial borders are still the most prevelent notion of political border (Newman \& Paasi 1998; Newman 2003; Newman 2006a; Newman 2006b; Vallet \& David 2012; Tripathi 2015).

\section{The Predominantly ‘Human' Endeavour of Walling and Excluding}

In addition to the prevailing salience of territorial inter-state borders, a renewed attention towards securitising and restricting them has been yet another considerable phenomenon in the post-9/11 era. In the aftermath of 9/11 terrorist attacks in the United States, the study of borders seem to have attained a "paradigm change" (Newman 2003, 149). Attention was refocused on "the process through which borders can be more rigidly controlled, closing rather than opening, in some cases almost being sealed" (Newman 2003, 149). According to Jones, "The framing of the war on terror as a global and interconnected problem has allowed sovereign states to consolidate power and move substantially closer to the territorial ideal of a closed and bounded container of an orderly population by attempting to lock down political borders" (2009: 1).

One essential tool for border management therefore has been the border wall. On defining a "wall", Vallet and David $(2012,112)$ draw from Sivan (2006) to state that, "depending on the speaker's political stance, ideology and universe of discourse, walled borders are variously referred to as security, separation, apartheid or anti-terror walls, obstacles, partitions, fences, barriers, barricades or borders". The term wall is used by them "to describe border barriers with fixed masonry foundations" (112) and "As of 2010, there were nearly 45 border walls (soon to be 48) totalling more than 29,000 km" (112). Academic works such as those of Andreas and Bierstaker (2003), Goldfarb and Robinson (2003), Hataley and Leuprecht (2018), Nevins (2002), Newman (2003), Payan (2010), Zaiotti (2011), duly highlights the survival and proliferation of border walls.

The phenomenon of walling out neighbours is however not a new strategy for sovereigns. Ranging from the Great Wall of China, Hadrian's Wall and the Antonine Wall in Scotland by the Romans, to its more recent manifestations, one significant element of the very 
bordered international system has been the border wall (Vallet \& David 2012). Building of walls was underway even as the world celebrated the crumbling of the Cold War iron curtain and apartheid in South Africa (Brown 2010, 8). With its decreasing and increasing prominence from time to time across events such as the Cold War, fall of the Berlin Wall, emergence of globalisation, terror attacks of 9/11, the border wall has maintained its existence in the international system. South Asia too is not an exception. India of course is known for its cruder attempts to "wall out Pakistan and Bangladesh" and "wall in disputed Kashmir territory" with objectives such as to "deter refugees from its poorer neighbour, to stake its side in a land dispute and suppress the movement of Islamic guerrillas and weapons" (Brown 2010, 8).

The idea of border walls, their securitisation and control of movement across them mostly revolves around the human agent. That is to say that the walls are for humans (in the understanding of the 'self') and endeavour to primarily keep the human (that is perceived as the 'other') out or to filter the movement of humans. Borders as we know them are either "human creations" Brunet-Jailly (2005), "process of social traditions" Brunet-Jailly (2011), or "artifacts of dominant discursive processes" John Agnew (2008). It appears to be clear that contemporary international borders are primarily endeavours of human agency. The inter-state borders are mostly drawn and redrawn at the political centres away from the borderlands by human hands that are often bereft of realities on the ground. They therefore at times pass through unscalable mountain ranges, meandering rivers, and social lives of borderlands people.

It is interesting to note that bordering is a fight of humans against primarily humans. That is to say that they are attempts by human to keep out or scrutinise and filter primarily humans that are considered as the 'other' (refugees, migrants, aliens, terrorists, etc.) and to secure the 'inside' from the 'outside'. The major function of a border then is "to act as a barrier, protecting the us insiders from the them outsiders" (Newman 2003, 14; see also Oomen 1995; Sibley 1995). The argument is even more convincing in the contemporary era of walled inter-state borders.

To further support this claim, a brief mention of some well known border walling projects can be cited.

- US-Mexico Border: The Executive Order 13767, also known as the Executive Order: Border Security and Immigration Enforcement Improvements, of the US President Donald Trump issued on January 25, 2017, aims to "secure the southern border of the United States through the immediate construction of a physical wall on the southern border" (US Executive Order 13767, 2017: Section 2). The wall is inter alia meant to keep out "aliens who illegally enter the United States" (Section 1). The order further claims that "continued illegal immigration presents a clear and present danger to the interests of the United States" (Section 1). Section 5 of the Order therefore proposes for the construction of detention facilities "to detain aliens at or near the land border with Mexico" (Section 5).

- India Bangladesh Border Fence: The Assam Accord explicitly mentions the rationale of the fence to be to prevent "future infiltration" and "prevent infiltrators crossing or attempting to cross it" (Assam Accord 1985).

- Botswana Zimbabwe Fence:In 2003, the government of Botswana proposed the erecting of a fence along its border with Zimbabwe. Although the Botswana government calls it an attempt to keep out foot and mouth disease among livestock, the Zimbabwean side claims that it is devised to keep out "humans from Zimbabwe” (Brown 2010; Piven 2015).

- Various other human attempts to wall out other humans include Uzbekistan fencing out Kyrgyzstan to prevent "Islamic terrorists", Brunei walling out "immigrants and smugglers coming from Limbang", China walling out the "tide of Korean refugees" etc. (Brown 2010).

It gives us ground to claim therefore that border walls inter alia revolve around the human agent to the extent that on the one hand they are aimed at keeping out "aliens", refugees", "terrorists", and "smugglers", and on the other hand they are devised and erected by the human itself. The walling or fencing project of the human agent, however, this paper argues, has failed on many occasions. One instance is the fencing project along the India-Bangladesh border, specifically the riverine stretch of the border in Assam, India. The perennial flooding and erosion of some of the border areas has been undermining the human centric approach to physically fencing the border, as the border fence is washed away every time including considerable amount of territory. The proposal to fence the border was accepted by the Government of India in 1985 and despite repeated attempts all these years to physically fence the border, the project is still incomplete.

\section{River, Flood, Erosion and the Mockery of Human Endeavour}

Three major challenges that the border fencing project along the particular section of the border in Assam faces are the changing course of rivers (mainly the Brahmaputra, but also the Gangadhar), perennial flooding and washing away of border posts and fence, 


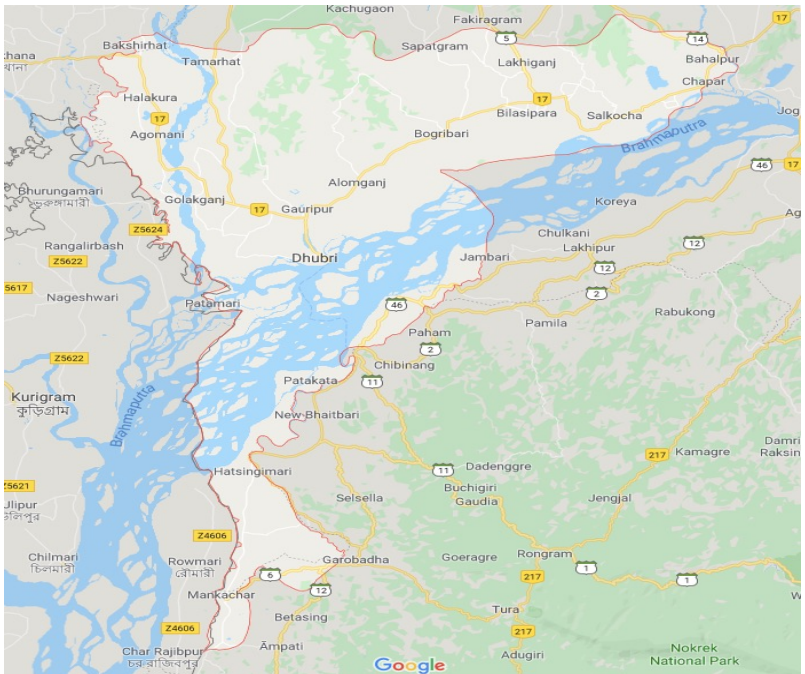

Figure 1. Map. Source: Google Maps.

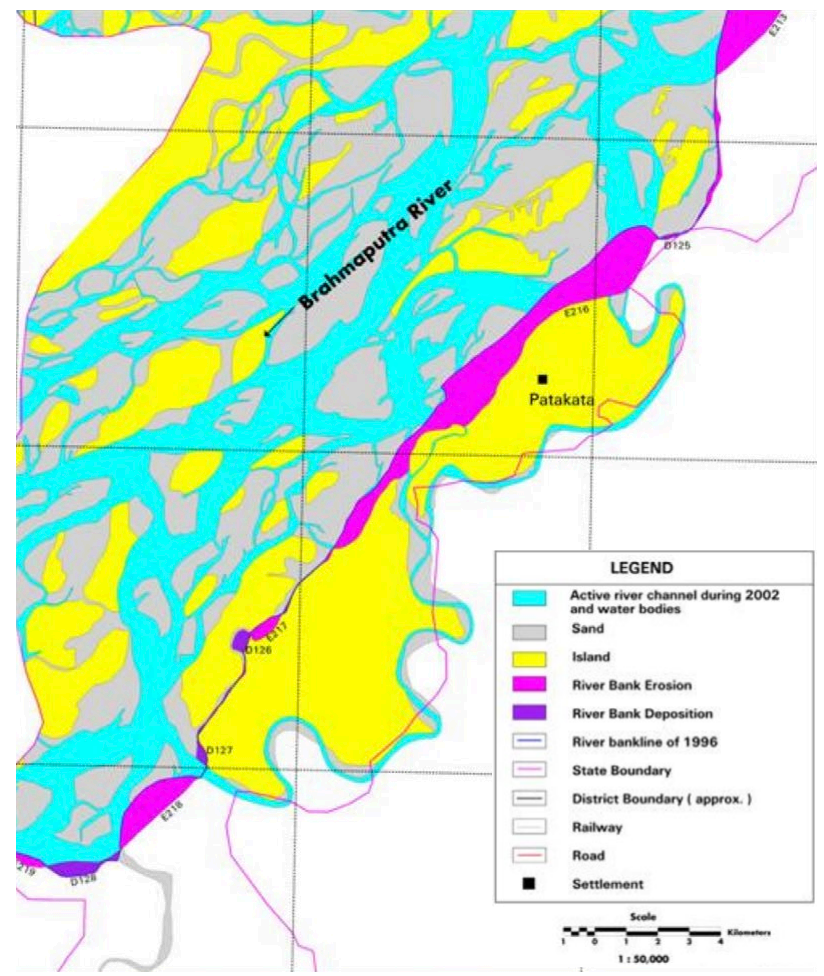

Figure 2. Bank Erorsion of Brahmaputra and Barak Rivers Assam using Satellite Remote Sensing. Source: Central Water Commission, Plate 34 (map placement slightly modified). http://old.cwc.gov.in/main/downloads/ brahmputra.pdf

Figure 3. Publicly available images of river damage to border fence. Source (right top): https://www. telegraphindia.com/states/north-east/border-fenceswashed-away/cid/322247 (right bottom): https://www. indiatoday.in/india/photo/assam-floods-pose-threat-tonational-security-367848-2012-07-03/4 erosion and alteration of borderland territory. This accrues to some of the characteristic features of the major river of the region, Brahmaputra itself. Some of them deserve brief mention here because the crisis that the paper talks about is dependent on them. First, the Brahmaputra is the second-highest sediment-carrying river in the world (Goswami 1985). Flowing through steep slopes of hills upstream and accompanied by high intensity of rainfall and seismicity of the area, the river brings down huge loads of sediment (Mahanta \& Saikia 2015). Due to the sudden fall in the slope as it approaches the lower catchment areas in Assam the river then deposits a great amount of the silt across the flood plains of Assam. This, in a way makes flooding a perennial phenomenon in the region. Second, and related to the first to some extent, the river is "prone to wide-scale channel migration and is a classic example of a braided river" (Mahanta \& Saikia 2015, 155). As a result, it can be seen in the map (Figure 1) that the river multiplies into several smaller streams before it leaves the Indian border. Third, and in addition to the above two, "in no other river is the bank erosion hazard as critical as in the Brahmaputra valley" (Mahanta \& Saikia 2015, 155).

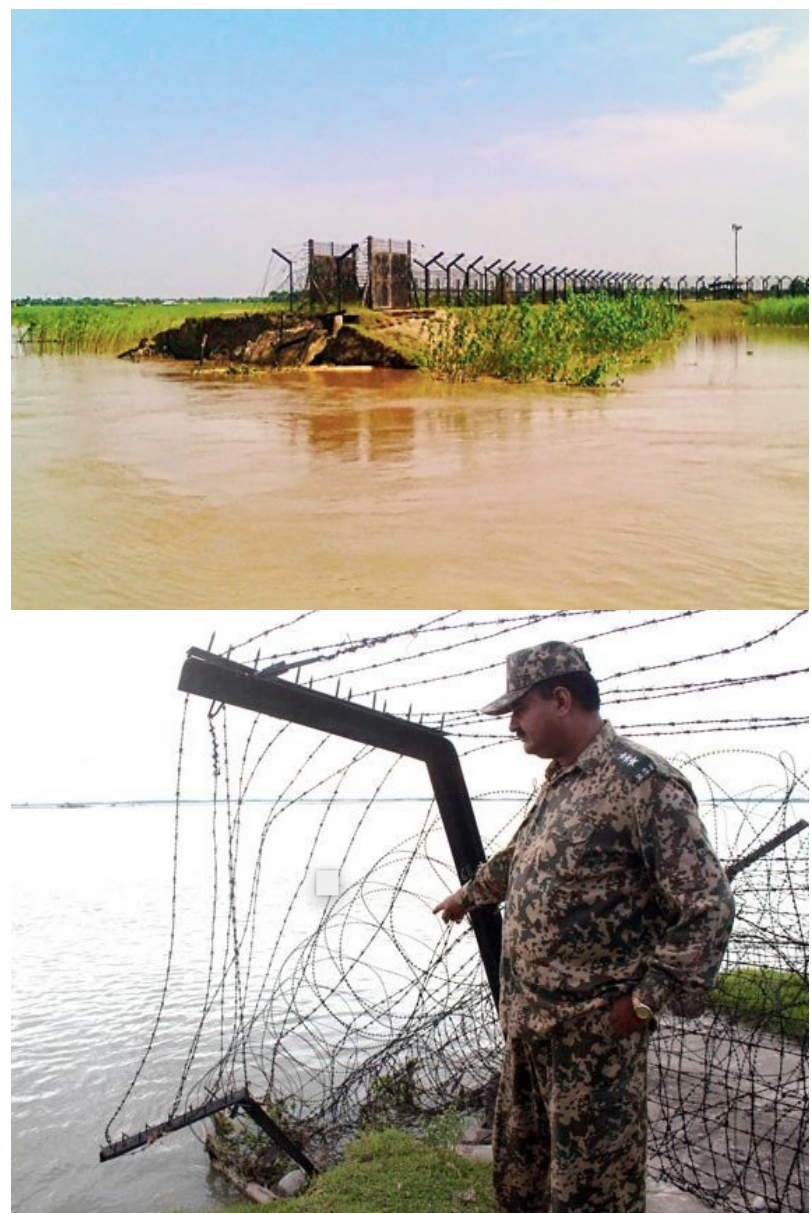


An extract of the erosion data of the Brahmaputra worked out by the Central Water Commission (Figure 2) gives a better classification of the border area into the sand, island, active river channel, and bank erosion.

A brief glance at the map is sufficient enough to highlight the complexity of fencing the international border here. The braided tracts of the river that range sometimes around four to five kilometres, and sometimes smaller, overlap during the monsoon. They deposit sediment as sand and islands in the dry season. Annual flooding by the river inundates segments of the international border including the border fence and BSF border posts (Dutta Choudhury 2013). In addition to inundation for weeks at length, several meters of the border fence are washed away by immense current of the flooding river (Sharma 2014; Karmakar 2019; Mondal 2019).

Images of the border fence (Figure 3) further illustrate the claims.

The same is true in case of the Karimganj sector of the international border in Assam wherein the Kushiyara, a distributary of the Barak river gets into the shoes of the Brahmaputra. The barbed wire fence in Karimganj too are washed away by the perennial flooding and river bank erosion caused by the Kushiyara (Times of India 2011). Also same is the case in Tripura accruing to Muhuri river.

To further concretise the point, a brief list of news items are presented below to give a sense of the scenario of the borderland.

- Time8 News: "The devastating floods caused by incessant rain over the past few days has washed away a vast stretch of a road along with a portion of the barbed wire fencing along the porous Indo-Bangla International Border (IB) at the Asmer-Alga area in South-Salmara Mankachar district of Assam... Around 15 meters of the road along with the fence near 1051-6S border post was washed away by flood waters on July 15th, 2019" (Mondal 2019).

- The Deccan Herald: "About 170 metre of the border fence at Asmer Alga under the Sisumara border outpost in Mankachar, Assam was washed away in July 2019 by the strong currents of the surging Brahmaputra" (Karmakar 2019).

- The Telegraph: "In Golokganj border sector, 222 metres of barbed wire fencing has been totally washed away owing to erosion by the Gangadhar river and still poses a threat to the rest of the fencing along the border" (Sharma 2014).
- The Times of India: "The erosion caused by the Kushiara river is posing a serious threat to the IndoBangladesh border fencing that has been constructed along the bank of the river in Karimganj district... In the border village of Jabainpur, the swelling river has destroyed 300 metre of barbed fencing in the past week. The erosion may also destroy the Jabainpur BOP of the BSF, a source said" (Times of India 2012).

- The Assam Tribune: "The erosion of river banks along the border has led to the collapse of the barbed wire fence, and damaged roads and border lines in many areas... Seasonal floods and heavy rains have made the border fence collapse... The collapse of border fencing and roads has allowed perpetrators to have a free run of unlawful activities" (Assam Tribune 2012).

\section{Agency of the Non-human: River as Actant}

It is now fairly apparent that the taken-for-granted status of the human actor in matters of border management is incomplete in understanding complex borders. Actor Network Theory (ANT) (Callon 1986, 1991; Latour 1987, 1992, 1993) however, enriches understandings of inter-state border management. The major takeaway from the ANT is its focus on alternatives to the "anthropocentrism and sociocentrism" of social sciences (Latour 1997) and the manner in which it looks at the minor distinction between actors and actants.

An actor in ANT is a semiotic definition-an actant-that is, something that acts or to which activity is granted by others. It implies no special motivation of human individual actors nor of humans in general. An actant can literally be anything provided it is granted to be the source of an action (Latour 1997).

Without engaging comprehensively in the specificities of ANT, this paper briefly draws from the following essential ideas of the ANT. The following concepts as compiled by Jackson (2015) which also borrows from Walsham (1997) are important for this paper:

- "An actor/actant ... any material, i.e. human beings or nonhuman actors / actants;

- Actor-network ... Related actors in a heterogeneous network of aligned interests;

- General symmetry ... The symmetrical treatment of humans and nonhumans as a priori equal;

- "The idea that neither a human nor a nonhuman is pure, that is, either human hybridity or nonhuman in an absolute sense but rather entities produced in associations between the former and the latter" (Jackson 2015, 30). 
Additionally, one of the distinguishing contributions of the ANT is:

its attribution of agency to nonhumans, including animals, materials, ideas, and concepts, acknowledging the ability of any entity (or actant) to make itself indispensable to its relationships with others and, by extension, to the continuation of the network" (Dwiartama \& Rosin 2014, 1).

Drawing from ANT, and keeping in mind the prominent role that the rivers have played in the India-Bangladesh borderlands it can therefore be argued that it is necessary to consider general symmetry between the human and the river as a priori equals in negotiating borders. The elevation of the river as an actant within the actor-network of border management makes it possible to engage with the various techniques of border management that have been made essential as a result. Allowing sufficient agency to the river makes the alternative approaches to border management along the India-Bangladesh border more relevant.

\section{River and Border Management: Alternatives}

As it appears, the idea of erecting a physical fence along the entire length of the India-Bangladesh border has not been a very successful project. The negotiating role that the river plays in the borderland has made essential various alternative approaches to border management. "Non-feasibility" along a considerable segment has been explicitly accepted by the Home Ministry. While duly accepting that "at various places, it is not possible to erect Border Fence due to the geographical barriers" the Ministry of Home Affairs eventually implemented some of the non-physical bordering techniques. BOLD-QIT (Border Electronically Dominated QRT Interception Technique) under CIBMS (Comprehensive Integrated Border Management system) on India-Bangladesh border in Dhubri District of Assam was inaugurated on March 5, 2019 by Union Home Minister, Rajnath Singh (PIB, 2019). There has also been huge expenditures on alternatives such as hovercraft and floating platforms for riverine borders.

The fact that despite the immense might of a state like India the physical fence cannot in any ways be sustained in certain segments of the border provides us with an entry point to consider the role of elements beyond the human agent in negotiating international borders. There may be a need for considering the rivers as not merely passive but an agent in a network of agents negotiating the India-Bangladesh border. This requires a shift from "self-assertive behaviour" of the human towards a more "integrative" approach (Capra 1996, 10). There is a need to realize that the human although being a primary actor in negotiating inter-state borders, is not the only actor. It calls for the realisation that elements beyond the human are not just part of our "global life support system but also that humanity need not be the mind of the planet" (Smith 2017, 109). The human should see itself as "pirmus inter pares" (first among equals) rather than as guiding intelligence" (Smith 2017, 109). If after witnessing such impact made by the rivers on the international border resulting in greater political ramifications, we still fail to accommodate the influence of agents beyond the human, political solutions are doomed to fail due to an "ignorance of variables" (Bryant 2011).

\section{Works Cited}

All hyperlinks last accessed December 2021 unless specified.

Agnew, J. 2007. "No Borders No Nations: Making Greece in Macedonia" Annals of the Association of American Geographers 97(2 June): 398-422. https://doi. org/10.1111/j.1467-8306.2007.00545.x

Agnew, J. 2008. "Borders on the Mind: Re-framing Border Thinking" Ethics \& Global Politics 1(4): 175-91. https://doi. org/10.3402/egp.v1i4.1892

Andreas, P. and Bierstaker, T. (eds.) 2003. The Re-bordering of North America: Integration and Exclusion in a New Security Context. New York: Routledge.

Assam Tribune. 2012. "River erosion upsets BSF at Indo-Bangla border" Assam Tribune (May 8). http://www. assamtribune.com/scripts/detailsnew.asp?id=may0812/ at0151 [Accessed on 10/11/2019].

Bhardwaj, Sanjay K. 2016. "India-Bangladesh Border Governance: Issues and Challenges" International Studies 50(1\&2): 109-129. https://doi.org/10.1177/0020881716654387

Branch, Jordan. 2014. The Cartographic State: Maps, Territory and the Origins of Sovereignty. Cambridge: Cambridge University Press.

Brown, Wendy. 2010. Walled States, Waning Sovereignty. Brooklyn, New York: Zone Books.

Browning, C.S.andP.Joenniemi.2004."Contending discourses of marginality: The case of Kaliningrad" Geopolitics 9(3): 699-730. https://doi.org/10.1080/14650040490478747

Brunet-Jailly, E. 2005. "Theorising Borders: An Interdisciplinary Perspective" Geopolitics 10(4): 633-649. https://doi.org/10.1080/14650040500318449

Brunet-Jailly, Emmanuel. 2011. "Special Section: Borders, Borderlands and Theory: An Introduction" Geopolitics 16(1): 1-6. https://doi.org/10.1080/14650045.2010.493765

Bryant, L.R. 2011. The Democracy of Object. Ann Arbor, Michigan: Open Humanities Press, University of Michigan Library.

Callon, Michael. 1986. "Some Elements of a Sociology of Translation: Domestication of the Scallops and the Fishermen of St Brieuc Bay" The Sociological Review 32(1). https://doi.org/10.1111/j.1467-954X.1984.tb00113.x

Callon, Michael. 1991. "Techno-Economic Networks and Irreversibility" in A Sociology of Monsters: Essays on Power, Technology and Domination, edited by J. Law, 132-161. London: Routledge. 
Capra, Fritjof. 1996. The Web of Life: A New Scientific Understanding of Living System. Michigan: Anchor Books.

Dutta Choudhury, R. 2013. Porous Border. Guwahati: Bhabani Books.

Dwiartama, A., and C. Rosin. 2014. "Exploring Agency Beyond Humans: The Compatibility of Actor-Network Theory (ANT) and Resilience Thinking" Ecology and Society 19(3): 28. http://dx.doi.org/10.5751/ES-06805-190328

Goettlich, Kerry. 2018. "The Rise of Linear Borders in World Politics', European Journal of International Relations 1(26): 1-26. https://doi.org/10.1177/1354066118760991

Goldfarb, D., and W. Robinson. 2003. "Risky Business: U.S. Border Security and the Threat to Canadian Exports" C.D. Howe Institute Commentary 177. https://www.cohowe.org/ public-policy-research/risky-business-us-border-securityand-threat-canadian-exports

Goswami, D.C. 1985. "Brahmaputra River, Assam, India: Physiography, Basin Denudation, and Channel Aggradation" Water Resources Research 21(7): 959-978. https://doi.org/10.1029/WR021i007p00959

Hataley, T. and C. Leuprecht. 2018. "Determinants of Cross-Border Cooperation" Journal of Borderlands Studies 33(3): 317-328. https://doi.org/10.1080/08865655 .2018 .1482776

Jackson, S. 2015. "Toward an Analytical and Methodological Understanding of Actor-network Theory" Journal of Arts and Humanities 4(2): 29-44. https://doi.org/10.18533/ journal.v4i2.210

Jones, R. 2009. "Geopolitical Boundary Narratives, the Global War on Terror, and Border Fencing in India" Transactions of the Institute of British Geographers 34(3): 290-304. https://doi.org/10.1111/j.1475-5661.2009.00350.x

Karmakar, S. 2019. "Floods break Indo-Bangla border fence in Assam" Deccan Herald, Guwahati. https://www. deccanherald.com/national/east-and-northeast/floodsbreach-indo-bangla-border-fence-in-assam-749138.html

Latour, B. 1987. Science in Action: How to Follow Scientists and Engineers Through Society. Open University Press: Milton Keynes.

Latour, B. 1992. "Where are the Missing Masses? The Sociology of a Few Mundane Artefacts" in Shaping Technology / Building Society: Studies in Sociotechnical Change, edited by W.E. Bijker, and J. Law, 205-224. Cambridge, Mass: MIT Press.

Latour, B. 1993. We Have Never Been Modern. London: Harvester Wheatsheaf.

Latour, B. 1997. "On Actor-Network Theory: A few Clarifications." Net Time. http://www.nettime.org/ListsArchives/nettime-l-9801/msg00019.html

Mahanta, C. and L. Saikia. 2015. "The Brahmaputra and Other Rivers of the North-East" in Living Rivers, Dying Rivers, edited by R.R. Iyer, 149-181. New Delhi: Oxford University Press.

Mondal, K. 2019. "Wire fencing along Indo-Bangla border washed away in South-Salmara Mankachar" Time8 News, Assam. https://www.time8.in/breaking-wire-fencing-alongindo-bangla-border-washed-away-in-south-salmaramankachar/

Nail, T. 2016. Theory of the Border. Oxford: Oxford University Press.
Nevins, J. 2002. Operation Gatekeeper: The Rise of the Illegal Alien and the Making of the U.S.- Mexico Border. New York: Routledge.

Newman, D. 2003, "On Borders and Power: A Theoretical Framework" Journal of Borderlands Studies 18(1): 13-25. https://doi.org/10.1080/08865655.2003.9695598

Newman, D. (2006a) "The Lines that Continue to Separate Us: Borders in our 'Borderless' World" Progress in Human Geography 32(2): 143-161. https://doi. org/10.1191/0309132506ph599xx

Newman, D. 2006b. "Borders and Bordering:Towards an Interdisciplinary Dialogue" European Journal of Social Theory 9(2): 171-186. https://doi. org/10.1177/1368431006063331

Newman, D. and A. Paasi. 1998. "Fences and Neighbours in the Postmodern World: Boundary Narratives in Political Geography" Progress in Human Geography 22(2):186-207. https://doi.org/10.1191\%2F030913298666039113

Oommen, T.K. 1995. "Contested Boundaries and Emerging Pluralism" International Sociology 10(3 September): 251-268. https://www.jstor.org/stable/23619647

Paasi, A. 1998. "Boundaries as Social Processes: Territoriality in the World of Flows" Geopolitics 3(1): 69-88. https://doi. org/10.1080/14650049808407608

Paasi, A. 2005. "Generations and the 'Development' of Border Studies" Geopolitics 10: 663-71. https://doi. org/10.1080/14650040500318563

Paasi, A. 2011. "A Border Theory: Un unattainable Dream or a Realistic Aim for Border Scholars?" in The Ashgate Research Companion to Border Studies, edited by D. WastIWalter, 11-31. London: Routledge.

Payan, T. 2010. The Three US-Mexico Border War: Drugs, Immigration and Homeland Security. Westport: Praeger Security International.

Piven, B. 2015. "Walls of the World Aim to Keep Unwanted Foreigners Out, Hold Prosperity In" Al-Jazeera America. http://america.aljazeera.com/articles/2015/9/5/wallsworld-keep-foreigners-out.html

Press Information Bureau. 2019. "Shri Rajnath Singh to inaugurate BOLD-QIT project along international border in Dhubri, Assam tomorrow" Press Information Bureau. https://pib.gov.in/Pressreleaseshare.aspx?PRID=1567263

Sharma, B. Kr. 2014. "Border Fences Washed Away" The Telegraph, Guwahati. https://www.telegraphindia. com/states/north-east/border-fences-washed-away/ $\mathrm{cid} / 322247$

Sibley, D. 1995. Geographies of Exclusion, Society and Difference in the West. London: Routledge.

Smith, J.L. 2017. "I, River? New Materialism, Riparian non-human Agency and the Scale of Democratic Reform" Asia Pacific Viewpoint 58(1): 99-111. https://doi.org/10.1111/ apv. 12140

Teschke, B. 2003. The Myth of 1648: Class Geopolitics and the Making of Modern International Relations. London and New York: Verso.

Times of India. 2012. "Kushiara destroys 300 metre border fence in Karimganj" (May 27). http://timesofindia. indiatimes.com/articleshow/13541070.cms?utm_ source=contentofinterest\&utm_medium =text\&utm_ campaign=cppst 
Tripathi, D. 2015. "Interrogating Linkages Between Borders, Regions, and Border Studies" Journal of Borderlands Studies 10: 1-13. https://doi.org/10.1080/08865655.2015.1042010

United States Executive Order 13767. 2017. "Executive Order: Border Security and Immigration Enforcement Improvements" https://www.whitehouse.gov/presidentialactions/executive-order-border-security-immigrationenforcement-improvements/ [Accessed on 07/11/2019].

Vallet, E. and C.-P. David. 2012. "The $(\mathrm{Re})$ Building of the Wall in International Relations" Journal of Borderlands Studies 27(2): 111-119. https://doi.org/10.1080/08865655.2012.687211

Walsham, G. 1997. "Actor-network Theory and IS Research: Current Status and Future Prospects" in Information Systems and Qualitative Research, edited by A. Lee, J. Liebenau, and J. DeGross. Chapman and Hall: London.

Zaiotti, R. 2011. Cultures of Border Control: Schengen and the Evolution of European Frontier. Chicago: University of Chicago Press. 